\title{
Predicting permeability and flow capacity distribution with back- propagation artificial neural networks
}

\author{
Alexis Jose Riera \\ West Virginia University
}

Follow this and additional works at: https://researchrepository.wvu.edu/etd

\section{Recommended Citation}

Riera, Alexis Jose, "Predicting permeability and flow capacity distribution with back-propagation artificial neural networks" (2000). Graduate Theses, Dissertations, and Problem Reports. 1184.

https://researchrepository.wvu.edu/etd/1184

This Thesis is protected by copyright and/or related rights. It has been brought to you by the The Research Repository @ WVU with permission from the rights-holder(s). You are free to use this Thesis in any way that is permitted by the copyright and related rights legislation that applies to your use. For other uses you must obtain permission from the rights-holder(s) directly, unless additional rights are indicated by a Creative Commons license in the record and/ or on the work itself. This Thesis has been accepted for inclusion in WVU Graduate Theses, Dissertations, and Problem Reports collection by an authorized administrator of The Research Repository @ WVU. For more information, please contact researchrepository@mail.wvu.edu. 
Predicting Permeability and Flow Capacity Distribution with Back-Propagation Artificial Neural Networks

\author{
Alexis J. Riera \\ Thesis Submitted to the Faculty of the \\ College of Engineering and Mineral Resources \\ West Virginia University \\ In Partial Fulfillment of the \\ Requirements for the Degree of \\ Master of Science \\ In \\ Petroleum and Natural Gas Engineering
}

Khashayar Aminian, Ph.D., PNGE, Co-Chair

H. Ilkin Bilgesu, Ph.D., PNGE, Co-Chair

Sam Ameri, M.S., PNGE

Daniel Della-Giustina, Ph.D., ISEM

Department of Petroleum and Natural Gas Engineering

Morgantown, West Virginia

2000

Keywords: Petroleum and Natural Gas Engineering, Artificial Neural Networks, Permeability Prediction, Flow Capacity Estimation, Reservoir Characterization 


\title{
ABSTRACT \\ Predicting Permeability and Flow Capacity Distribution with \\ Back-Propagation Artificial Neural Networks
}

\begin{abstract}
Alexis Riera
The prediction of permeability is a critical, key step for reservoir modeling and management of oil recovery operations. Previous studies have successfully demonstrated that the new technology called Artificial Neural Network (ANN), a biologically inspired, massive parallel, distributed information processing system, is an excellent tool for permeability predictions using well log data. This technology overcomes the drawbacks caused by the inherent heterogeneity of the reservoir and lack of sufficient cores or pressure transient tests, allowing to define reservoir characterization within an acceptable accuracy while maintaining costs low. The methodology used in this study takes advantage of this technology to accomplish such a task.
\end{abstract}

An ANN was developed obtaining a correlation coefficient $\mathrm{R}^{2}$ of 0.975 when compared permeability predictions to actual measurements for seven wells using their well $\log$ data in a reservoir in West Virginia, USA. Thereafter, the ANN was used to forecast the permeability for the rest of the wells in the reservoir. Thus, based on the well permeability profile, the Flow Capacity and Average Permeability was determined and mapped throughout the field which defined the most productive areas in the reservoir and helped to improve the production history matching. 


\section{Acknowledgments}

First and foremost, to God for the innumerable gifts and blessings given to me and my family, without which this endeavor would have not been finished.

I wish to express my deepest appreciation to my academic adviser Dr. Khashayar Aminian for his support and guidance.

I acknowledge the paramount help and counseling I received from Dr. H. Ilkin Bilgesu.

To Professor Samuel Ameri for his words to encourage me to continue in good standing and help me foresee and plan for the future.

To Dr. Daniel Della-Giustina for his support and for being part of my examining committee.

I thank my wife, Ysol, for being there for me, her support and her love.

I dedicate this thesis to my parents for their continuous encouragement and love. 


\section{Table of Contents}

Chapter 1: Introduction 1

Chapter 2: Background and Theory 3

2.1 Stringtown Field 3

2.2 Permeability Estimation $\quad 5$

2.3 Flow Capacity Determination $\quad 8$

$\begin{array}{ll}2.4 \text { Artificial Neural Networks } & 10\end{array}$

$\begin{array}{ll}\text { 2.4.1 Components } & 11\end{array}$

2.4.2 Architectures 13

$\begin{array}{ll}\text { 2.4.3 Algorithms } & 16\end{array}$

$\begin{array}{ll}2.4 .4 \text { Activation Functions } & 17\end{array}$

$\begin{array}{ll}2.4 .5 \text { Training } & 20\end{array}$

2.4.6 Verification 23

$\begin{array}{ll}\text { Chapter 3: Methodology } 26 & 26\end{array}$

$\begin{array}{ll}3.1 \text { Objective of the Study } & 26\end{array}$

$\begin{array}{ll}\text { 3.2 Data Available } & 27\end{array}$

3.3 Core - Log Correlation $\quad 30$

3.4 Input Selection $\quad 35$

$\begin{array}{ll}\text { 3.5 Neural Network Development } & 38\end{array}$

$\begin{array}{ll}\text { 3.6 Neural Network Training } & 40\end{array}$

$\begin{array}{ll}3.7 \text { Neural Network Verification } & 43\end{array}$

3.8 Neural Network Prediction 46 
$\begin{array}{ll}\text { Chapter 4: Results } & 48\end{array}$

4.1 Pilot Area 48

4.2 Flow Capacity Zones $\quad 52$

$\begin{array}{ll}\text { 4.3 Discussion } & 56\end{array}$

Chapter 5: Conclusions and Recommendations 58

$\begin{array}{ll}5.1 \text { Conclusions } & 58\end{array}$

$\begin{array}{lr}5.2 \text { Recommendations } & 59\end{array}$

$\begin{array}{ll}\text { References } & 61\end{array}$

Appendix I - Cored Well Graphs 64

$\begin{array}{ll}\text { Annex A - Well Cw1 } & 65\end{array}$

$\begin{array}{ll}\text { Annex B - Well Cw2 } & 67\end{array}$

Annex C - Well Cw3 69

$\begin{array}{ll}\text { Annex D - Well Cw4 } & 71\end{array}$

$\begin{array}{ll}\text { Annex E - Well Cw5 } & 73\end{array}$

$\begin{array}{ll}\text { Annex F - Well Cw6 } & 75\end{array}$

$\begin{array}{ll}\text { Annex G - Well Cw7 } & 77\end{array}$

Appendix II - Permeability Profile (Pilot Wells) 79

Appendix III - Thickness Distribution Map of the Stringtown Field 84 


\section{List of Figures}

Figure 1. Location of the Stringtown Field in West Virginia 3

Figure 2. Stringtown Field 5

Figure 3. Flow Capacity from Well Testing $\quad 9$

Figure 4. Flow Capacity from Core Data 9

Figure 5. A Simple Artificial Neural Network 12

$\begin{array}{ll}\text { Figure 6. Standard Nets } & 13\end{array}$

$\begin{array}{ll}\text { Figure 7. Jump Connection Nets } & 13\end{array}$

$\begin{array}{ll}\text { Figure 8. Recurrent Network } & 14\end{array}$

$\begin{array}{ll}\text { Figure 9. Ward Nets } & 14\end{array}$

$\begin{array}{ll}\text { Figure 10. Kohonen Network } & 15\end{array}$

$\begin{array}{ll}\text { Figure 11. GMDH Network } & 16\end{array}$

$\begin{array}{lr}\text { Figure 12. Sigmoid Functions } & 19\end{array}$

Figure 13. Probabilistic Functions 20

Figure 14. Training of an ANN by Backpropagation 22

Figure 15. Assuring Good Generalization of ANN 24

Figure 16. Stringtown Field Well Location 28

Figure 17. Pilot Area Wells $\quad 29$

Figure 18. Core and Log Porosity vs. Depth for Well Cw5 31

Figure 19. Porosity Correlation for All Wells 32

Figure 20. Permeability vs. Log Response for Well Cw4 34

Figure 21. Core Permeability - Log Porosity Correlation 35 
Figure 22. Derivative Calculation Using the Three-point Method

Figure 23. ANN Architecture Selected

Figure 24. Comparison of ANN Predictions vs. Actual Core Permeability (Well Cw4)

Figure 25. Correlation between Predicted and Actual Core Permeability (Complete Pattern Set)

Figure 26. Correlation between Predicted and Actual Core Permeability (Test Set Only)

Figure 27. Permeability Profile Based on ANN Predictions for Well Cw5

Figure 28. Permeability Profile Based on ANN Predictions for Well Pi1

Figure 29. Flow Capacity Surface Map (kh) for the Pilot Area

Figure 30. Permeability Distribution in the Pilot Area

Figure 31. Flow Capacity Distribution in the Upper Layer of the Pilot Area

Figure 32. Flow Capacity Distribution in the Lower Layer of the Pilot Area

Figure 33. History Production Match

Figure 34. Flow Capacity Distribution in the Stringtown Field

Figure 35. Flow Capacity Contoured Map of the Stringtown Field

Figure 36. Average Permeability Distribution in the Stringtown Field

Figure 37. Average Permeability Contoured Map of the Stringtown Field

Figure 38. Core and Log Porosity vs. Depth (Well Cw1)

Figure 39. Porosity Correlation for Well Cw1

Figure 40. Core Permeability vs. Log Responses (Well Cw1)

Figure 41. ANN Predictions and Core Permeability vs. Depth (Well Cw1)

Figure 42. Core and Log Porosity vs. Depth (Well Cw2)

Figure 43. Porosity Correlation for Well Cw2

Figure 44. Core Permeability vs. Log Responses (Well Cw2) 
Figure 45. ANN Predictions and Core Permeability vs. Depth (Well Cw2) 68

Figure 46. Core and Log Porosity vs. Depth (Well Cw3) 69

Figure 47. Porosity Correlation for Well Cw3 69

Figure 48. Core Permeability vs. Log Responses (Well Cw3) 70

Figure 49. ANN Predictions and Core Permeability vs. Depth (Well Cw3) 70

Figure 50. Core and Log Porosity vs. Depth (Well Cw4) 71

Figure 51. Porosity Correlation for Well Cw4 71

Figure 52. Core Permeability vs. Log Responses (Well Cw4) 72

Figure 53. ANN Predictions and Core Permeability vs. Depth (Well Cw4) 72

Figure 54. Core and Log Porosity vs. Depth (Well Cw5) 73

Figure 55. Porosity Correlation for Well Cw5 73

Figure 56. Core Permeability vs. Log Responses (Well Cw5) 74

Figure 57 ANN Predictions and Core Permeability vs. Depth (Well Cw5) 74

Figure 58. Core and Log Porosity vs. Depth (Well Cw6) 75

Figure 59. Porosity Correlation for Well Cw6 75

Figure 60. Core Permeability vs. Log Responses (Well Cw6) 76

Figure 61. ANN Predictions and Core Permeability vs. Depth (Well Cw6) 76

Figure 62. Core and Log Porosity vs. Depth (Well Cw7) 77

Figure 63. Porosity Correlation for Well Cw7 77

Figure 64. Core Permeability vs. Log Responses (Well Cw7) 78

Figure 65. ANN Predictions and Core Permeability vs. Depth (Well Cw7) 78

Figure 66. Permeability Profile based on ANN Predictions (Well Pi1) 80

Figure 67. Permeability Profile based on ANN Predictions (Well Pi2) 80

Figure 68. Permeability Profile based on ANN Predictions (Well Pi3) 81 
Figure 69. Permeability Profile based on ANN Predictions (Well Pi4) 81

Figure 70. Permeability Profile based on ANN Predictions (Well Pp1) 82

Figure 71. Permeability Profile based on ANN Predictions (Well Cw1) 82

Figure 72. Permeability Profile based on ANN Predictions (Well Cw2) 83

Figure 73. Thickness Distribution Map of the Stringtown Field 85

Figure 74. Thickness Distribution Contoured Map of the Stringtown Field 86 


\section{List of Tables}

Table 1. Core and Log Data Summary 29

Table 2. Core Analysis Results 30

Table 3. Average Core Depth Shifting 32

Table 4. ANN Statistical Results 41

Table 5. Input Strength 43

Table 6. Production Set Results 44

Table 7. ANN Results when Excluding Inputs 45

Table 8. Flow Capacity and Layer Delimitation (Pilot Wells) 50 


\section{Nomenclature}

ANN: Artificial Neural Networks

$\mathrm{CF}_{1}$ : Correction Factor adjusting the weights of the connection links between the middle and output layer in an ANN.

$\mathrm{CF}_{2}$ : Correction Factor adjusting the weights of the connection links between the input and middle layer in an ANN.

Cw1: Cored Well \# 1

Cw2: Cored Well \# 2

Cw3: Cored Well \# 3

Cw4: Cored Well \# 4

Cw5: Cored Well \# 5

Cw6: Cored Well \# 6

Cw7: Cored Well \# 7

Cw8: Cored Well \# 8

Cw9: Cored Well \# 9

GR: Gamma Ray Log

ft: foot, feet (length)

h: Formation Thickness

k: Permeability

kh: Flow Capacity

md: milidarcys

Pi1: Pilot Injection Well \# 1

Pi2: Pilot Injection Well \# 2

Pi3: Pilot Injection Well \# 3 
Pi4: Pilot Injection Well \# 4

Pp1: Pilot Producer Well \# 1

Pp2: Pilot Producer Well \# 2

$\mathrm{R}^{2}$ : Correlation Coefficient

RHOB: Density Log 


\section{Chapter 1: Introduction}

Characterizing a reservoir is a very complex task since its inherent heterogeneity provokes large changes of its properties within small areas and spaces. Acquiring enough data to directly measure such properties from point to point is an extremely expensive and time-consuming practice. The heterogeneity of a formation is the result of distinct geological ages, depositional environments, and lithology among other factors.

One of the essential parameters to define an accurate reservoir model is the permeability distribution. Permeability is often evaluated using cores extracted from wells or pressure transient tests conducted on the wells. However, due to the high cost associated with those procedures, cores and well tests are available from a limited number of wells in a reservoir while geophysical logs are commonly available from the most, if not all, of the wells. Therefore, the evaluation of permeability from well log data is an important step to reduce cost while keeping reservoir modeling within an acceptable accuracy.

Previous studies ${ }^{1-6}$ have successfully demonstrated that obtaining reliable permeability values from geophysical log data using Artificial Neural Networks is possible. Even though these preliminary approaches were useful in predicting permeability, they did not predict the distribution of this rock property reservoir-wide.

The goal of this study was to map the permeability distribution in a reservoir utilizing the typical geophysical well logs commonly run in a well, which are Gamma 
Ray (GR) and Density (RHOB). More than 120 well logs were used to predict and map permeability throughout the entire reservoir. Furthermore, the flow capacity (kh) was calculated to define the most productive parts of the reservoir.

The Stringtown Oilfield was selected to conduct this study. This field is located in Tyler, Wetzel and Doddridge Counties in West Virginia. Its discovery dates back to early 1890's. Significant volume of oil remains in this reservoir that can be recovered through waterflooding operations. However, the permeability distribution is required to accurately estimate the waterflood performance and effectively plan the secondary oil recovery operation. 


\section{Chapter 2: Background and Theory}

\subsection{Stringtown Field}

The Stringtown Oil Field is located in the northwestern part of West Virginia, in Tyler, Wetzel and Doddridge Counties. The producing horizon ${ }^{7-8}$ in this field is the Upper Devonian Gordon Sandstone. On average, the pay zone starts at a depth of 2950 feet and is in the range from 10 to 25 feet in thickness, being thickest along a north-east and south-west trend, which is interpreted as shallow marine, shoreline deposits. Within the field, the Gordon interval consists of sandstone and thin inter-bedded shales and conglomerate. The field started its productive development as early as 1890, however, due to some factors such as recurrent paraffin deposition and lack of durability of primary recovery, led the field to a rather low recovery. A gas-recycling project was initiated in mid 1940's, with poor results. Nevertheless, production has continued to present day.

\section{Figure 1. Location of the Stringtown Field in West Virginia}

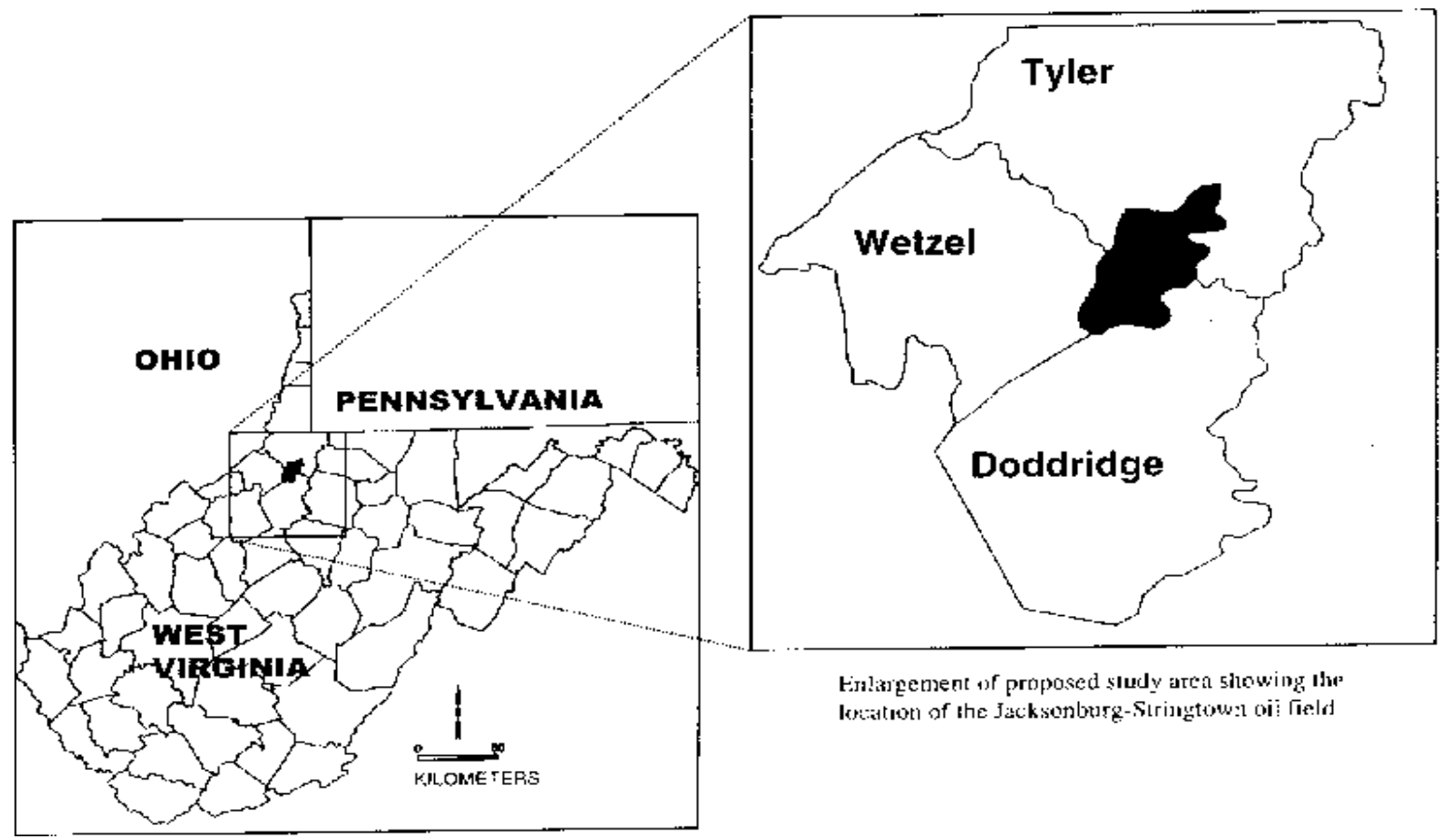


The field is roughly 5 miles long (north-south trend) and its width is about 2.5 miles, so the total productive area is approximately 8900 acres. The reservoir area is shaped like an inverted cone, wider in the north, narrower in the south. The oil in the Stringtown Field has a viscosity of $3.5 \mathrm{cp}$. at atmospheric pressure and $75^{\circ} \mathrm{F}$; gravity of $44^{\circ} \mathrm{API}$ at $60^{\circ} \mathrm{F}$. Total oil production is estimated in some 13 millions barrels to date and the initial oil in place was estimated in 88.5 million barrels.

The Stringtown field has experienced two main periods of drilling since discovery. Over 500 wells were drilled before 1901, but most were plugged by 1910 . More than 100 water injection wells and 40 new producing wells have been drilled since 1990 when a full-scale waterflood began after a successful pilot project initiated in a dual-five-spot pattern (33 acres) in 1980 and lasted until 1985. Total production from secondary oil operations resulted in an estimated of 1.8 millions barrels.

The operating company divided the field into three development areas: Unit 1 (1815 acres), located in the middle of the field and contains the pilot waterflood was formed in 1981; Unit 2 (5723 acres) located north of and adjacent to Unit 1 was formed in 1986; finally Unit 3 consisting of 1360 acres and is located south of Unit 1 . Figure 2 depicts a map of the Stringtown Field with the location of the cored wells (referred to by a convenient nomenclature assumed in this study), and areas of development as previously defined. 
Figure 2. Stringtown Field

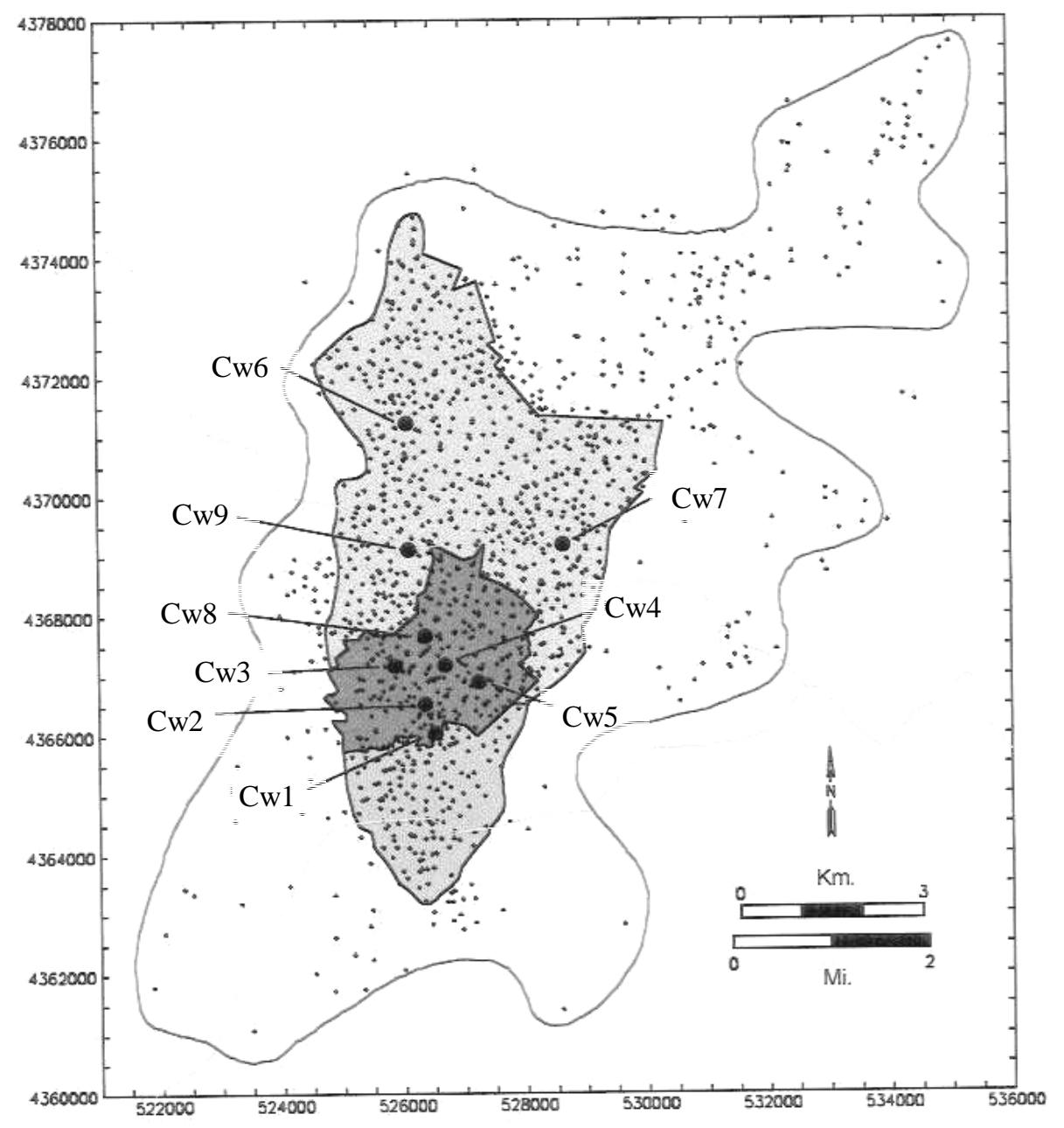

\subsection{Permeability Estimation}

Gaining knowledge of formation permeability is one of the fundamental challenges of petroleum engineers ever since the beginning of oil industry. This rock property is essential to engineers, since it governs the way a fluid flows through a porous media, thus, giving them the ability to design and manage more efficiently the operations of primary and secondary recovery. 
Typically, permeability is obtained from cores or pressure transient tests. The utilization of coring tools, picking samples of the zone of interest and bringing them to the surface, and finally, measuring their permeability under simulated bottom-hole conditions is an old practice in the oil industry. However, coring is expensive, nevertheless it is necessary and inevitable to core some of the wells, regardless of the size of the field. Thus, it is important to define a representative sample of wells to core, strategically distributed in the field. A reliable permeability distribution in a heterogeneous formation, where this property varies rapidly with space, may be effectively used in reservoir simulation studies.

The second traditional procedure to get the formation permeability is by means of well testing. A carefully designed well test helps engineers to calculate an average permeability of the formation, among other parameters such as skin and wellbore storage. Again, it is a valuable and necessary procedure, although its high cost due to loss of revenue and production, and the expenses associated to the execution of the test itself, makes well testing applicable only to a limited number of candidates.

Until a few years ago, many researchers applied rules of thumb developed over the years for given fields and formations to estimate rock permeability. These rules basically stated that a relationship between porosity and permeability might be established. Petroleum engineering concepts also inspired many empirical models to estimate formation permeability from well log responses. These models established the existence of a relationship between permeability, porosity and fluid saturation. Although 
these efforts resulted in a major advance in this area, their main drawback is the relations based on the assumption of the homogeneity of the reservoir. Other approaches have also used multiple regression analysis based on statistical methods to estimate formation permeability from well logs. Again, these methods perform poorly when applied to highly heterogeneous formations.

In the recent years, a number of studies have demonstrated that Artificial Neural Networks (ANN) may be successfully used to estimate formation permeability with an acceptable level of accuracy with geophysical well logs as input. Log data is available from nearly, if not all, of the wells in a field, either during or immediately after drilling. Two of the most common logs run in a well are the gamma ray (GR) and the density (RHOB) logs. Other useful logs are the spontaneous potential (SP) log and the induction $\log$, either with shallow, medium or deep radius of investigation.

Analysis of the log data yield to a variety of information such as shaliness of formation rocks, porosity, water saturation, depth of invasion and thickness among others. ANN uses the log data to predict formation permeability without any assumption previously stated or predefined model, rather its estimation is based on the particular characteristics of the formation defined in terms of the relationship among log responses. This relationship is completely different from well to well and even from point to point in a same well due to the inherent formation heterogeneity. Since, ANN overcomes this heterogeneity drawback; it is a powerful, rapid, low cost alternative to obtain the rock permeability with a reliable level of accuracy. 


\subsection{Flow Capacity Determination}

Flow capacity (kh) is a measure of how productive a formation can be and is determined as:

$$
\mathrm{kh}=\mathrm{k} * \mathrm{~h},
$$

Where $\mathrm{k}$ is permeability (md) and $\mathrm{h}$ is formation thickness ( $\mathrm{ft}$ ). A formation with high permeability does not necessarily mean that it will be productive because it also depends on how thick that formation is. A thick, low permeable formation may produce similar results to those of a thin, high permeable formation.

There are two ways to estimate the flow capacity of a given well based on the data available: well test analysis or permeability profile values. The permeability profile values are given on a length interval basis such as core analysis or ANN predictions.

If data is provided from a pressure transient test, the flow capacity is computed as a function of the volumetric average permeability obtained from that test, after a Horner Analysis, and formation thickness. In fact, a flow capacity value obtained in this fashion is a relatively good indicator, since the test reflects only the average permeability of the formation and does not consider the large changes that this property may has from point to point. This is demonstrated in Figure 3.

A second way to determine the flow capacity of a well is based on the permeability profile. Both core data and ANN predictions are usually given on a length 
interval basis, thus performing a numerical integration of the permeability profile results in a more reliable value of flow capacity for a given well. See Figure 4.

Figure 3. Flow Capacity from Well Testing

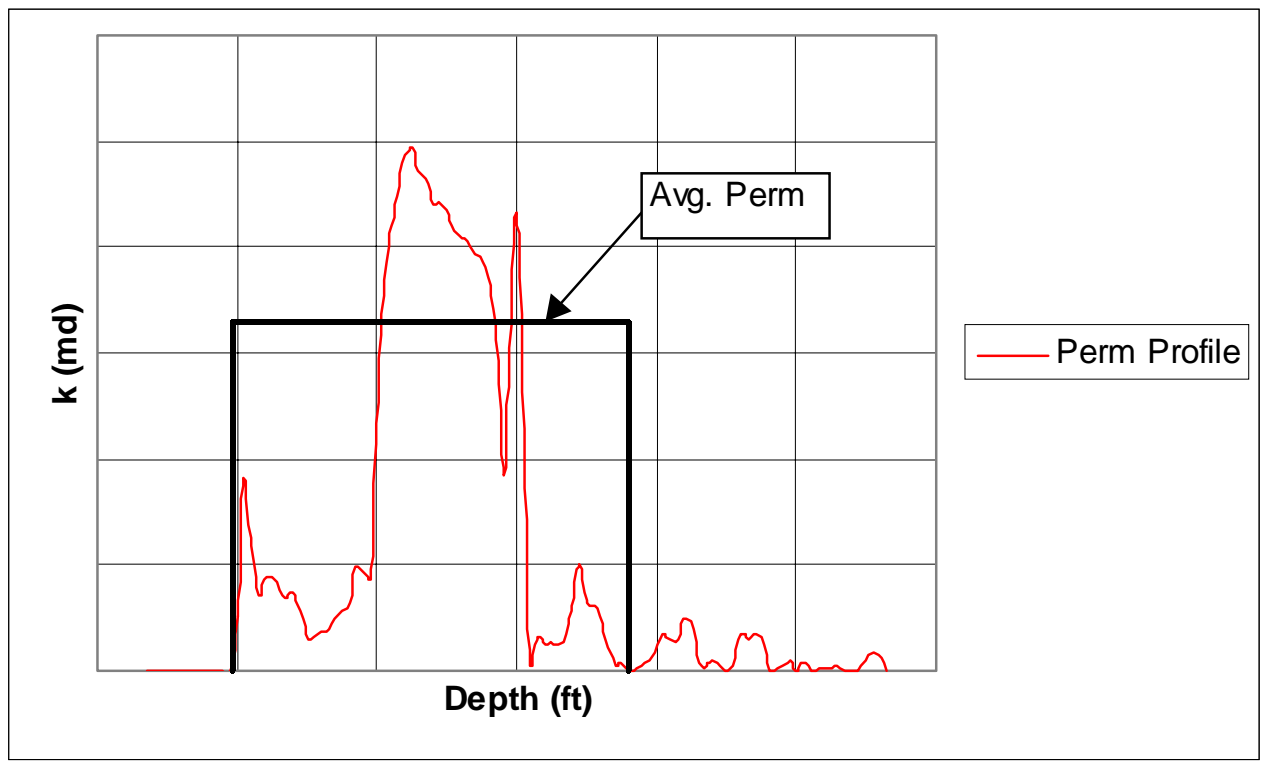

Figure 4. Flow Capacity from Core Data

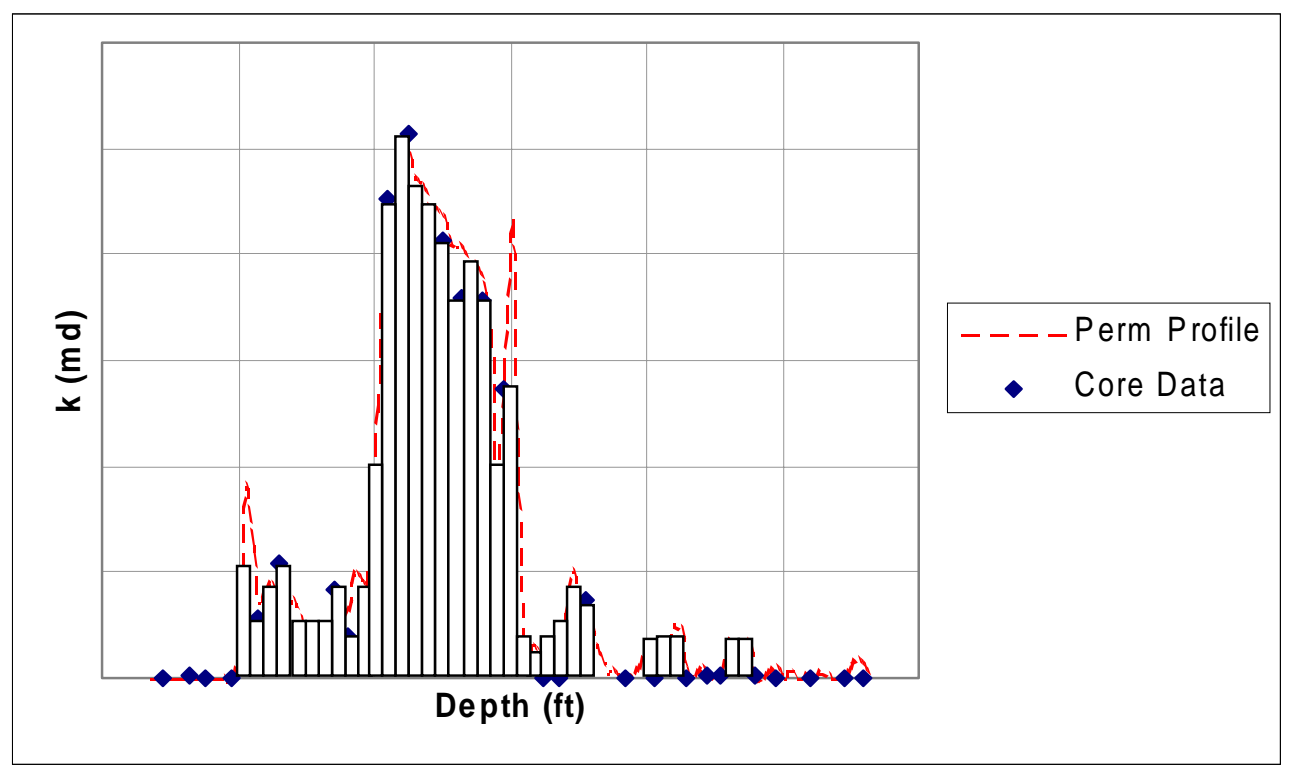




\subsection{Artificial Neural Networks}

Artificial Neural Networks have had a strong comeback since the mid 1980's when several and major advances were made by mathematicians. The application of ANN extends different areas: from finances to engineering, from medicine to administration, from social studies to management. ANN is a biologically inspired, massive parallel, distributed information system that mimics the human brain regarding the pattern recognition, learning and memorization process of those patterns.

In Neural Networks terminology, patterns recognition ${ }^{9}$ can be described as the determination of a mapping from a pattern space into a class space. Most researchers refer to pattern recognition as the process by which classes are determined for sets of features in a robust, well defined fashion, regardless of variations, omissions or distortions, in other words, this process defines the ability to retrieve information (complete patterns) from associated clues, which in this case, consist of a subset of representative features. The interrelationship (implicit or explicit) of these characteristics provides a meaningful interpretation of the information supplied.

Neural Networks, as any other Artificial Intelligence model, stems from the idea of a hypothesis of representation, i.e., knowledge can be acquired, manipulated and interpreted in a symbolic manner. Although, it is practically impossible to model the complexity of Mother Nature, as the previous hypothesis assumes, a large amount of successful applications has been developed with this approach. 


\subsubsection{Components}

ANN's were inspired by and mimic the biological nervous system. They offer an alternative computing paradigm closer to reality, independent of pre-established rules or models. To fully understand how an ANN works, let's first get familiar with its components $^{8}$.

The very basic element of an ANN is called Neuron. Neurons are elemental processors that execute simple tasks. They process the information it receives by applying a mathematical Activation Function that is usually non-linear, to its net input, producing an Output Signal as a result. A Neuron's net input is basically a weighted sum of all of its inputs. As the biological nervous system, Neurons are connected through Links, which transmit the signals among them. Each Connection Link has an associated Weight that, in turn, modify the signal transmitted.

Often, Neurons are grouped in so-called Slabs. Similarly, Slabs are grouped in Layers. Usually, an ANN comprises three layers: Input, Middle and Output Layer. The Input Layer receives information (set of features representing the pattern) from the environment or surroundings and transmits it to the Middle Layer. At this point, it is important to clarify that every Neuron located in the Input Layer is interconnected with all of the Neurons in the Middle Layer, such that the information processing task is carried out parallel and simultaneously. The same is true for the interconnection between the Middle and Output Layer. 
It is often said that the Middle Layer is the one that actually analyzes or executes the mapping of the information supplied to the ANN. This layer carries out the pattern recognition task among all input information by re-coding it to generate an appropriate internal representation, so that the essential features of the patterns are retained. The Output Layer receives this analysis and converts it into a meaningful interpretation to communicate it back to the environment. A simplistic schematic of an ANN is depicted in Figure 5.

\section{Figure 5. A Simple Artificial Neural Network}

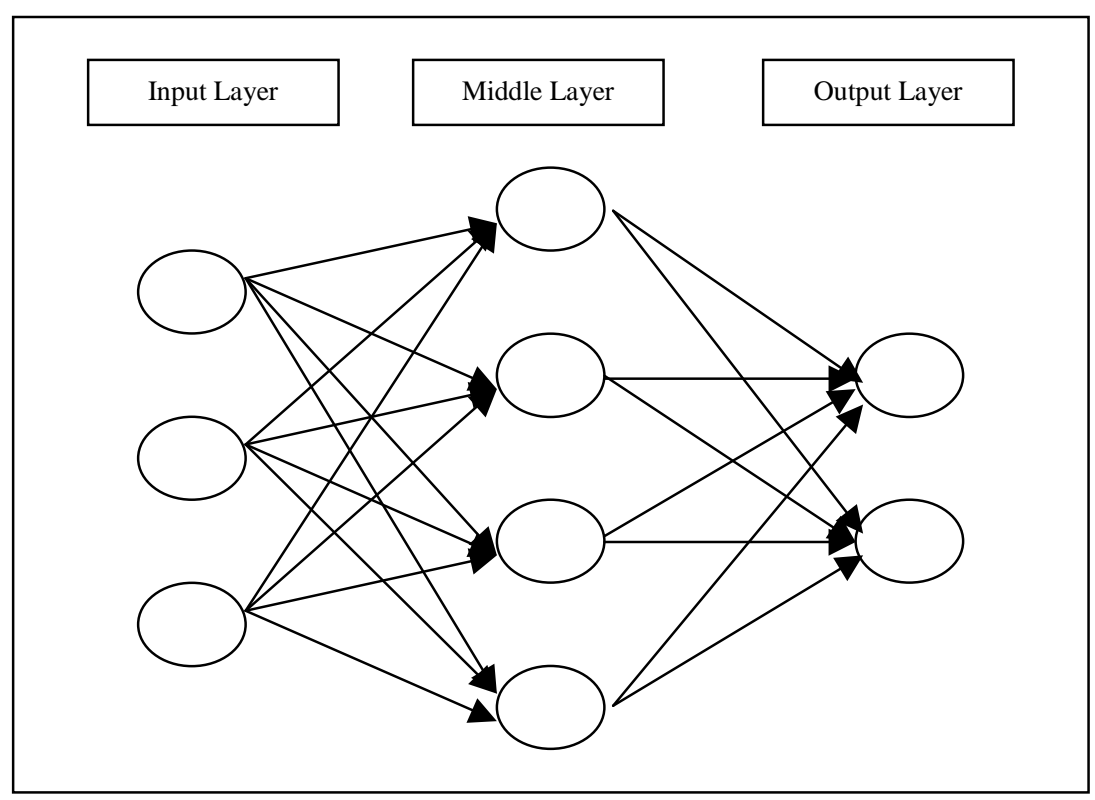

Three properties characterize an ANN:

1. Architecture: the connectivity pattern among neurons

2. Algorithm: its method of determining the weights on the connections

3. Activation Function: a mathematical function that maps a neuron's net input into its output value. 
Each of these characteristics shall be discussed in the following sections

\subsubsection{Architectures}

The Neural Network's Architecture or its pattern of connectivity defines how much knowledge is stored in it. It also determines the algorithm to be used in updating the weights of each connection. Several different $\operatorname{architectures}^{10-11}$ and learning paradigms have been developed in the past years, among them are:

\section{Backpropagation Models}

Backpropagation networks are known for their prediction capabilities and ability to generalize well on a wide variety of problems. These models are a supervised type of network, in other words, trained with both inputs and target outputs. Many variations of these nets are encountered in the literature, following a list of a few is shown:

a. Standard Nets: each layer connected to the immediately previous layer.

\section{Figure 6. Standard Nets}

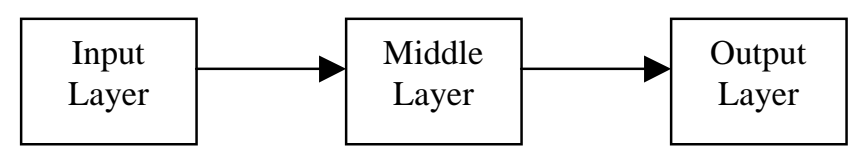

b. Jump Connection Nets: each layer connected to every previous layer

\section{Figure 7. Jump Connection Nets}

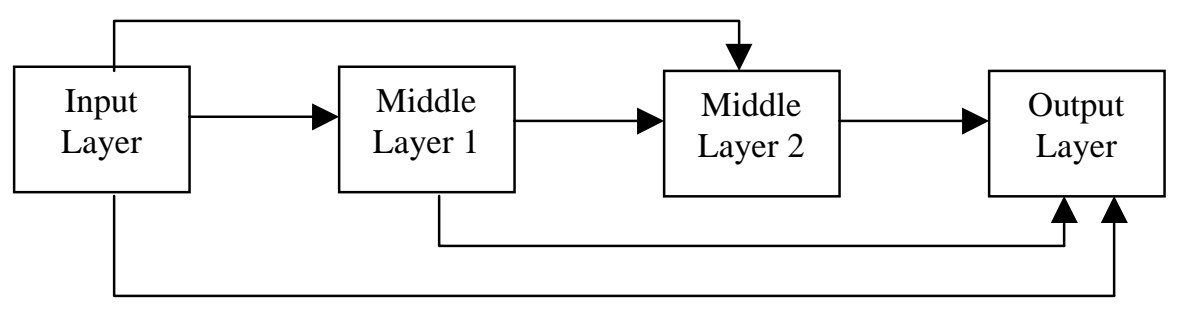


c. Recurrent networks with dampened feedback from either the input, hidden, or output layer.

Figure 8. Recurrent Network

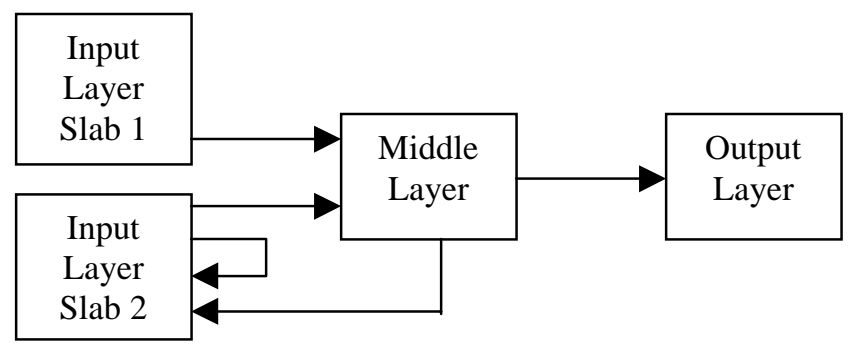

d. Ward networks with multiple slabs in the middle layer: these networks are very powerful when each hidden slab is given a different activation function from the other slabs because they detect different features of the input vectors. This gives the output layer different viewpoints of the data.

\section{Figure 9. Ward Nets}

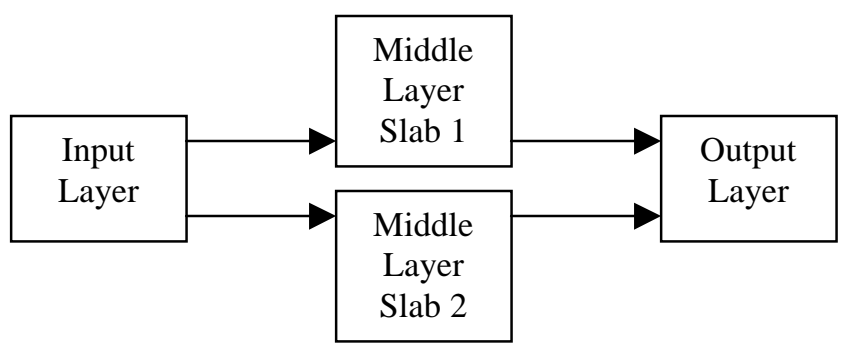

\section{Unsupervised (Kohonen)}

The Kohonen Self Organizing Map network is a type of unsupervised network, and its architecture is the simplest of all with only two layers: input and output. The Kohonen network has the ability to learn without being shown correct outputs in sample 
patterns. These networks are able to separate data patterns into a specified number of classes.

\section{Figure 10. Kohonen Network}

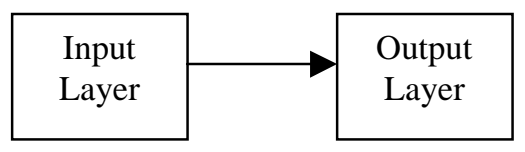

\section{Probabilistic Neural Network (PNN)}

This network is a type of supervised network known for their ability to train quickly on sparse data sets. PNN also separates data into a specified number of output categories.

\section{General Regression Neural Network (GRNN)}

Like PNN networks, General Regression Neural Network is a type of supervised network and also to trains quickly on sparse data sets but, rather than categorizing it, GRNN applications are able to produce continuous valued outputs. GRNN can have multidimensional input, and it will fit multidimensional surfaces through data. Because GRNN networks evaluate each output independently of the other outputs, GRNN networks may be more accurate than Backpropagation networks when there are multiple outputs. Its architecture is similar to that of a standard network.

\section{GMDH Network (Group Method of Data Handling or Polynomial Nets)}

GMDH works by building successive layers with links that are simple polynomial terms, which are created by using linear and non-linear regression. The initial layer is simply the input layer. The first layer created is made by computing regressions of the input variables and then choosing the best ones. The second layer is created by 
computing regressions of the values in the first layer along with the input variables. Again, the algorithm chooses only the best, which are called survivors. This process continues until the net stops getting better, according to a prespecified selection criterion. The resulting network can be represented as a complex polynomial, in other words, a familiar formula describing the model and it should contain the most significant input variables. In some respects, this procedure resembles very much regression analysis, but it is far more powerful than this. GMDH can build very complex models while avoiding overfitting problems.

\section{Figure 11. GMDH Network}

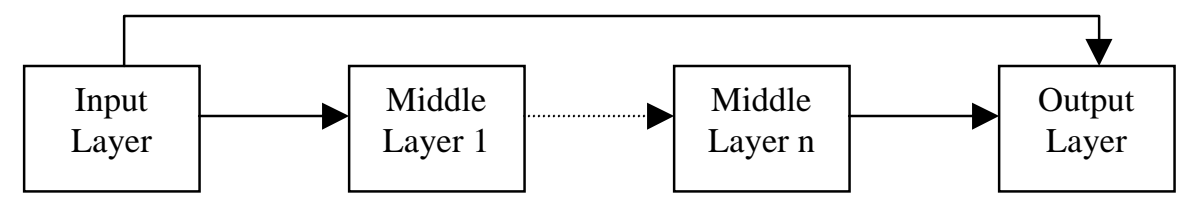

\subsubsection{Algorithms}

The algorithm defines how the weights on the connections are updated. This requires a specification of the network's architecture. In some models new values of weights associated to links are determined at a regular time and applied to all units simultaneously, while in other models the rule is applied to a certain number of connection links at a time. In the latter case the model is said to perform asynchronically.

Since in ANN's, a specific mapping is implemented through the learning process by iteratively adjusting the weights, the algorithm and the network's response to a 
training signal become of paramount importance. Generally, the mapping to be learnt is represented by a training set of input patterns and the correspondent target outputs.

There are two basic classes of learning in parallel-distributed processing models: associative learning and regularity detectors. In the former, the goal is to learn the association between patterns such that if the network is exposed to noisy or a good pattern, it will respond with the appropriate output. This association is either heteroassociation or auto-association. In hetero-associative learning two distinctive patterns are shown to the network, the input pattern and the required output, whereas for autoassociative systems, the same pattern is used both for input and output.

No output is provided for regularity detectors. The unit will learn to respond to certain features depending on an internal teaching function and the nature of the input patterns. In this case, it is said that system undertakes an unsupervised learning.

\subsubsection{Activation Functions}

As mentioned before, the basic operation of an artificial neuron involves summing its weighted input signal and applying an activation function to it, which as a result produces an output signal to be transmitted to the next layer. For the input layer, this function is the linear or identity function. Generally, the same activation function is used for all neurons in any particular slab. In order to obtain the benefits of parallel-distributed processing system that ANN's offer a non-linear activation function is generally used. 
Activation functions may be divided into four categories: linear, binary, sigmoid and probabilistic. The most common functions are listed below:

\section{Linear Functions:}

- Identity: $f(x)=x$

- Linear Scaled: $f(x)=m x+b$

These functions are used primarily in the input layer so that the input pattern data set is passed just as is to the middle layer.

\section{Binary Functions:}

- Step: $f(x)=1$ if $\mathrm{x} \geq \mathrm{b}$ or $f(x)=0$ if $\mathrm{x}<\mathrm{b}$

This function is utilized to convert continuo data into a binary unit. This feature is very helpful when building net to establish classes or categories

3. Sigmoid Functions:

- Logistic: $f(x)=\frac{1}{\left(1+e^{-\sigma x}\right)}$

- Hyperbolic Tangent: $f(x)=\tanh (x)$

- Hyperbolic Tangent 1.5: $f(x)=\tanh (1.5 x)$

- Symmetric Logistic: $f(x)=\frac{2}{\left(1+e^{-\sigma x}\right)}-1$

Sigmoid functions (S-shaped curves) are useful activation functions. They are especially advantageous for use in neural nets trained by the back-propagation paradigm, because the simple relationship between the value of the function at a point and the value of the derivative at that point reduces the computational overburden during training. For instance, in the case of the logistic function, the relationship is: 


$$
\begin{aligned}
& f(x)=\frac{1}{\left(1+e^{-\sigma x}\right)} \\
& f^{\prime}(x)=\sigma f(x)[1-f(x)]
\end{aligned}
$$

If taking the hyperbolic tangent as example:

$$
\begin{aligned}
& f(x)=\frac{e^{x}-e^{-x}}{e^{x}+e^{-x}}=\frac{1-e^{-2 x}}{1+e^{-2 x}} \\
& f^{\prime}(x)=(1+f(x))(1-f(x))
\end{aligned}
$$

The range of these functions is emphasized by the steepness parameter $\sigma$.

\section{Figure 12. Sigmoid Functions}

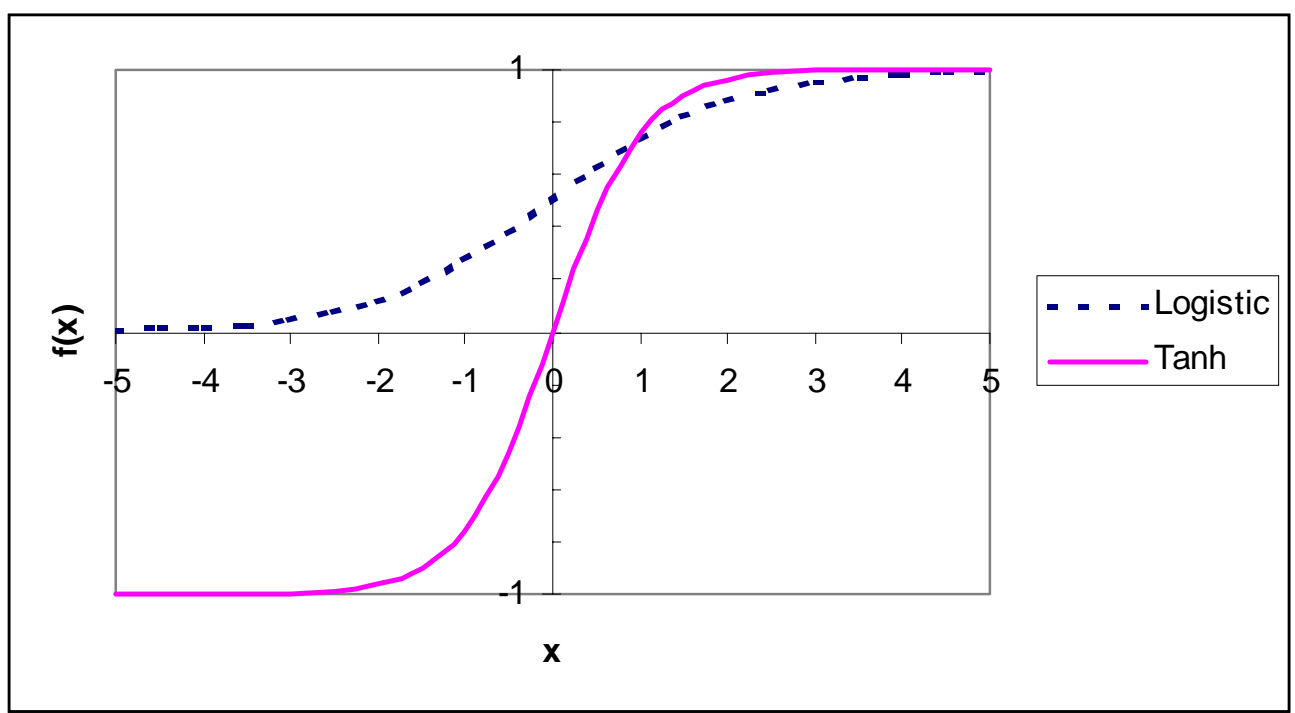

4. Probabilistic Functions:

- Gaussian: $f(x)=e^{-x^{2}}$

- Gaussian Complement: $f(x)=1-e^{-x^{2}}$

The probabilistic functions are unique in ANN's applications, because unlike the others, they are not increasing functions. The Gaussian function is the classic bell shaped 
curve, which maps high values into low ones, and maps mid-range values into high ones. It brings out meaningful characteristics not found at the extreme ends of the sum of weighted values. On the other hand, the Gaussian Complement function tends to bring out meaningful characteristics in the extremes of the data. Both functions are very useful in Ward networks.

\section{Figure 13. Probabilistic Functions}

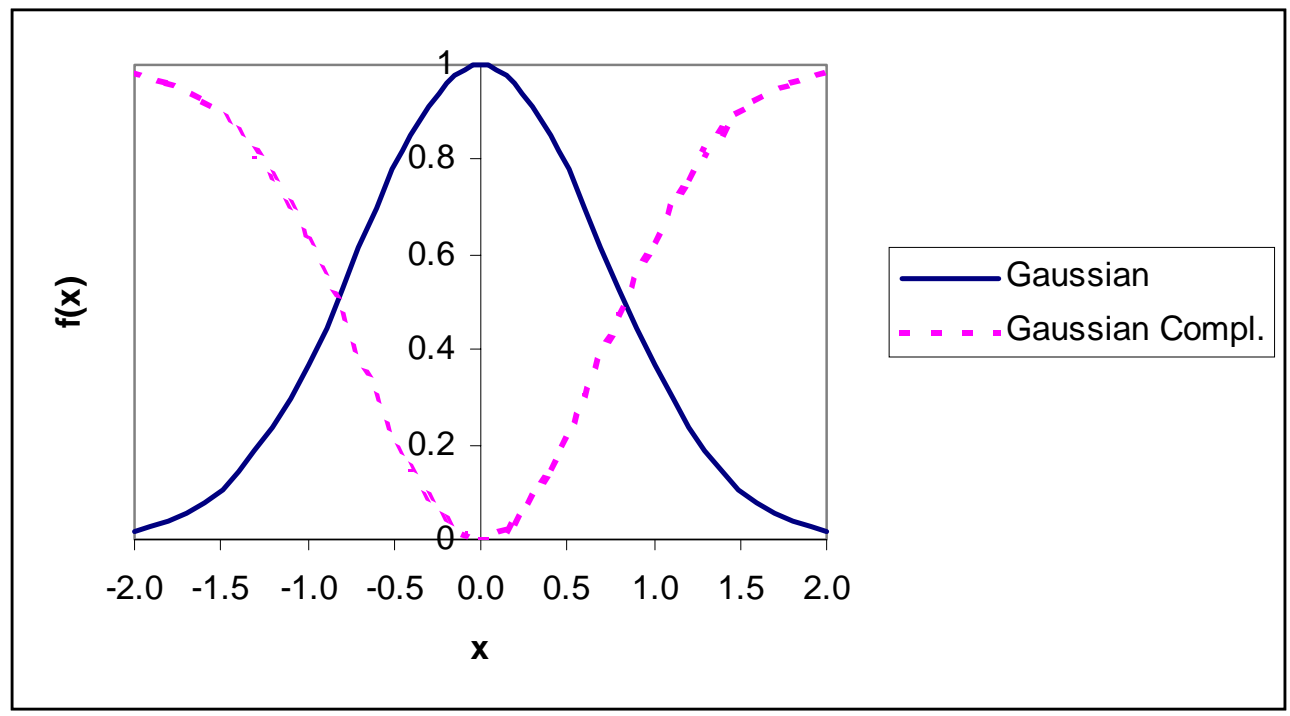

\subsubsection{Training}

Although the specific training of a given network depends on its architecture, most nets undergo a training process similar to that of a backpropagation model. The back-propagation algorithm uses the generalized delta rule, which is simply a gradient descent method to minimize the total squared error of the output compute by the net ${ }^{8}$. Backpropagation stands for propagating or sending back this error to the previous connection links between layers and adjust the correspondent weights accordingly. 
The goal with this network model, as is the case with most nets, is to achieve a training that balance its ability to respond correctly to the input patterns that are used for training (the memorization process) and its ability to give reasonable good responses to similar, yet not identical, input used in the same training process (generalization).

The training of a network by backpropagation involves three stages: the feedforward of the input training pattern, the calculation and backpropagation of the associated error and the adjustment of the weights.

During the feedforward process, all weights associated to the connection links are initialized and information is provided to the network via the input layer. Input data is multiplied by those weights. The sum of the product of all input neurons and their corresponding weights are then transmitted toward each middle neuron. Each of these middle neurons executes a simple computation by mapping the sum to output signal using its own activation function. The result is again multiplied this time by the weights of the connection links between each middle and output neuron. Output neurons calculate the sum of their weighted inputs to determine the final network output.

At his point, each output unit compares its computed value with its target output, to determine the associated error for that pattern with that unit, which initiates the second stage of the training: the backpropagation of this error. Based on this error, a correction factor $\left(\mathrm{CF}_{1}\right)$ is calculated using the generalized delta rule. This correction factor helps to distribute the error from each output neuron back to all middle neurons that are connected 
to it. Similarly, another correction factor $\left(\mathrm{CF}_{2}\right)$ is computed for each middle neuron to propagate the error back to the neurons in the input layer.

After all of the correction factors have been determined, the weights for all layers are adjusted simultaneously. The adjustment for each weight is a function of the correspondent correction factor and the activation function of the previous neuron. That is, the adjustment of the weights of the connection links between the input and middle layer depends on $\mathrm{CF}_{2}$ and the activation function of the input neurons. Whereas weights of the connection links between the middle and output layer are altered based on $\mathrm{CF}_{1}$ and the activation function of the middle neurons

Figure 14. Training of an ANN by Backpropagation

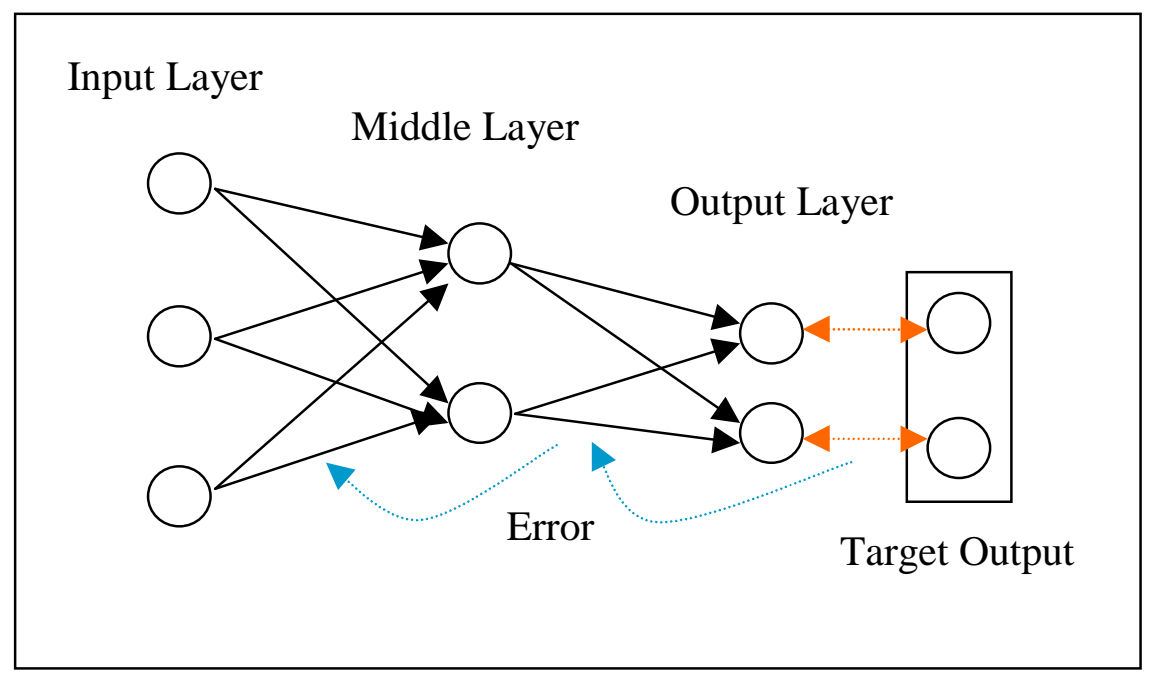

When training a net by backpropagation, there are several parameters that must be set before training actually begins. Two of the most important settings are the Learning 
Rate and Momentum. These two parameters work together and help to define how fast and how stable the learning process is.

Each time a pattern is presented to the network, the weights leading to an output neuron are modified slightly during learning in the direction required to produce a smaller error the next time the same pattern is presented. Learning Rate controls the amount of modification in weights leading toward a smaller error. The larger the learning rate, the larger the weight changes, and the faster the learning will proceed while.

However, large learning rates often lead to oscillation of weight changes and learning might never complete, or the model converges to a solution that is not the optimum. Momentum prevents oscillation of weight changes and control convergence by making the weight change a function of the previous weight change to provide a smoothing effect. The momentum factor determines the proportion of the last weight change that is added into the new weight change.

\subsubsection{Verification}

As aforementioned, the usual motivation for applying an ANN is to achieve a balance between correct responses to training patterns and good responses to new input patterns, in other words a balance between memorization and generalization. Therefore, it is not necessarily advantageous to continue training until the total squared error actually reaches a minimum. To accomplish this goal, two sets of data are used during training, which are completely disjoint: a set of training patterns and set of training-testing 
patterns. In other words, the pattern data set is formed by the training set and the test set. Weight adjustments are based on the training set, however, at intervals during training, the error is computed using the test set. As long as the error on the test set decreases, training continues. The net is saved on the best performance on the test set. When the error begins to increase, the net starts to memorize the training data set too specifically and begins to lose its ability to generalize as well. At this point, training is should be concluded.

Figure 15. Assuring Good Generalization of ANN

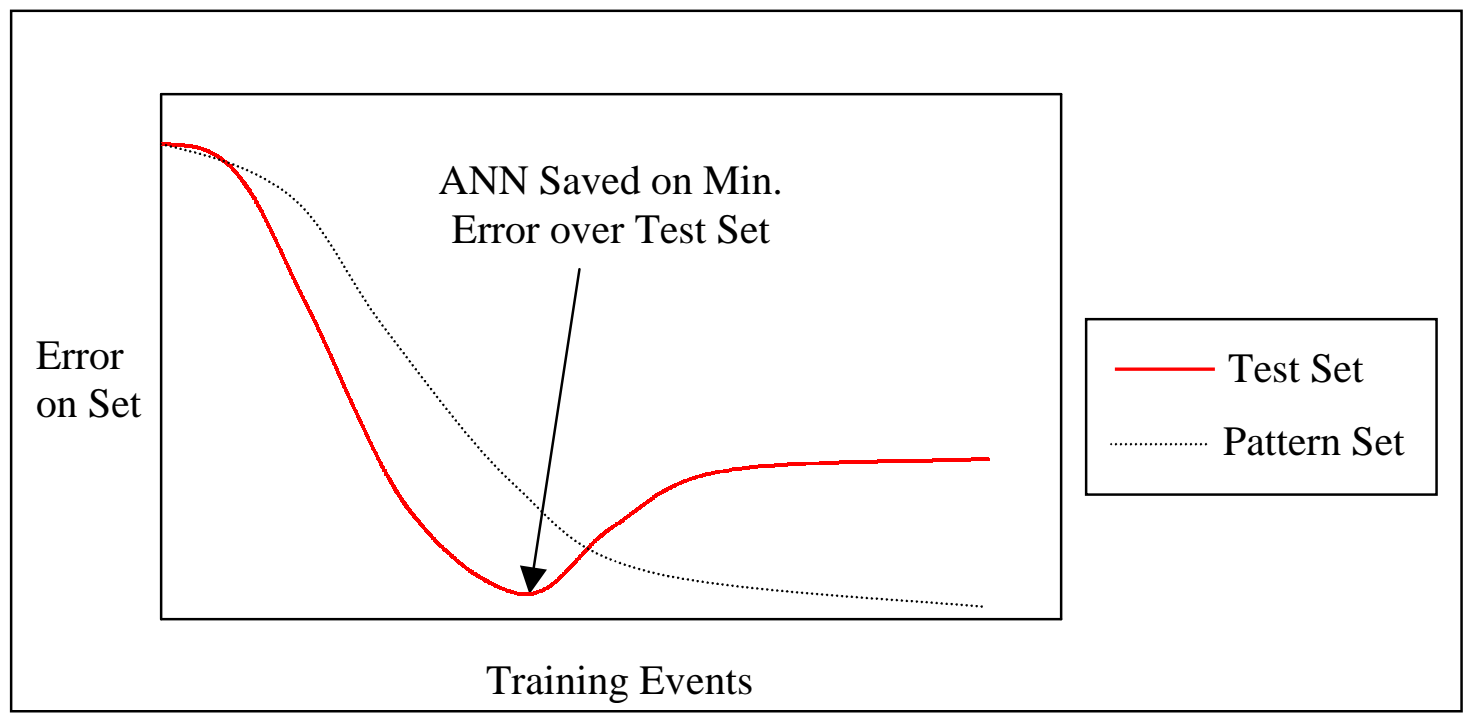

Calibration is another useful parameter when training a net, since it defines how often the test set is evaluated, thus optimizing the network's generalization.

Other way to verify the network's predictions is by using a third data set called the production set, which is not used in the training process of the net. The production set 
contains similar data to that of the pattern set, that is, a set of inputs describing features as well as its correspondent target outputs. This data set is rather utilized to compare the predictions of the network with the actual target values by exposing the net developed to that set. In other words, by applying the ANN just created to this new data in the feedforward mode only.

After training has been successfully accomplished in the sense that network predictions are reasonable good, application of the net involves only the computations in the feedforward phase to make forecasts on new data sets. The only requirement is that these new sets must be formatted in the same fashion as the input parameters used during training. Even if training is slow, a trained network can produce its outputs very fast. 


\section{Chapter 3: Methodology}

In the following sections, the approach used in this study is described thoroughly. First, the goal of the study is addressed as well as its justification. Then, it is described how the correlation between core and log data was determined. Second, the input selection criteria and the development of the ANN are discussed. Third, the training and verification of the neural net are carried out to finally obtain the net predictions.

\subsection{Objective of the Study}

Characterizing and describing a reservoir is a very complex task since its inherent heterogeneity provokes large changes of its properties in small portions of area and space. In addition, acquiring enough data to directly measure such properties from point to point is an extremely expensive and time-consuming practice. The heterogeneity of a formation is caused by several factors; among them are distinct geological ages of creation, different depositional environments, and nature of the rocks.

Permeability distribution is one of the essential parameters to define a good reservoir model. Permeability is usually evaluated from cores extracted from wells or pressure-time tests executed on the wells. However, due to the additional time and cost, cores and well tests are available from few wells in a reservoir while geophysical logs are available from most, if not all, of the wells. Therefore, the evaluation of permeability from well log data is an important step to reduce cost while keeping reservoir modeling within an acceptable accuracy. 
Previous studies ${ }^{1-6}$ have successfully proven that obtaining reliable permeability values from geophysical log data using Artificial Neural Networks is possible. However, although those useful, preliminary approaches established that good permeability predictions could be made, they did not really carry out any prediction to extend the net's forecast field-wide or yet, on a small area of the field.

In this study, the goal is to map the permeability and flow capacity distribution (kh) to define the most productive zones in the Stringtown Oil Field utilizing the most common geophysical logs run in a well, Gamma Ray (GR) and Density (RHOB).

The Stringtown Oil Field is located in the borderline between the Tyler and Wetzel Counties in West Virginia. Its discovery dates from early 1890's. Significant volume of oil remains in this reservoir that can be recovered through waterflooding operations. However, accurately estimate this waterflooding performance and efficiently plan this operation depends, as stated previously, on the permeability distribution, hence, the importance and justification of this study is stressed.

\subsection{Data Available}

For the purpose of this study, the core data from seven wells (Cw1 to $\mathrm{Cw} 7)$ in the reservoir was collected; two of which are located in the waterflooded pilot area. The data from two other cored wells ( $\mathrm{Cw} 8$ and $\mathrm{Cw} 9)$ was not used because these wells did not have logs. The geophysical well logs from 125 wells strategically distributed in the field were also collected, as well as the Production and Water Injection History from the pilot 
area. A map with the location of the cored, pilot waterflood and all of the uncored wells is shown in Figure 16.

Figure 16. Stringtown Field Well Location

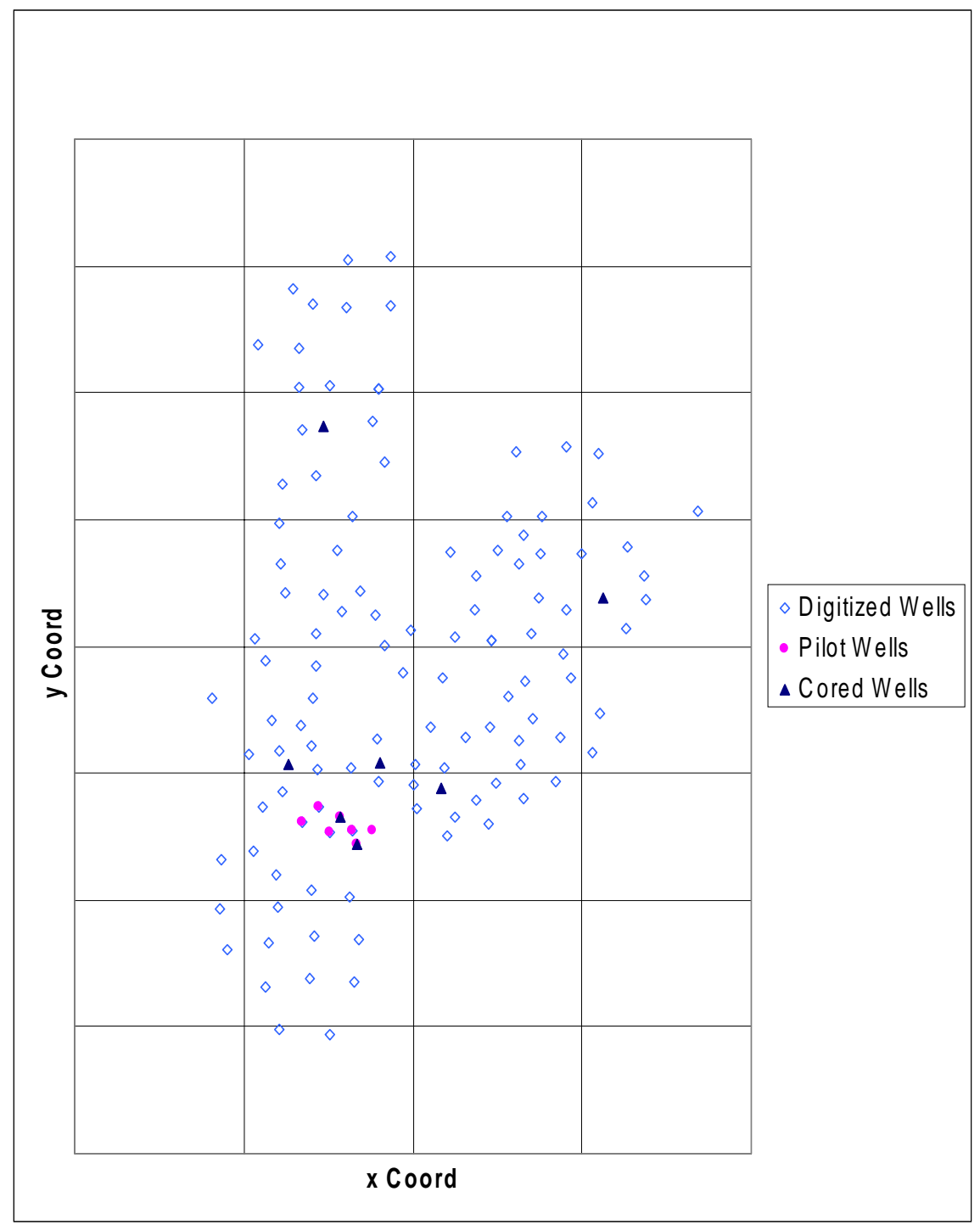

The location of the wells in the pilot area is given in Figure 17, which depicts the dual-five spot pattern with six injector wells and two producers. One of the producer wells (Pw2) did not have any data log available since it was drilled in the 1890's. The two wells with cores in this area are $\mathrm{Cw} 1$ and $\mathrm{Cw} 2$. 
Figure 17. Pilot Area Wells

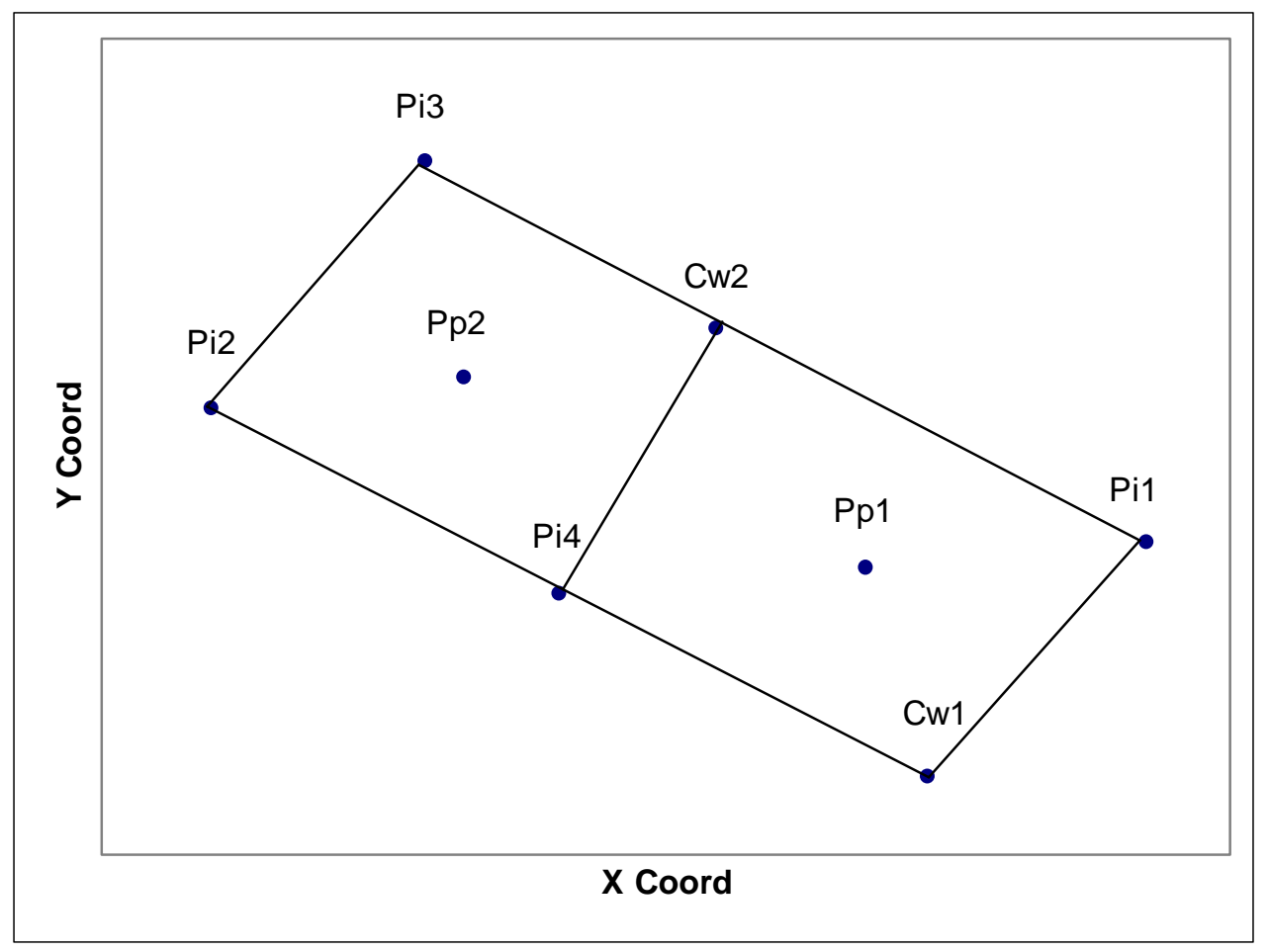

Table 1. Core and Log Data Summary

\begin{tabular}{|c|c|c|c|c|c|c|c|}
\hline Well Name & Core Date & Location & Top & Bottom & $\begin{array}{c}\text { Core Interval (ft) } \\
\text { (ft) }\end{array}$ & Analysis Performed & $\begin{array}{c}\text { Digitazed } \\
\text { Logs }\end{array}$ \\
\cline { 3 - 7 } Cw1 & 14-Dec-79 & $\begin{array}{c}\text { Middle of Field } \\
\text { Pilot Area }\end{array}$ & 2889.6 & 2909.8 & 20.2 & $\begin{array}{c}\text { Conventional Plug } \\
\text { and Full Diameter } \\
\text { Type }\end{array}$ & $\begin{array}{c}\text { GR, RHOB, } \\
\text { ILD }\end{array}$ \\
\hline Cw2 & 04-Dec-80 & $\begin{array}{c}\text { Middle of Field } \\
\text { Pilot Area }\end{array}$ & 3083.4 & 3101.0 & 17.6 & $\begin{array}{c}\text { Conventional Plug } \\
\text { Type }\end{array}$ & $\begin{array}{c}\text { GR, RHOB, } \\
\text { ILD }\end{array}$ \\
\hline Cw3 & 24-Jan-86 & $\begin{array}{c}\text { Middle of Field } \\
\text { Next to Pilot Area }\end{array}$ & 2779.0 & 2799.0 & 20.0 & $\begin{array}{c}\text { Conventional Plug } \\
\text { Type }\end{array}$ & $\begin{array}{c}\text { GR, RHOB, } \\
\text { Neutron, LLD }\end{array}$ \\
\hline Cw4 & $24-J a n-86$ & $\begin{array}{c}\text { Middle of Field } \\
\text { Next to Pilot Area }\end{array}$ & 2988.5 & 3015.0 & 26.5 & $\begin{array}{c}\text { Conventional Plug } \\
\text { Type }\end{array}$ & $\begin{array}{c}\text { GR, RHOB, } \\
\text { Neutron, LLD }\end{array}$ \\
\hline Cw5 & 26 -Dec-85 & $\begin{array}{c}\text { Middle of Field } \\
\text { Next to Pilot Area }\end{array}$ & 3086.0 & 3115.0 & 29.0 & $\begin{array}{c}\text { Conventional Plug } \\
\text { Type }\end{array}$ & $\begin{array}{c}\text { GR, RHOB, } \\
\text { Neutron, ILD }\end{array}$ \\
\hline Cw6 & $27-D e c-84$ & $\begin{array}{c}\text { Northern Area of } \\
\text { the Field }\end{array}$ & 2880.7 & 2896.5 & 15.8 & $\begin{array}{c}\text { Conventional Plug } \\
\text { and Full Diameter } \\
\text { Type }\end{array}$ & $\begin{array}{c}\text { GR, RHOB, } \\
\text { ILD }\end{array}$ \\
\hline Cw7 & 08-0ct-93 & $\begin{array}{c}\text { North-Eastern } \\
\text { Area of the Field }\end{array}$ & 3032.4 & 3061.5 & 29.1 & $\begin{array}{c}\text { Conventional Plug } \\
\text { Type }\end{array}$ & $\begin{array}{c}\text { GR, RHOB, } \\
\text { Neutron }\end{array}$ \\
\hline
\end{tabular}


The core analysis usually included determination of maximum, horizontal and vertical permeability, helium porosity and grain density as well as fluid saturation. With the exception of well $\mathrm{Cw} 7$, the same laboratory analyzed all of the cored wells. Results of these analyses are shown on Table 2.

Table 2. Core Analysis Results

\begin{tabular}{|c|c|c|c|c|c|c|c|}
\hline \multirow{2}{*}{$\begin{array}{l}\text { Well } \\
\text { Name }\end{array}$} & \multicolumn{3}{|c|}{ Plug Permeability (md) } & \multirow{2}{*}{$\begin{array}{l}\text { Avg. Helium } \\
\text { Porosity \% }\end{array}$} & \multirow{2}{*}{$\begin{array}{c}\text { Analyzed } \\
\text { Thickness (ft) }\end{array}$} & \multirow{2}{*}{$\begin{array}{c}\text { Storage } \\
\text { Capacity }(\phi-\mathrm{ft})\end{array}$} & \multirow{2}{*}{$\begin{array}{c}\text { Flow } \\
\text { Capacity (md-ft) }\end{array}$} \\
\hline & Arithmetic & Harmonic & Geometric & & & & \\
\hline Cw1 & 106 & 2.7 & 57 & 18.2 & 17.5 & 290.7 & 1698.7 \\
\hline Cw2 & 72 & 1.5 & 19 & 18.8 & 11.7 & 158.1 & 603.7 \\
\hline Cw3 & 6.5 & 0.09 & 0.75 & 12.4 & 16.0 & 199.0 & 104.1 \\
\hline Cw4 & 52 & 0.23 & 2.7 & 14.7 & 26.5 & 389.4 & 1372.3 \\
\hline Cw5 & 41 & 0.3 & 6.2 & 14.9 & 29.0 & 415.9 & 1155.8 \\
\hline Cw6 & 0.35 & 0.24 & 0.29 & 7.1 & 15.8 & 81.4 & 4.0 \\
\hline Cw7 & 2.4 & 0.07 & 0.18 & 8.3 & 29.0 & 240.7 & 69.6 \\
\hline
\end{tabular}

\subsection{Core - Log Correlation}

Core Permeability-Log Data correlation began with the determination of the Pay Zone and digitalization of GR and RHOB logs. A comparison was made between core porosity and log porosity (derived from density log) for a given depth. For this matter, assumptions for the matrix and fluid density had to be stated. The zone matrix was assumed to be Limy Sandstone with a density $\left(\rho_{\mathrm{m}}\right)$ of $2.68 \mathrm{gr} . / \mathrm{cc}$ and the fluid as water ( $\rho_{\mathrm{f}}=1$ gr./cc), thus log porosity $\left(\phi_{\mathrm{l}}\right)$ was derived as:

$$
\theta_{l}=\frac{\left(\rho_{m}-\rho_{b}\right)}{\left(\rho_{m}-\rho_{f}\right)} * 100
$$


Most of the core plugs are taken in a per-foot basis for all the wells, through the sample, while the resolution of the digitalization process was selected to be at every three inches, so that there would be four data points per foot interval.

The comparison of the measured helium porosity values for core plugs and the porosity values derived from density log suggested the need for some adjustment in core depths to overcome the inherent inadequacies in coring and core handling techniques ${ }^{11-12}$. In other words, the core depths were shifted up or down to provide a good match with log porosity values. In fact, some points were adjusted individually to match better according to $\log$ porosity trends. Figure 18 shows the porosity correlation for the well Cw5.

Figure 18. Core and Log Porosity vs. Depth for Well Cw5

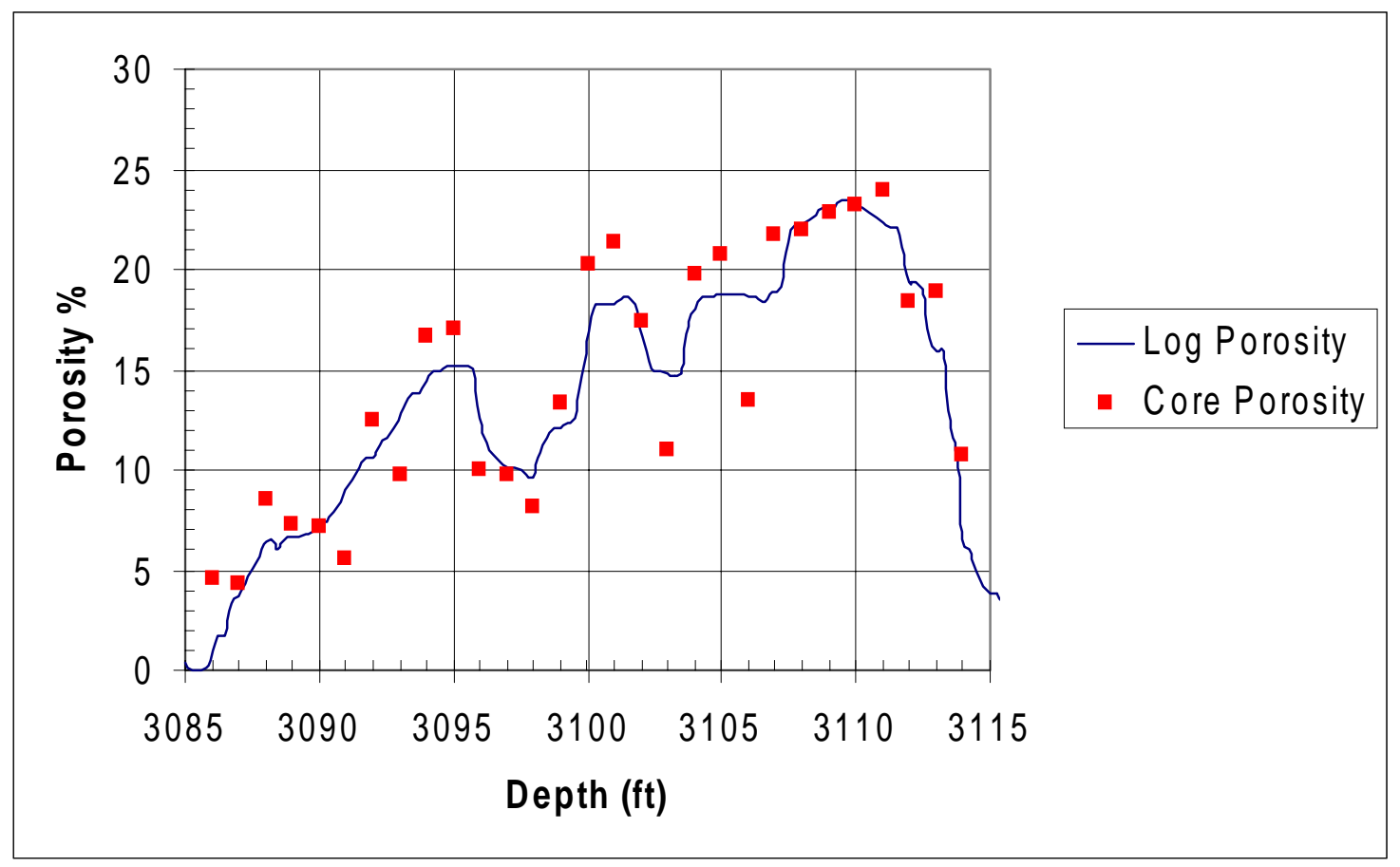


Porosity correlation graphs for the rest of the cored wells in the field may be found in Appendix I. Table 3 shows the average depth shifting applied to each of the cored wells for porosity correlation.

As it is seen in Figure 19 Core Porosity versus Log Porosity for all wells is plotted with $\mathrm{a} \pm 10 \%$ off limit line to show how well they correlate each other. The $\mathrm{R}^{2}$ coefficient for this correlation is 0.843 .

Table 3. Average Core Depth Shifting

\begin{tabular}{|c|c|c|}
\hline Well Name & $\begin{array}{c}\text { Core Depth } \\
\text { Shifting (ft) }\end{array}$ & Direction \\
\hline Cw1 & 0.12 & Downward \\
\hline Cw2 & 1.63 & Upward \\
\hline Cw3 & 0.95 & Downward \\
\hline Cw4 & 1.50 & Upward \\
\hline Cw5 & 0.50 & Upward \\
\hline Cw6 & 0.50 & Downward \\
\hline Cw7 & 1.75 & Upward \\
\hline
\end{tabular}

Figure 19. Porosity Correlation for All Wells

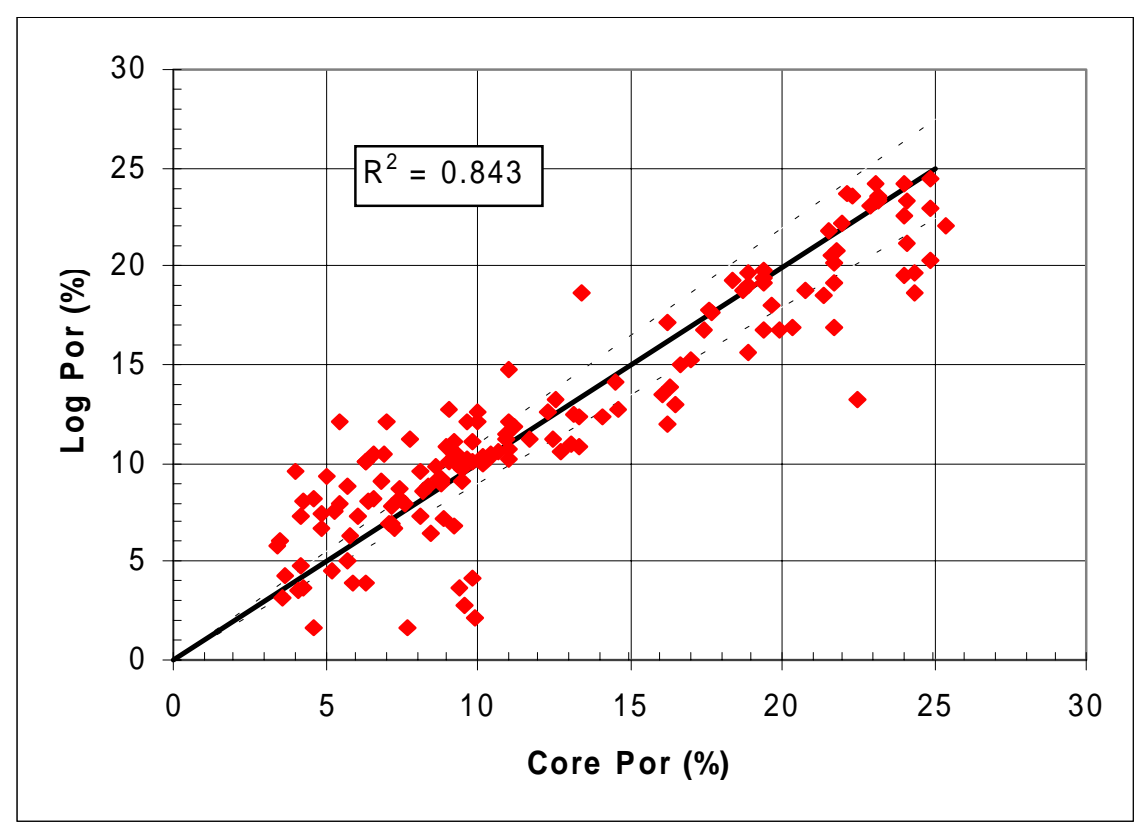


Even though core porosity values are not exactly the same as porosity values determined from logs, the important point here is that porosity trends follow the same profile at a given depth interval in the pay zone.

Among the factors that contribute with the fact that core and log porosity values are not the same are the heterogeneity of the formation, so the matrix density is not constant in the zone of interest, and the limitations of the methods to estimate porosity. Logging tools record values based on the average of the surroundings at a given point whereas core plug measurements reflect more details of that specific point. This effect can be seen in Figure 18 for well Cw5, at 3103 and $3106 \mathrm{ft}$. core porosity is less that log porosity because at these depths are two thin conglomerate-shale layers of 3 to 4 inches each that the logging tool can not detect but core plug method can.

Once all of the wells were correlated in porosity, the second step correlating the core-log data was to plot the permeability and log responses (RHOB and GR) versus depth as resulted in the previous step to observe the similar relationships between them as it is seen in Figure 20. Annexes A through G show plots for all of the cored wells. In the development of these plots, a cut-off value in permeability of $0.1 \mathrm{md}$ was considered. since an interval in the formation having such low permeability would not be of interest. In addition these low permeable zones do not form part of the main pay zone. 


\section{Figure 20. Permeability vs. Log Responses for Well Cw4}

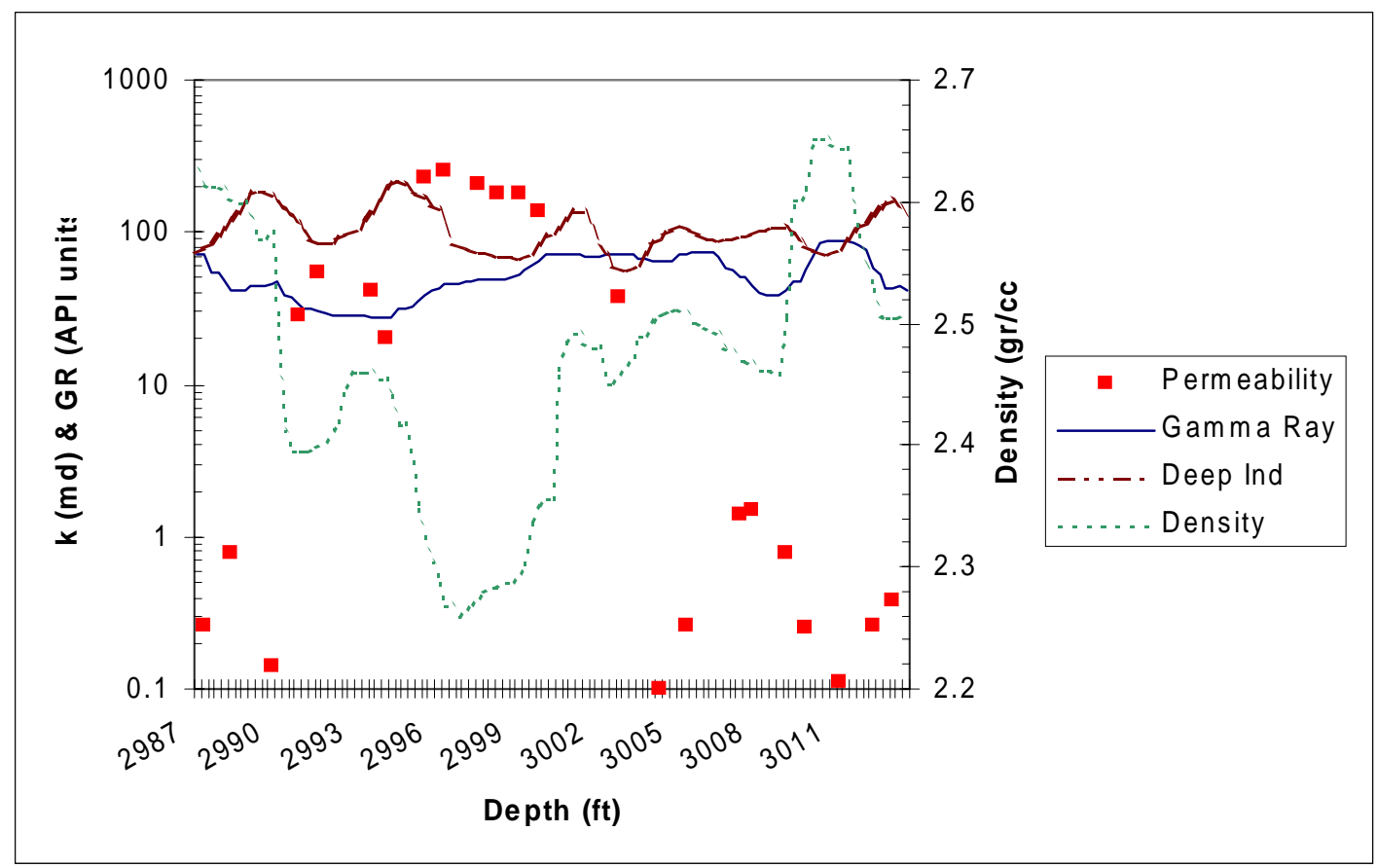

An empirical correlation with the following function was obtained for the cored wells, which was initially used to estimate permeability in the pilot wells:

$$
k=0.0275 e^{0.3853 \phi}
$$

Where:

k: Permeability (md)

$\phi=$ Porosity $(\%)$

This function gives an $\mathrm{R}^{2}$ correlation coefficient of about $73.3 \%$, which is considered unsatisfactory for the purpose of this study and is also indicative of the heterogeneous nature of the formation. This confirms that a simple relationship between permeability and porosity can not be established in such formations to accurately estimate this rock property. Observe Figure 21. 
Figure 21. Core Permeability - Log Porosity Correlation

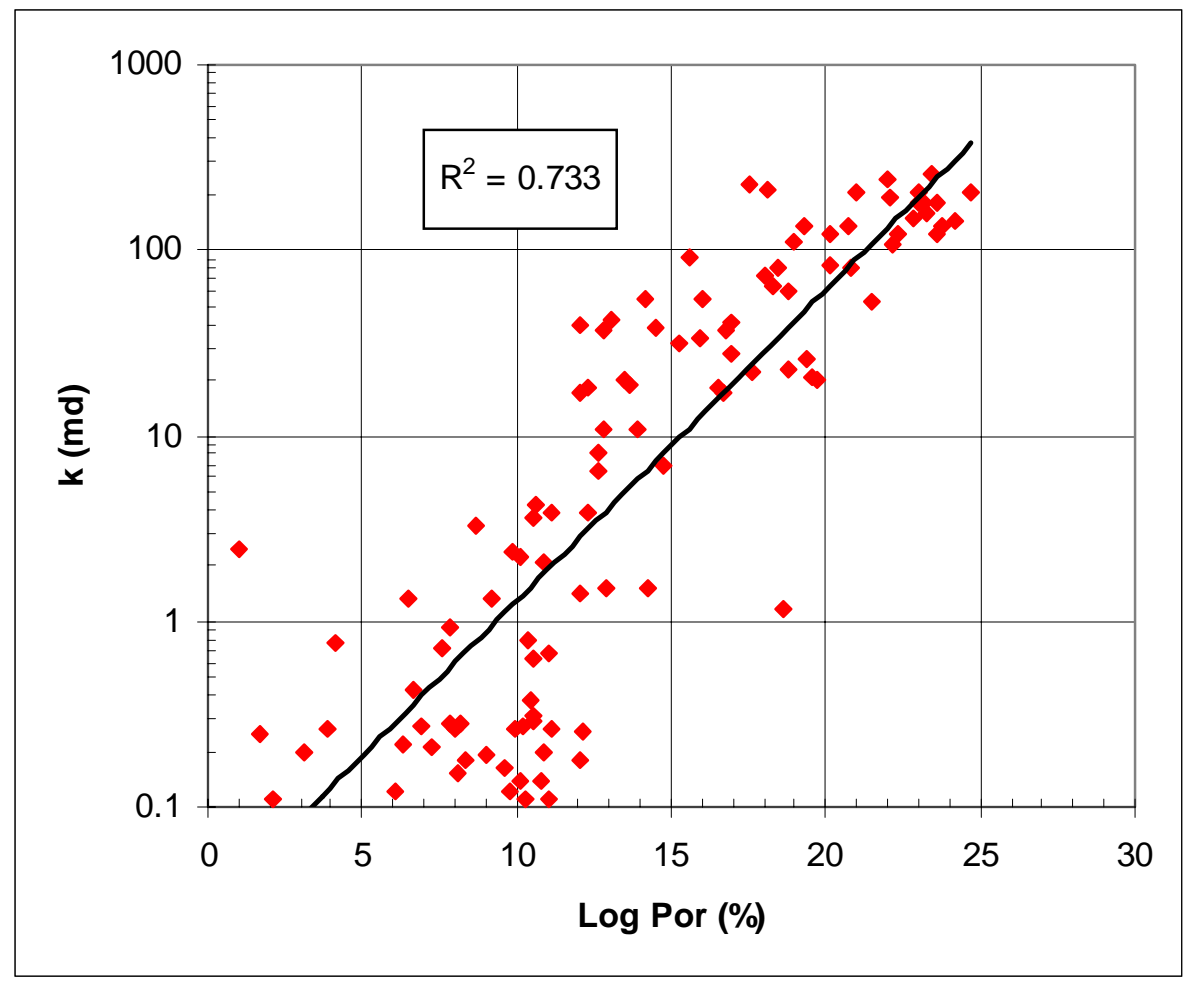

\subsection{Input Selection}

As stated previously, Pattern Recognition, one of the strong points of Neural Networks, stems from the idea of a hypothesis of representation, in other words, knowledge can be acquired, manipulated and interpreted in a symbolic manner.

For a successful application of pattern recognition it is necessary to describe the details of the nature of the object. This stage is of paramount importance since if object is not described in terms of appropriate physical or conceptual features can lead to complex decision rules in the ANN, while the choice of adequate features based on a theoretical guidance will result in simple and comprehensive rules. 
This study departs from the assumption that geophysical log data can provide valuable information about formation permeability. This relationship between permeability and log data may not be direct and explicit. Since the objective of the study is to obtain permeability values from log data, the first and logical selection as input data was the Gamma Ray (GR) and Density (RHOB) logs. GR logs are an indication of the clay content and shaliness of the rock, while RHOB log responses measure the porosity of the formation. Although there were other logs available in the reservoir such as neutron porosity and induction logs, the choice of this particular set of logs (GR and RHOB) was primarily dictated by their availability in the majority of the wells in the Stringtown field.

The second set of input data consisted of the well coordinates and depth intervals for that well. This data set defines the points where core plugs were taken from the outcrop, hence locating them in a three-dimensional spatial model.

The slopes of the log responses versus depth, i.e., the first derivative of these variables, formed the third set of input data since they would provide useful information as the rate of change to the neural net. The slopes were computed using the three-point method, which considers that the value of the derivative at a given point is a function of the weighted average of the previous and next slopes relative to that point. See Figure 22. 
Figure 22. Derivative Calculation Using the Three-point Method

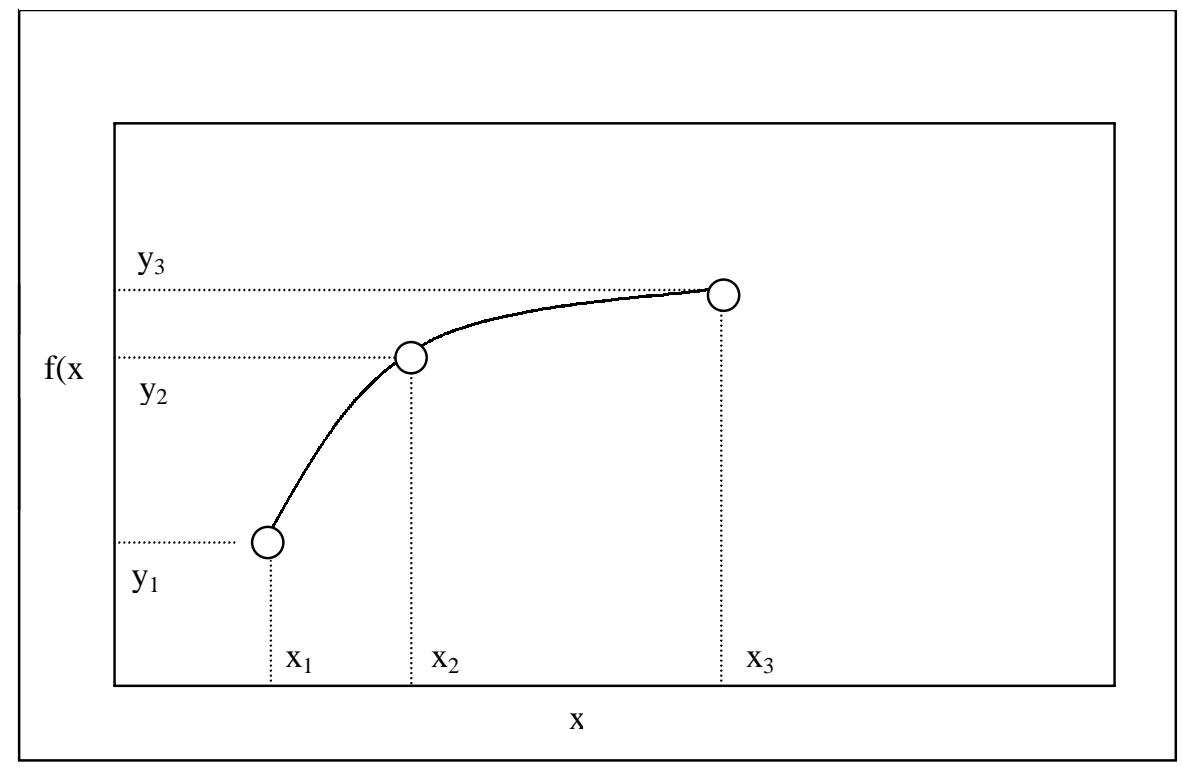

According to the fore statement, the value of the derivative at point $2, \mathrm{~m}_{2}$, is:

$$
\begin{aligned}
& m_{l}=\frac{y_{2}-y_{1}}{x_{2}-x_{1}} \quad m_{r}=\frac{y_{3}-y_{2}}{x_{3}-x_{2}} \\
& m_{2}=\frac{\left(x_{3}-x_{2}\right) m_{l}+\left(x_{2}-x_{1}\right) m_{r}}{\left(x_{3}-x_{2}\right)+\left(x_{2}-x_{1}\right)}
\end{aligned}
$$

The next set of input data is conformed by the second derivatives of the log responses. Second derivatives, along with the first derivatives give details of relative minimum and maximum, points of inflexion and curve shape in general. These derivatives were computed using the same method of three-point used in the calculation of the first derivatives.

The final set of input data consisted of the GR and RHOB log baselines. They define important data during the logging procedure such as the tool calibration; also, GR $\log$ baseline helps define the shaliness of the formation surroundings. 
In summary, the input data selected to train the ANN consisted of eleven parameters: RHOB and GR log values, well coordinates and depth, the first and second derivatives of the $\log$ responses and the log baselines. Of course, the input data set also featured the correspondent values of core plug permeability as target outputs of the supplied log and spatial information.

\subsection{Neural Network Development}

In order to obtain reliable results of the permeability predictions, several artificial neural network architectures and paradigms were used. It has been concluded that a threelayer back-propagation network with three slabs in the middle layer, each slab having a different activation function is the most appropriate architecture to make forecasts, because of its prediction capabilities and ability to generalize well on a wide variety of problems. This type of network is very powerful when each middle slab is given a different activation function from the other slabs because they detect different features of the input vectors. This gives the output layer three different viewpoints of the data simultaneously.

The activation functions used for the middle slabs in this model were a sigmoid function (hyperbolic tangent) and two probabilistic functions (Gaussian and Gaussian complement). Sigmoid functions are very useful since they stresses the range of the input data so if it is not above a certain value a weak output is transmitted, in other words, it detects the amount of its preferred feature present. On the other hand, probabilistic 
functions are unique in ANN's applications, because unlike other sigmoid activation functions, they are not increasing functions. The Gaussian function maps high values into low ones, and maps mid-range values into high ones. It brings out meaningful characteristics not found at the extreme ends of the sum of weighted values. On the other hand, the Gaussian Complement function tends to bring out meaningful characteristics in the extremes of the data. Figure 23 depicts a schematic of the network architecture.

Figure 23. ANN Architecture Selected

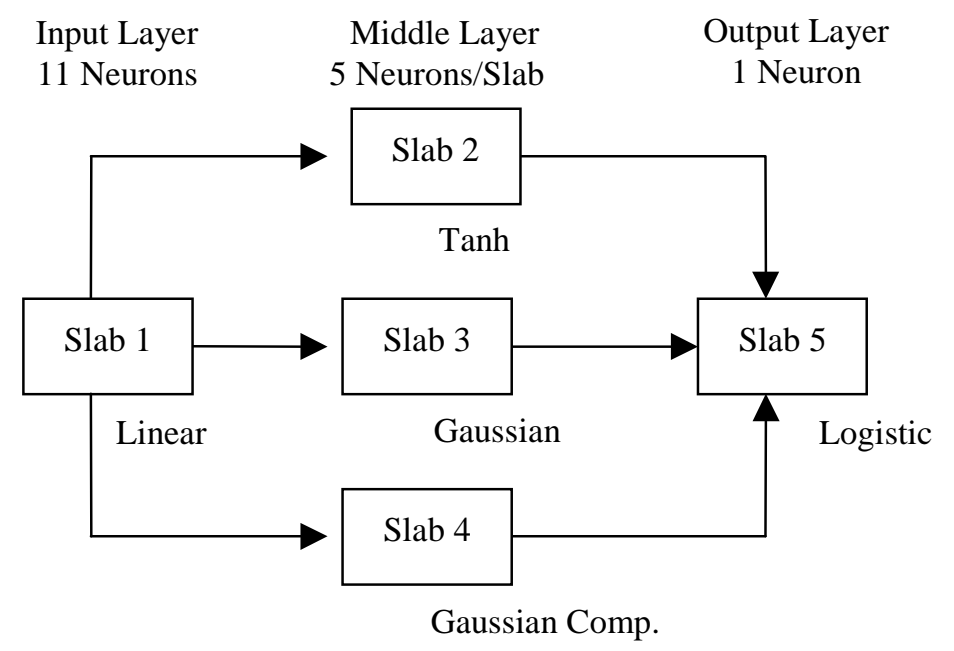

As usual, the activation function is linear so input variables are passed as such to the middle layer. Finally the logistic function is selected as the output layer's activation function to accent the range of its net input, in addition, as a type of sigmoid function it helps to reduce the computational overburden during training because of the simple relationship between the function itself and its derivative.

The number of neurons in the input layer is naturally the same as the number of relevant variables describing the features of the object in this case eleven; and since there 
is only one output variable to predict, a neuron is used in the output layer. The number of neurons in the middle layer is given by the following formula:

$$
\begin{aligned}
& \text { number of neurons }=\frac{(\text { inputs }+ \text { outputs })}{2}+\sqrt{\text { data point } s \text { in training set }} \\
& \text { number of neurons }=\frac{(1+11)}{2}+\sqrt{96} \approx 15.8
\end{aligned}
$$

The number of data points in the training set equals 96 since the test set was selected as $20 \%$ of the pattern set, which is conformed by 119 points. Therefore, the 96 data points in the pattern set form the remaining $80 \%$. The total number of neurons in the middle layer is evenly distributed among the three slabs so five neurons are assigned to each middle slab.

\subsection{Neural Network Training}

The training of the selected artificial neural network took place based on a total of 119 training data points from the cored wells. It is considered that this kind of problem was very complex and noisy so the learning rate and momentum were set at 0.1 each. The training data set was split in a pattern set and a test set. The test set was chosen as $20 \%$ of the training set. The data points in the test set were randomly selected. The values to initialize the weights on all connection links were set at 0.3 and the calibration interval was set at 200 learning events. The criterion to stop training was set when the number of training events reached 20,000 after a minimum error on the test set was computed. With this configuration, the ANN supplied the following results. 
Table 4. ANN Statistical Results

\begin{tabular}{|l|r|}
\hline & \multicolumn{1}{|c|}{$\begin{array}{c}\text { Core Plug } \\
\text { Oermeability }(\mathrm{md})\end{array}$} \\
\hline R squared (pattern set): & 0.975 \\
\hline r squared (pattern set): & 0.9757 \\
\hline Mean squared error: & 110.144 \\
\hline Mean absolute error: & 6.186 \\
\hline Min. absolute error: & 0.015 \\
\hline Max. absolute error: & 46.221 \\
\hline Correlation coefficient $r:$ & 0.9878 \\
\hline r squared (training set only): & 0.980 \\
\hline r squared (test set only): & 0.969 \\
\hline
\end{tabular}

The most important feature to notice in Table 4 is that the $\mathrm{R}^{2}$ coefficient for the pattern set is as high as 0.9757 , where 1.0 is a perfect match. For the training and test set the $\mathrm{R}^{2}$ coefficient is respectively 0.98 and 0.969 . To compare the network predictions versus actual core permeability data; a plot of these two values versus depth was made for each of the cored wells used in training. Figure 24 shows the results for well $\mathrm{Cw} 4$.

Figure 24. Comparison of ANN Predictions vs. Actual Core Permeability (Well Cw4)

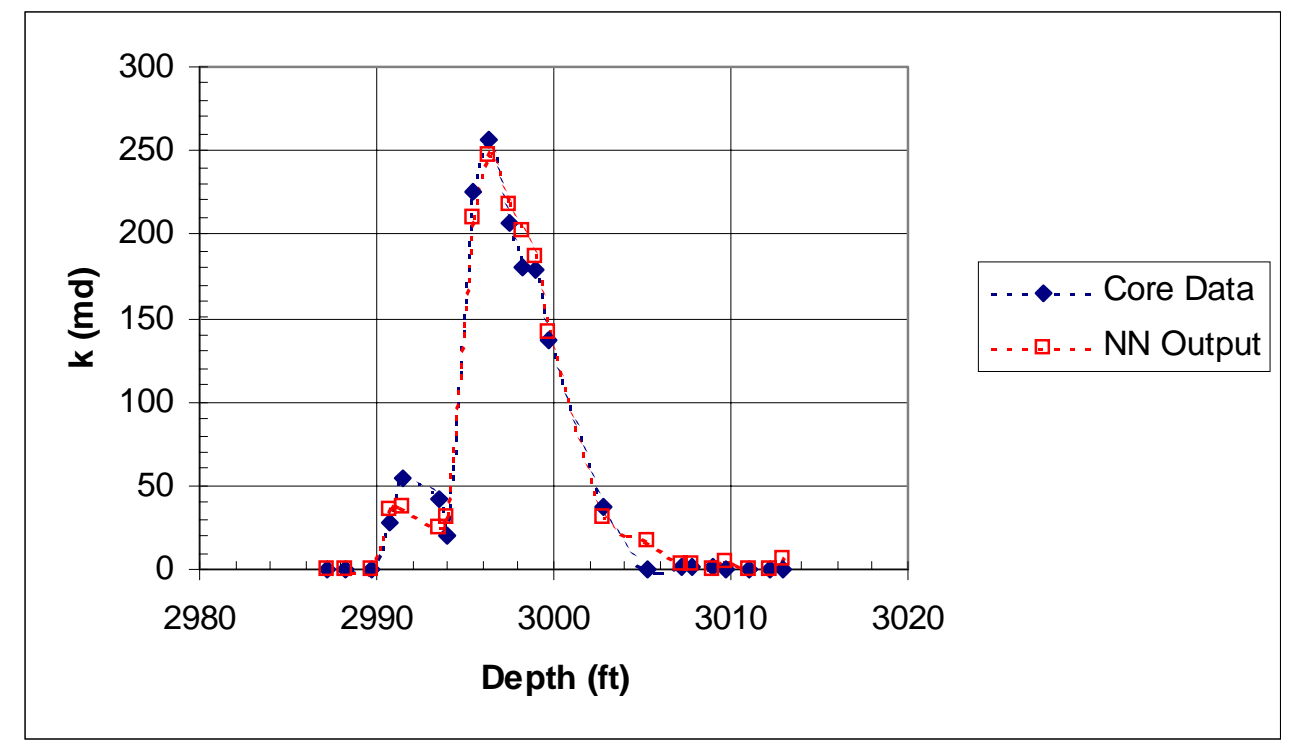


As it is seen in Figure 25, ANN Predictions versus Actual Core Permeability for all of the wells is plotted with a $\pm 10 \%$ off limit line to show how well they correlate each other. This graph includes all of the 119 data points used in training.

Figure 25. Correlation between Predicted and Actual Core Permeability (Complete Pattern Set)

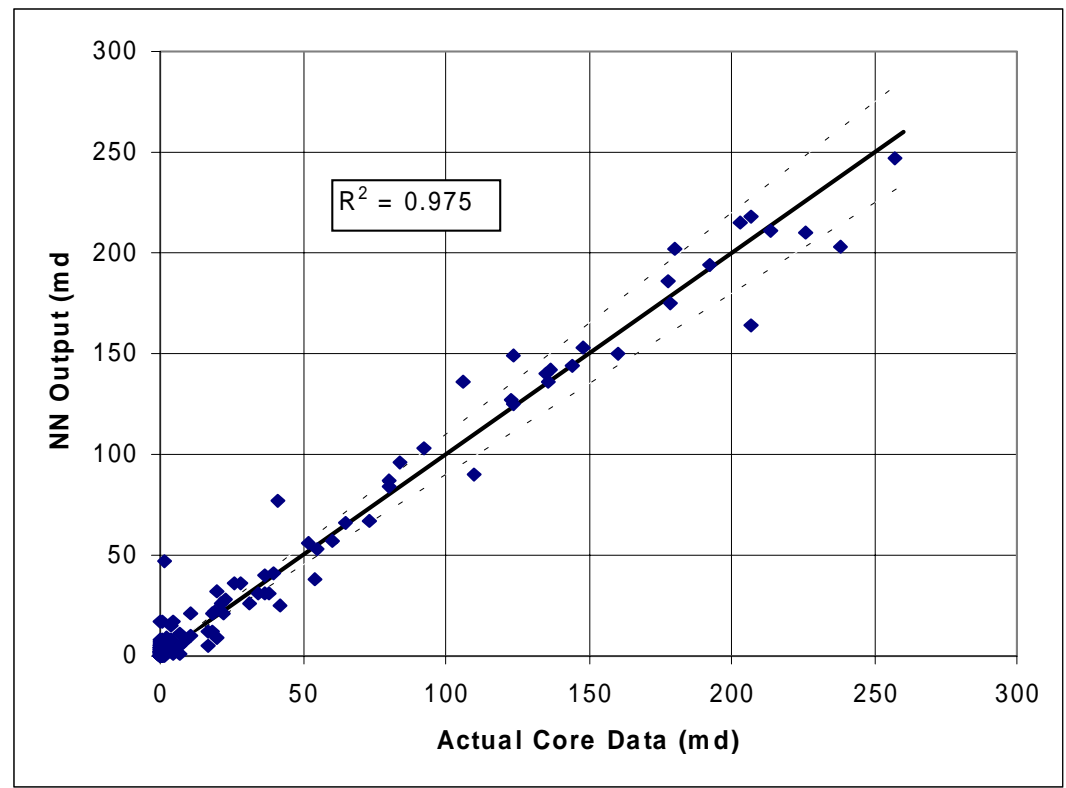

Figure 26. Correlation between Predicted and Actual Core Permeability (Test Set Only)

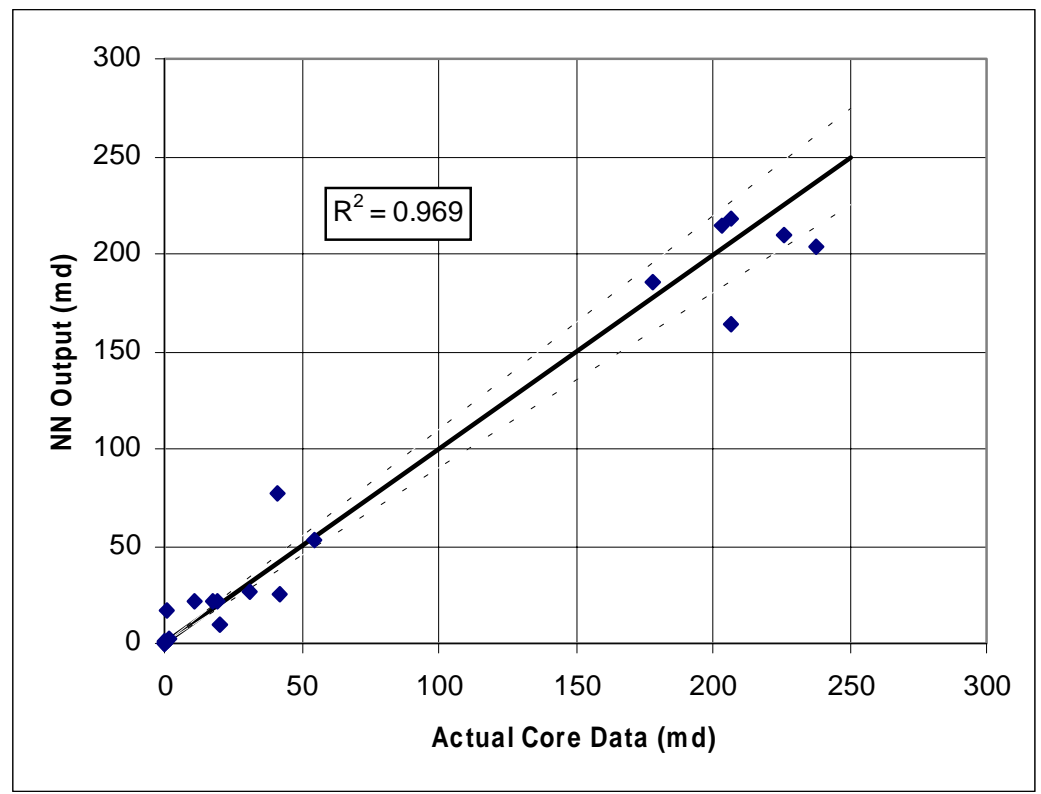


The strength of the input variables to predict permeability is given by their degree of contribution to the output layer, which is determined by the weights of the connection links between layers. On a percentile scale, contribution factors are shown in Table 5. It is observed from Table 5 that the two most important variables to the ANN are the RHOB and GR logs. Depth and the log first derivatives also play a significant role in the model. The weakest variables are the log second derivatives. However this does not mean that they may be taken out of the model, as it will be seen in the ANN verification process doing so decreases the $\mathrm{R}^{2}$ coefficient and worsens the permeability forecast.

\section{Table 5. Input strength}

\begin{tabular}{|l|r|}
\hline Input Variable & Input Strength \\
\hline RHOB Log & 14.65 \\
\hline GR Log & 11.80 \\
\hline Depth & 10.15 \\
\hline RHOB Log 1st Derivative & 9.56 \\
\hline Y Coordinate & 9.14 \\
\hline GR Log 1st Derivative & 9.04 \\
\hline RHOB Log Baseline & 8.02 \\
\hline GR Log Baseline & 7.40 \\
\hline X Coordinate & 7.35 \\
\hline RHOB Log 2nd Derivative & 6.50 \\
\hline GR 2nd Derivative & 6.40 \\
\hline & 100.00 \\
\hline
\end{tabular}

\subsection{Neural Network Verification}

Back-propagation models are known by their ability to generalize well on data that they have never seen due to the use of test sets during training. The ANN was also carefully designed in terms of setting parameters such as calibration, learning rate and momentum. The selected ANN architecture provides a great advantage as the 
simultaneous analysis of the data from three different standpoints. Finally, the results obtained in terms of the $\mathrm{R}^{2}$ coefficient were promising, both for the pattern and test set, as well as for the training set. Despite all of the previous facts, one further step was taken to verify the ANN model and its predictions. This was done by means of production sets.

A production set consists in one input data set with its correspondent actual target outputs, which was not used during training. Thus, to verify the robustness of the ANN model, several similar networks were developed, while a cored well was put aside during training. The net just created was used with the input data set of that well to obtain the permeability predictions. Then the predictions were compared against the actual core permeability for that given well. The results of this process are shown in Table 6.

\section{Table 6. Production Sets Results}

\begin{tabular}{|c|c|c|r|}
\hline $\begin{array}{c}\text { Well in } \\
\text { Production Set }\end{array}$ & $\begin{array}{c}\mathrm{R}^{2} \text { Coefficient } \\
\text { (Training + Test + Production Set) }\end{array}$ & $\begin{array}{c}\mathrm{R}^{2} \text { Coefficient } \\
\text { (Training + Test Set) }\end{array}$ & $\begin{array}{c}\mathrm{R}^{2} \text { Coefficient } \\
\text { (Production Set) }\end{array}$ \\
\hline Cw1 & 0.882 & 0.978 & 0.861 \\
\hline Cw2 & 0.932 & 0.972 & 0.909 \\
\hline Cw3 & 0.937 & 0.981 & 0.914 \\
\hline Cw4 & 0.956 & 0.973 & 0.932 \\
\hline Cw5 & 0.873 & 0.979 & 0.851 \\
\hline Cw6 & 0.929 & 0.973 & 0.906 \\
\hline Cw7 & 0.842 & 0.843 & 0.821 \\
\hline
\end{tabular}

In all cases, when the training excluded the production set, the $\mathrm{R}^{2}$ coefficient computed for the pattern set (training + test set) was higher than that calculated using the whole data set, meaning that the ANN learned well during training. Nevertheless, when computing the $\mathrm{R}^{2}$ coefficient for all of the data points, it is still acceptable since this value 
is higher than 0.84. One of the factors affecting this situation is the fact that when production sets are used, the ANN trains on fewer points than the complete pattern set, so it has to infer permeability values based on less knowledge. Yet, in all cases, the $\mathrm{R}^{2}$ coefficient for the production set was reasonably good when compared to that obtained from the pattern data set.

Three additional verifications were carried out during this process. First, the ANN was trained excluding the least important inputs according to the input strengths shown on Table 5, namely the second derivatives of the log responses. Second, the spatial coordinates were excluded from the training set. Third, since induction digitized logs were also available for six out of the seven cored wells, this variable and its related inputs (log baseline, first and second derivative) were included in a training run. Table 7 shows the results of these three cases.

Table 7. ANN Results When Excluding Inputs

\begin{tabular}{|l|r|r|r|}
\hline & \multicolumn{2}{|c|}{ Excluding } & \multicolumn{2}{c|}{$\begin{array}{c}\text { Including } \\
\text { Induction Logs }\end{array}$} \\
\cline { 2 - 3 } & $2^{\text {nd }}$ Derivatives & Spatial Coordinates & 0.965 \\
R squared: & 0.953 & 0.778 & 0.966 \\
r squared: & 0.955 & 0.794 & 165.108 \\
Mean squared error: & 207.715 & 977.172 & 8.188 \\
Mean absolute error: & 7.852 & 20.956 & 0.024 \\
Min. absolute error: & 0.046 & 0.074 & 58.037 \\
Max. absolute error: & 94.424 & 106.461 & 0.983 \\
Correlation coefficient $r:$ & 0.977 & 0.891 & \\
\hline
\end{tabular}


Results from Table 7 suggest that excluding the log second derivatives may as well lead to reasonable good permeability predictions. Induction log inputs provide similar results when included in the model, but spatial coordinates ( $\mathrm{x}$ and $\mathrm{y}$ coordinates and depth) play a significant role in the model. Induction logs were not included in the final model because they were available only for a few wells field-wide.

\subsection{Neural Network Prediction}

With these promising results, permeability was predicted for the rest of the uncored wells in the reservoir. Finally, an integration by numerical methods of the permeability profile for each well was made to compute the flow capacity $\mathrm{k} * \mathrm{~h}$. The results are shown in Figures 27 (cored well Cw5) and 28 (uncored well Pi1).

Figure 27. Permeability Profile Based on ANN Predictions for Well Cw5

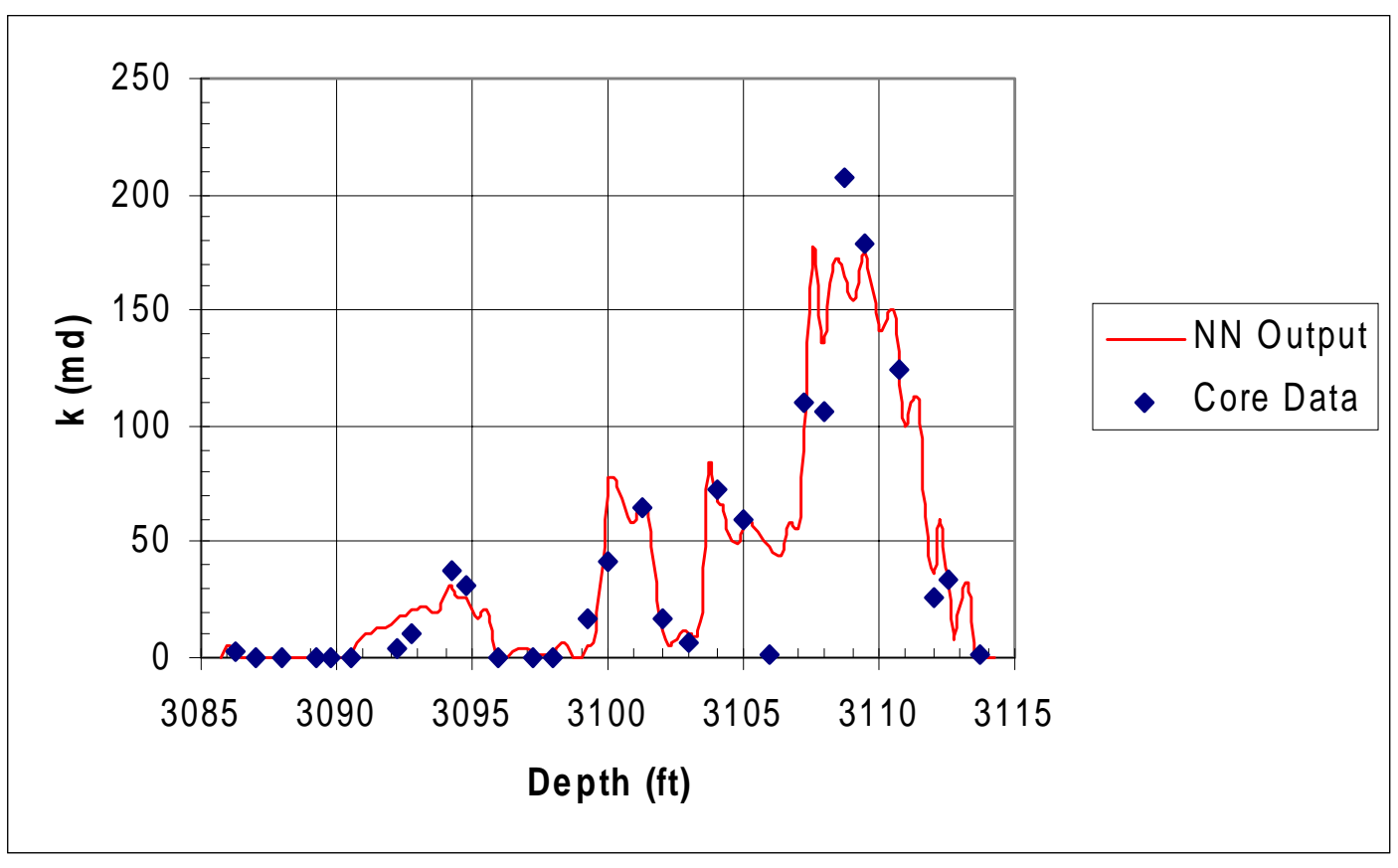


Figure 28. Permeability Profile Based on ANN Predictions for Well Pi1

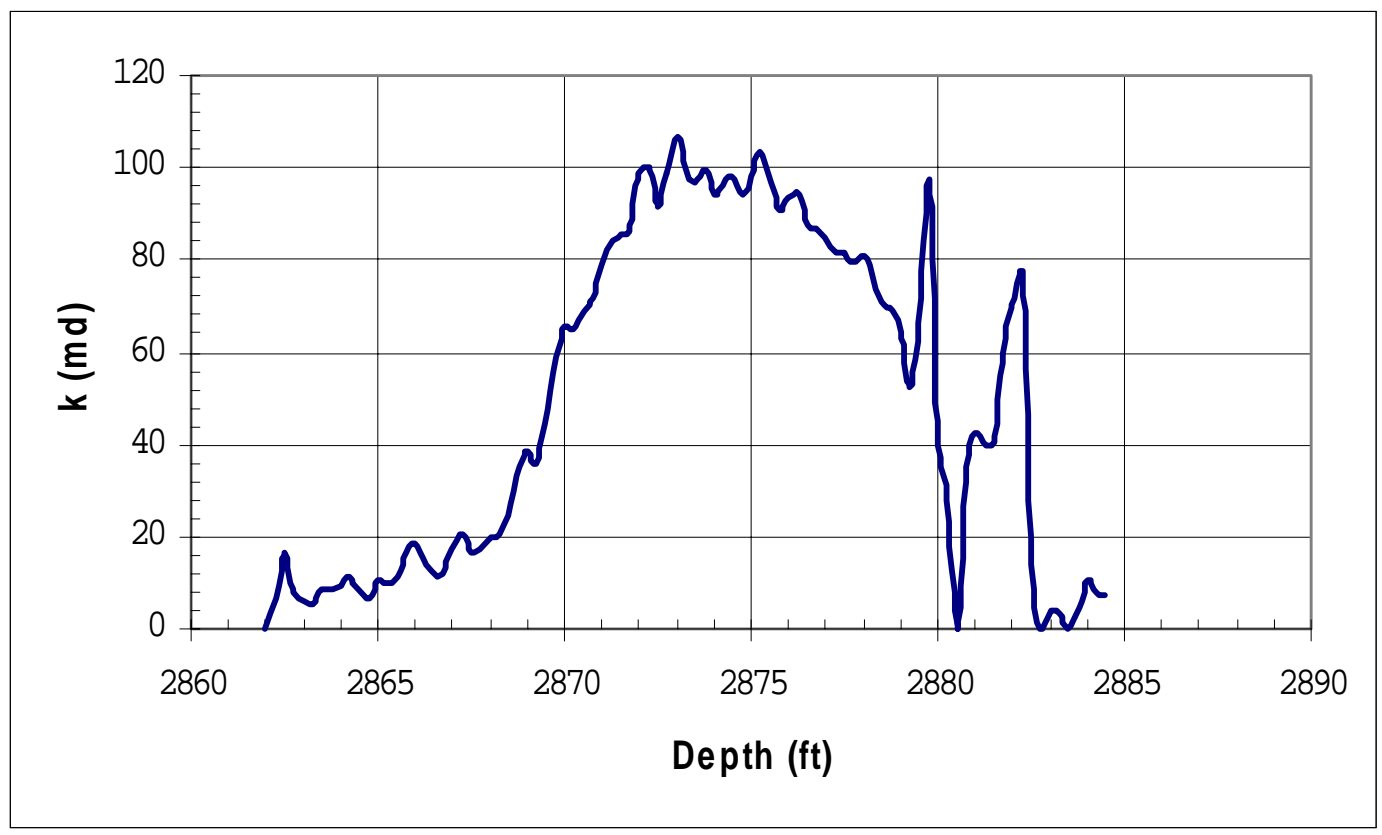

Since the digitalization process of the log responses provided a resolution of a quarter foot, it was possible to obtain a permeability value every three inches in the pay zone interval for any well. Thus the flow capacity for each well was calculated by the method described in section 2.3. The average permeability per well was computed simply as the ratio between flow capacity and thickness. 


\section{Chapter 4: Results}

With such promising results from the verification process, permeability was predicted by exposing the ANN developed to the rest of the uncored wells in the reservoir. Finally, an integration by numerical methods of the permeability profile for each well was made to compute the flow capacity $k * h$. This was made first, for the waterflooded pilot area and then, for the entire field.

\subsection{Pilot Area}

The permeability and flow capacity distribution for the pilot area is shown in Figures 29 and 30 as pattern grid is defined by the block configuration used in the oil simulator software to match production history.

Figure 29. Flow Capacity Surface Map (kh) for the Pilot Area

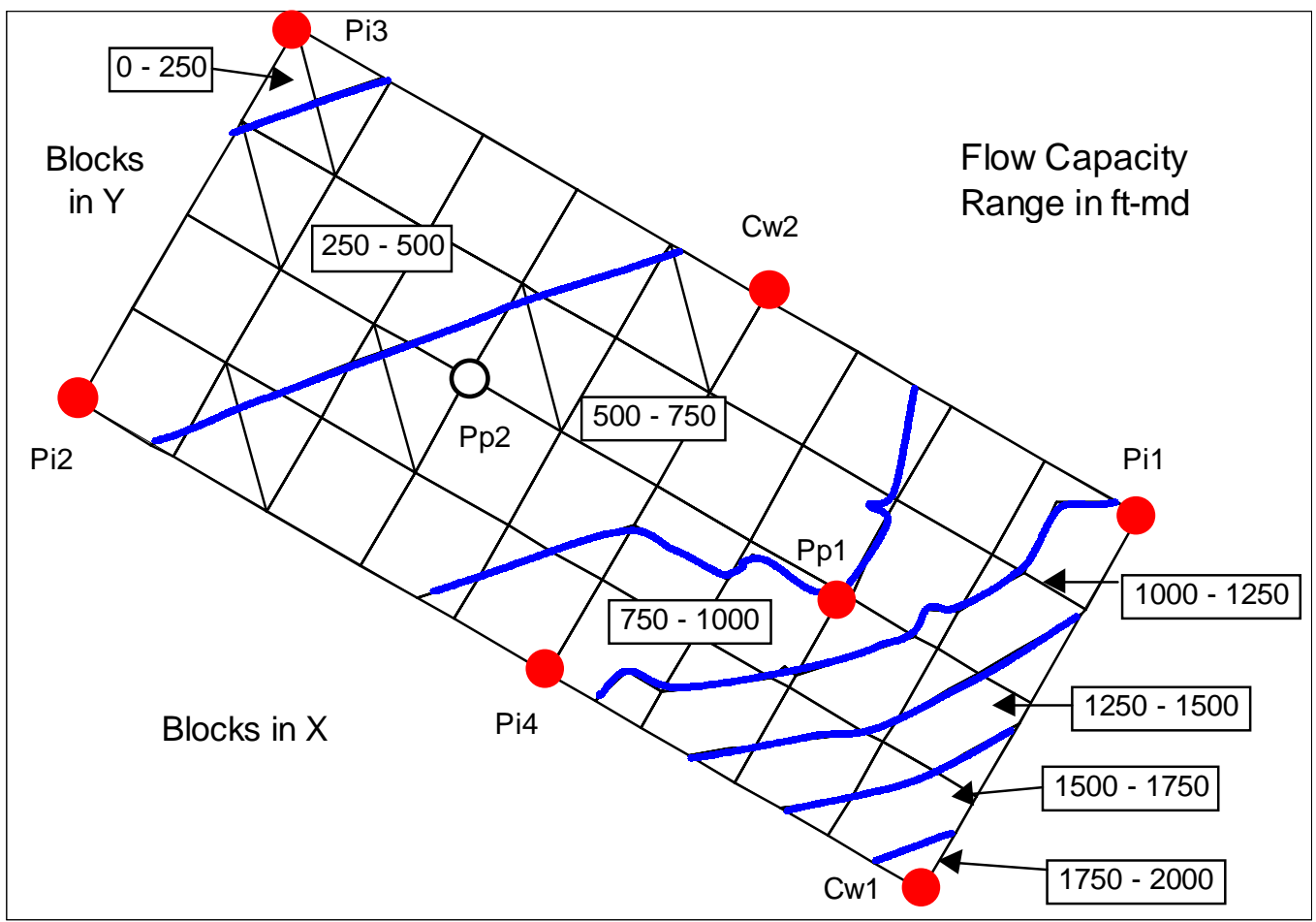


Figure 30. Permeability Distribution in the Pilot Area

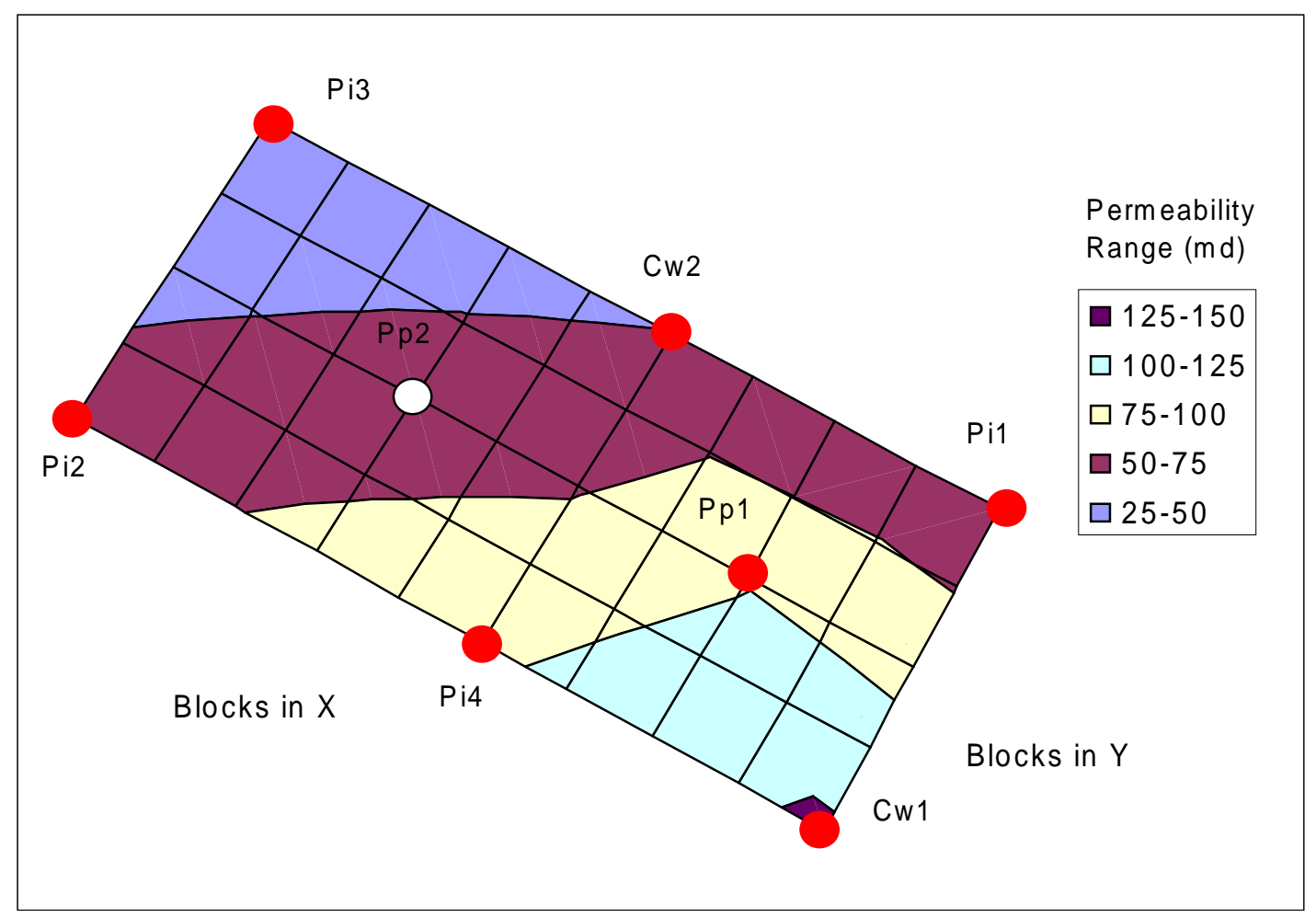

From Figures 29 and 30, it is clearly seen that flow capacity and average permeability distribution in the waterflooded pilot area follow the same trend, with the lowest value at injection well $\mathrm{Pi} 3$ and the highest at well $\mathrm{Cw} 1$. Formation properties at producer well Pp2 (white circle in both figures) were interpolated among injection wells defining the corners of its five-spot pattern, since no log data was available for it.

A close look at the permeability profile for each pilot well (Appendix II), suggests that the pay zone is made of two layers, the upper one with low permeability and the lower layer with high permeability. The values are given in Table 6 and also plotted in Figures 31 and 32. With these considerations, an oil simulator was run including the permeability prediction from the ANN. A better match in the production history was 
achieved from the permeability distribution in the pilot area, not only upon the cumulative production but also on the general shape of the curve. See Figure 33.

Table 8. Flow Capacity and Layer Delimitation (Pilot Wells)

\begin{tabular}{|c|c|c|c|r|r|r|}
\hline & \multirow{2}{*}{$\begin{array}{c}\text { Pay Zone } \\
\text { Well }\end{array}$} & \multirow{2}{*}{$\begin{array}{c}\text { Thickness } \\
\text { Interval (ft) }\end{array}$} & \multicolumn{2}{|c|}{ Layer Delimitation } & \multicolumn{2}{c|}{ Flow Capacity (md-ft) } \\
\cline { 4 - 7 } & 2863 to 2881 & 18 & 2863 & 2869 & 94.9 & 1024.9 \\
\hline Pi1 & & & 2869 & 2881 & 930.0 & \\
\hline Pi2 & 2794 to 2801 & 7 & 2794 & 2798 & 137.6 & 431.9 \\
& & & 2798 & 2801 & 294.2 & \\
\hline Pi3 & 2840 to 2846 & 6 & 2840 & 2843 & 93.8 & 178.0 \\
& & & 2843 & 2846 & 84.2 & \\
\hline Pi4 & 2955 to 2964 & 9 & 2955 & 2960 & 269.4 & 870.9 \\
& & & 2960 & 2964 & 601.6 & \\
\hline Pp1 & 2944 to 2950 & 6 & 2944 & 2947 & 402.9 & 717.6 \\
& & & 2947 & 2950 & 314.7 & \\
\hline Cw1 & 2894 to 2907 & 13 & 2894 & 2900 & 706.0 & 1881.4 \\
& & & 2900 & 2907 & 1175.4 & \\
\hline Cw2 & \multirow{2}{*}{3084 to 3094} & 10 & 3084 & 3090 & 127.0 & 565.5 \\
& & & 3090 & 3094 & 438.5 & \\
\hline
\end{tabular}

Figure 31. Flow Capacity Distribution in the Upper Layer of the Pilot Area

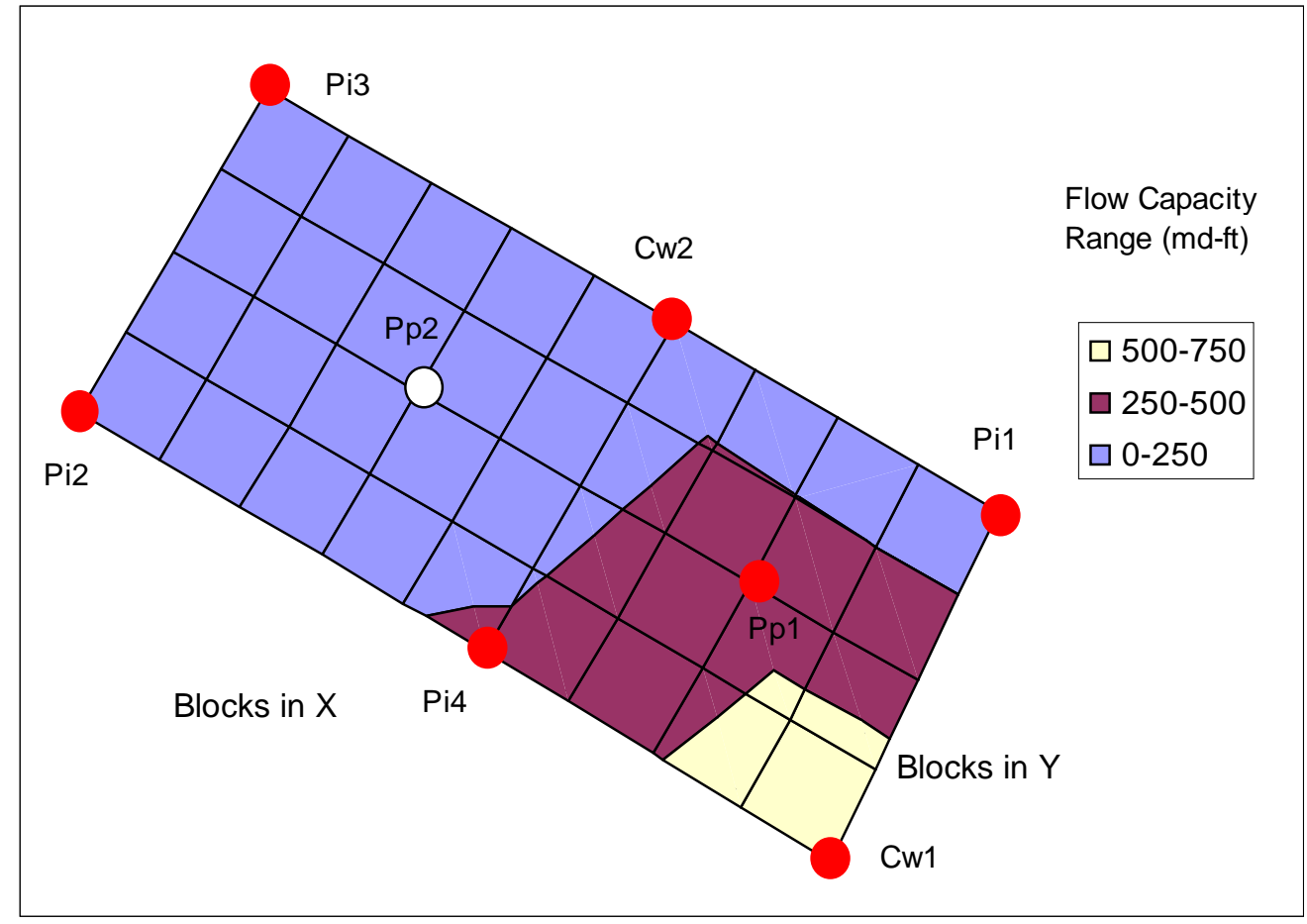


Figure 32. Flow Capacity Distribution for the Lower Layer of the Pilot Area

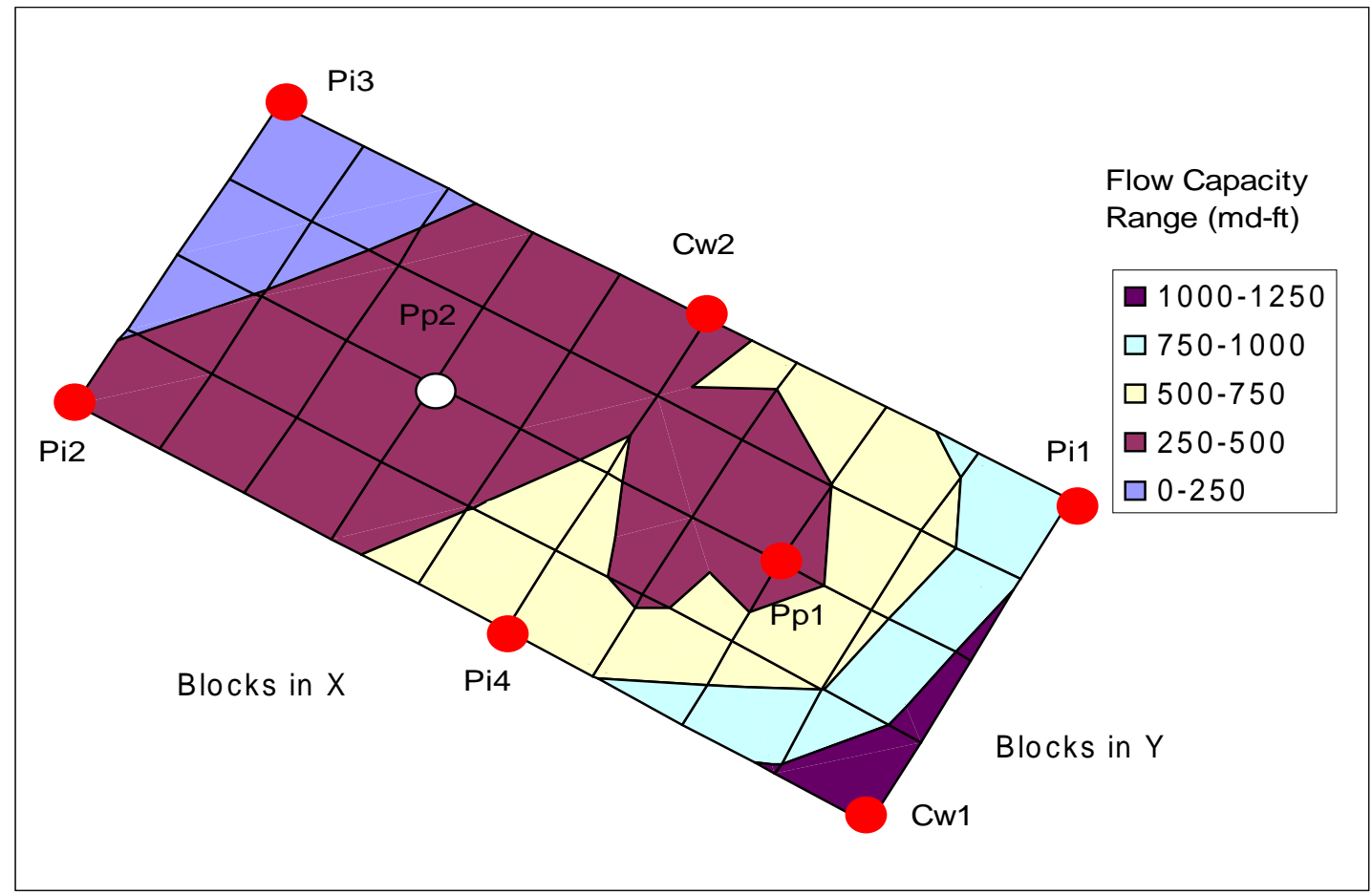

Figure 33. History Production Match

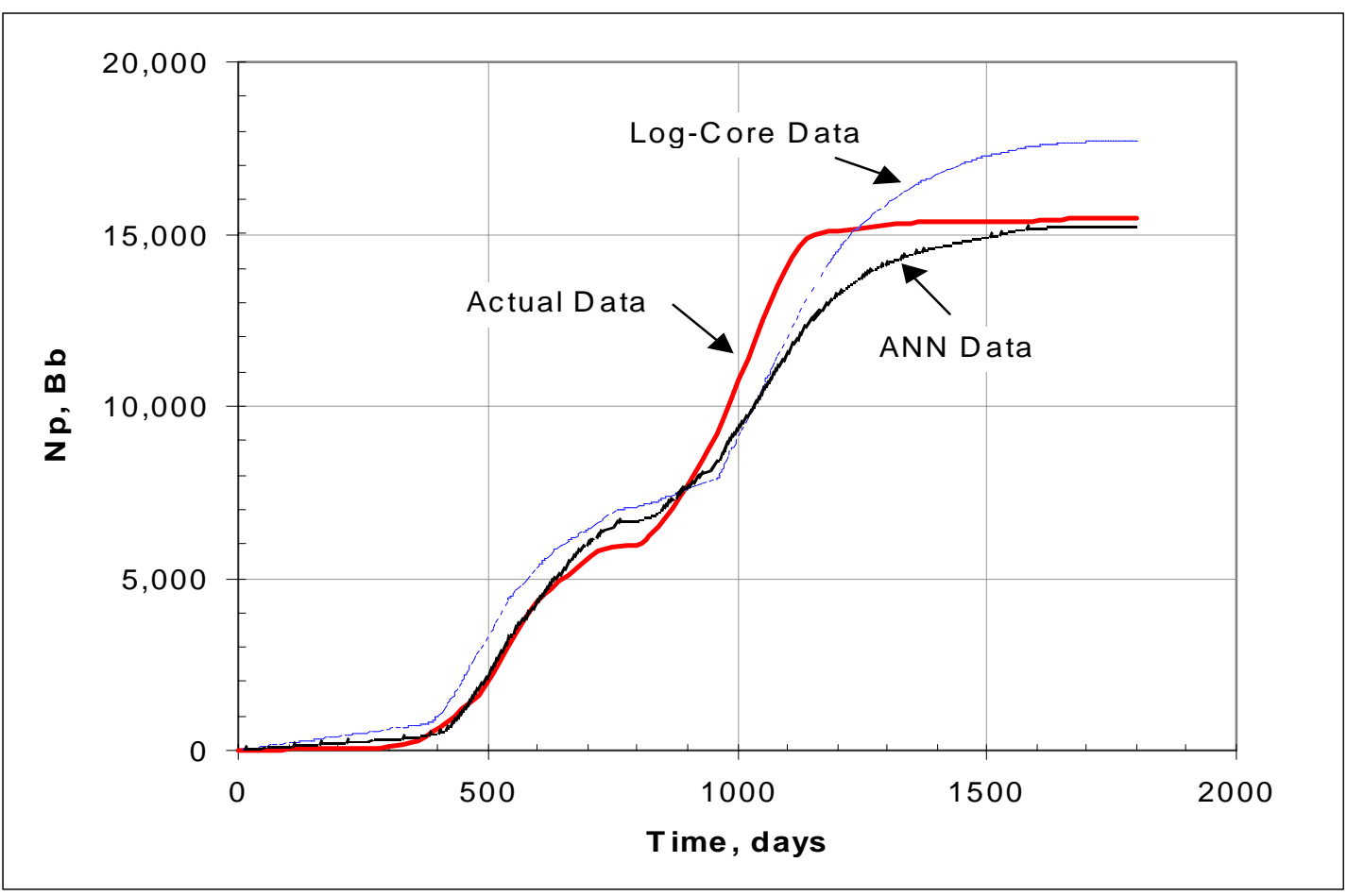




\subsection{Flow Capacity Zones}

Once the permeability prediction was done for the pilot area, ANN forecast was extended field-wide. Similarly, the permeability profile per well was obtained, along with the computation of the flow capacity $\mathrm{k}^{*} \mathrm{~h}$ and average permeability. The results were mapped, hence defining the most productive zones in the reservoir.

Figure 34. Flow Capacity Distribution in the Stringtown Field

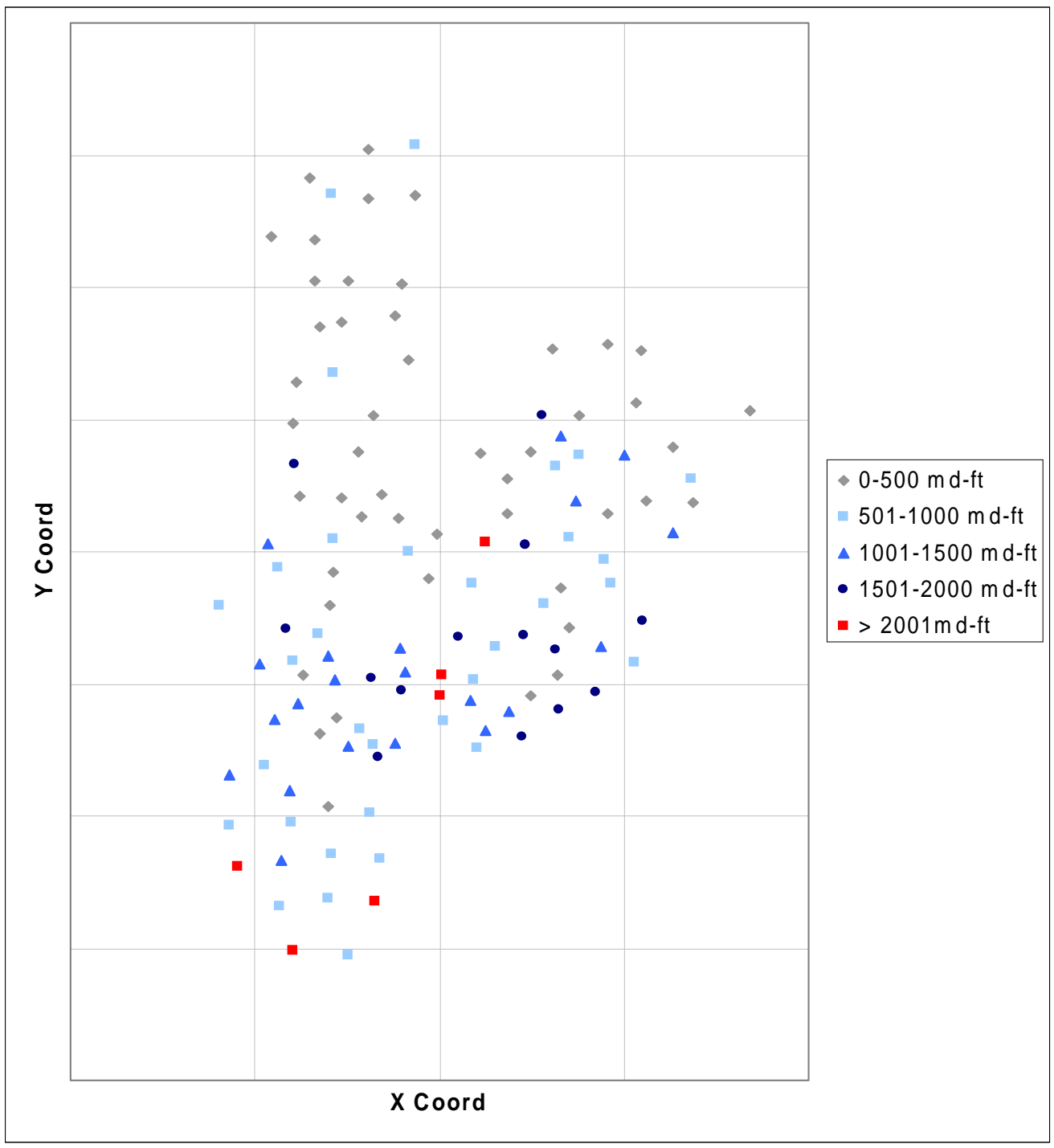


Figure 35. Flow Capacity Contoured Map of the Stringtown Field

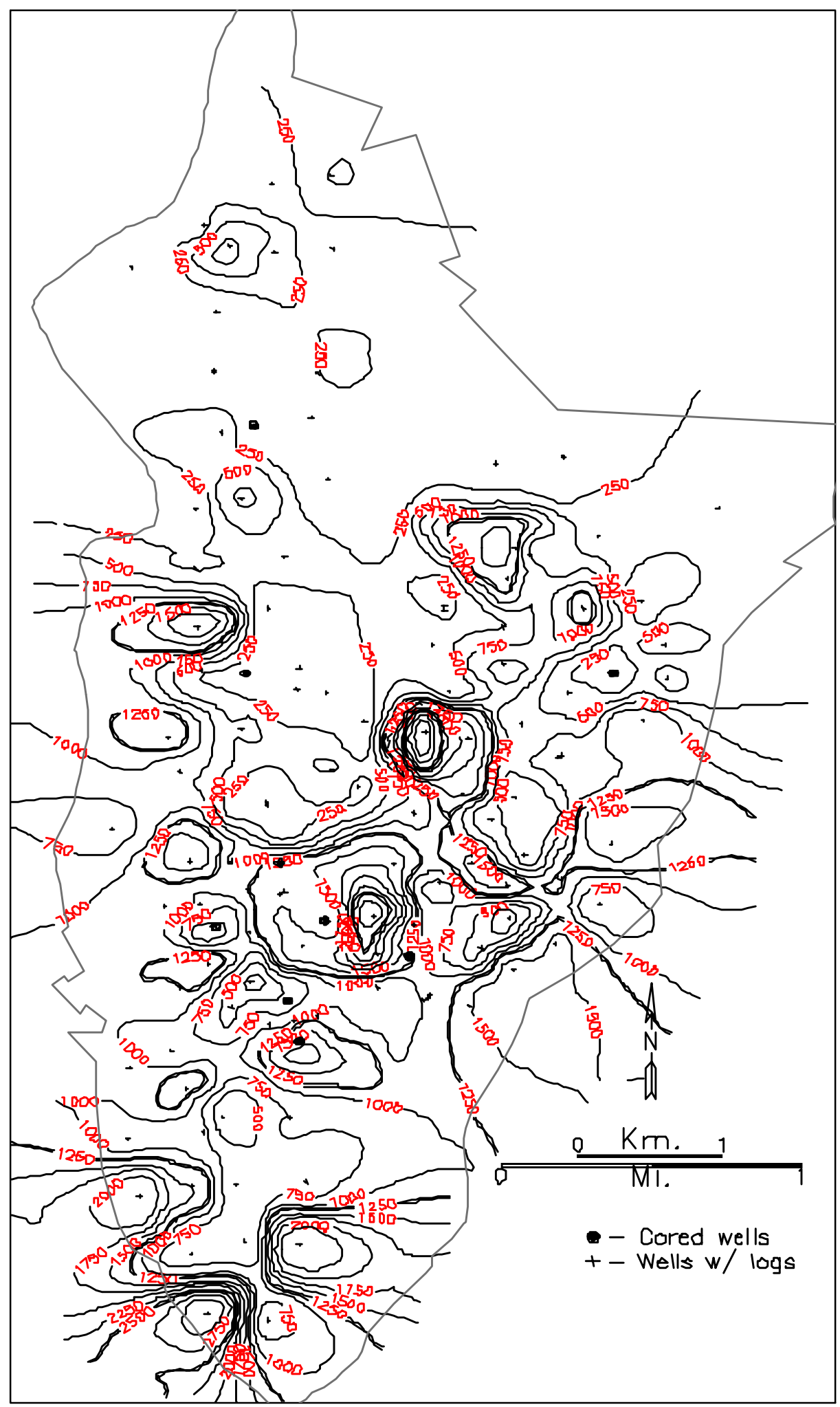


Figure 36. Average Permeability Distribution in the Stringtown Field

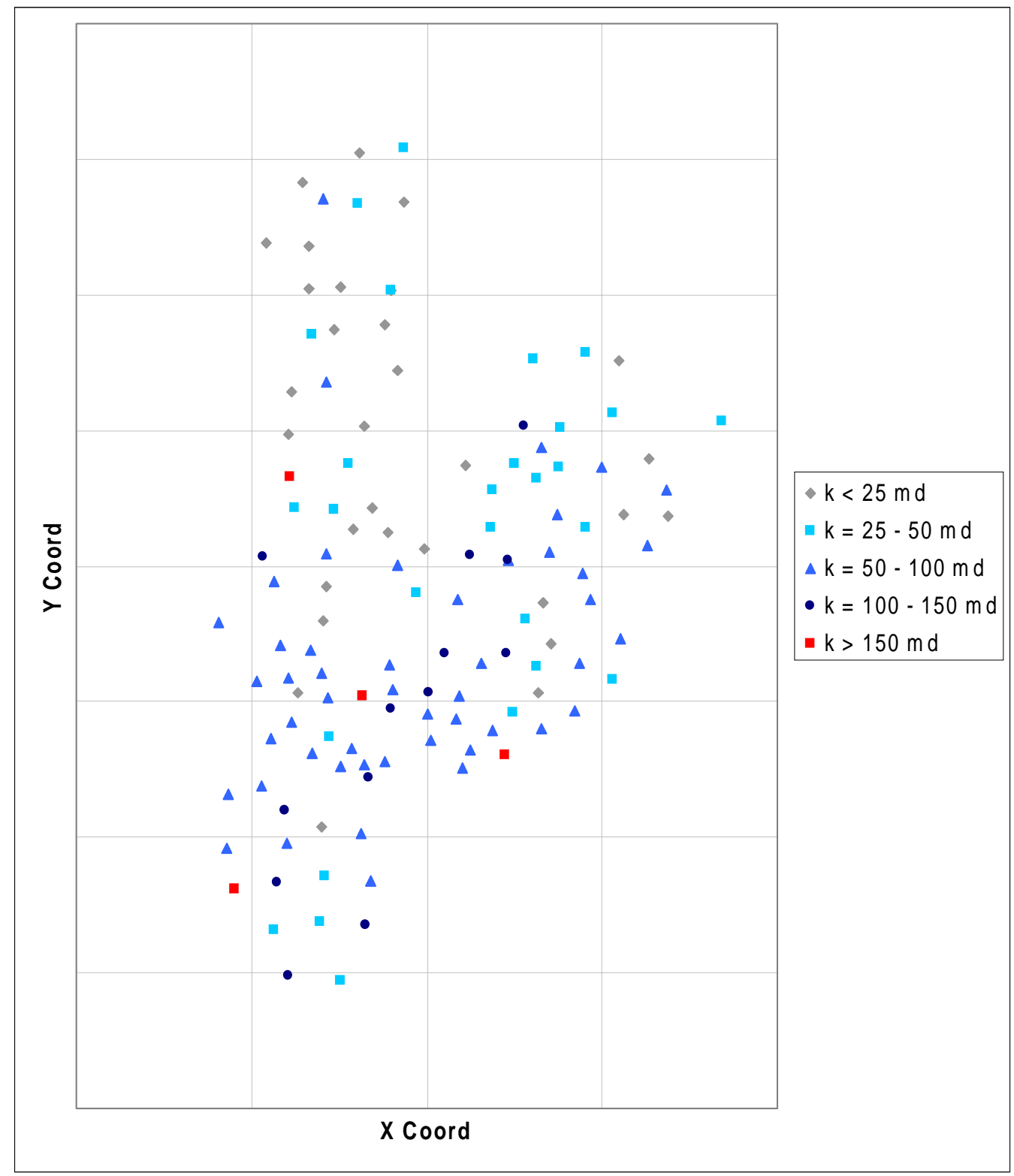

Similar trends can be observed between the flow capacity and average permeability distribution from Figures 34, 35, 36 and 37. This indicates that results are not influenced by the fact that a well might have a thick pay zone leading to a high flow capacity, it is rather the result of a high permeability. 
Figure 37. Avg. Permeability Contoured Map of the Stringtown Field

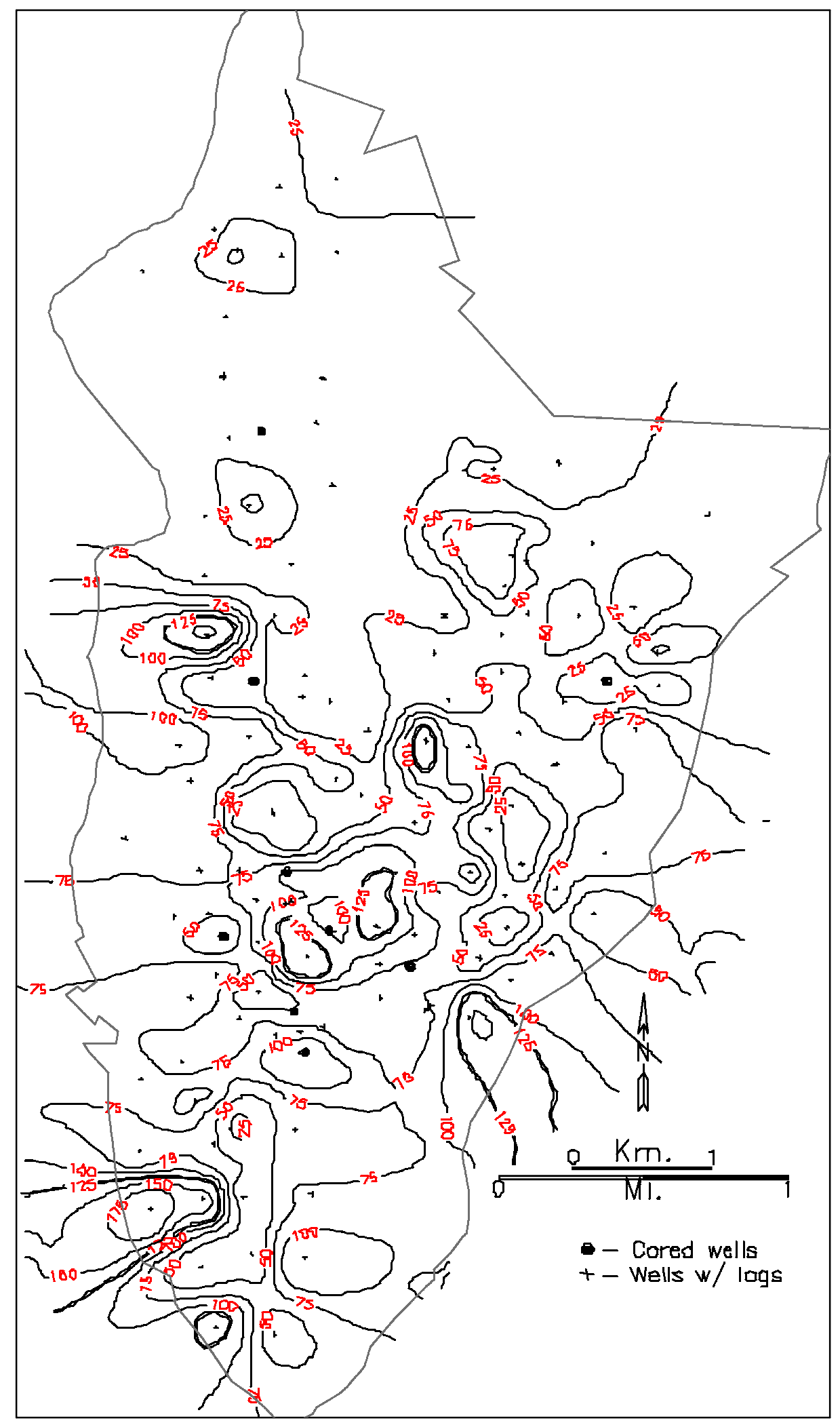




\subsection{Discussion}

The verification process of the ANN assured that permeability prediction was not biased by the data from any particular well, since each of the seven cored wells was put aside while training and the results achieved in every case (Table 6) demonstrated that an accurate prediction could be obtained regardless of a particular production set.

The robustness of the architecture selected and the importance of each input were stressed when excluding some of these variables from the training set and testing various architectures. The best model included 11 inputs (spatial coordinates, GR and RHOB log responses, first and second derivatives of log responses and log baselines) and a 3-layer backpropagation network with three middle slabs having a different activation function each, which led to a $\mathrm{R}^{2}$ correlation coefficient as high as 0.975 .

Flow capacity and average permeability distribution was successfully determined for the waterflooded pilot area using the Artificial Neural Network selected. Similar trends between these two variables were found. The analysis of each permeability profile in this area also indicated that two layers formed the pay zone, a low permeable upper layer and a highly permeable lower layer. More over, the flow capacity trend between the two layers was also the same. The spatial distribution of this rock property yielded to a better match in the production history of the pilot area, which is an alternate approach to verify the ANN forecast. 
Regarding the field-wide flow capacity distribution, Figure 34 shows that the most productive areas in the Stringtown field as a NE-SW trend and that these areas are located to the eastern side of the reservoir. The northern area of the field has rather a poor permeability and low flow capacity, suggesting that secondary oil procedures must be reinforced in this part of the reservoir.

The best zones are located in the mid-field. This part of the reservoir was the first area subject to waterflood operations and is where cumulative production peaks are found when studying the production history of the field.

One key factor to notice in Figures 34 and 35 is that southern areas show better potential than those of northern. This is of paramount importance if one takes into account that the development pattern of the field did not consider the exploitation of the south part of the reservoir until late in the life of the Stringtown field. 


\section{Chapter 5: Conclusions and Recommendations}

\subsection{Conclusions}

The results indicated that the methodology described using Backpropagation Artificial Neural Networks is a useful, powerful tool not only for accurately predicting permeability, but also to identify productive areas, pay zone limits and suggest areas of completion. The ANN overcame the drawback of the heterogeneity of the formation; making it a powerful, rapid, low cost alternative to obtain the rock permeability with a reliable level of accuracy.

The approach shown in this work served to define productive areas in the Stringtown Field, thus narrowing target zones to execute and/or reinforce oil recovery procedures.

Permeability predictions obtained from ANN improved the production history matching with an oil simulator, verifying once more the spatial distribution of this rock property as defined previously.

All of the results obtained with this approach and the verifications carried out demonstrated, once more, the applicability of artificial neural networks in the Petroleum Industry. 
The most important factors in developing an Artificial Neural Network are the input data selection to properly describe a given problem and its architecture.

\subsection{Recommendations}

A more exact distribution of rock permeability may be obtained if an ANN is developed using continuos seismic data and geological considerations are included in the model. Integrating geological interpretations and trend variations per location may help to further substantiate any decision to divide the heterogeneous formation into several zones.

Several ANN architectures were used in the development of this study such as back-propagation models with one or two slabs in the middle layer, General Regression Nets and GMDH models (Polynomial nets). It was found that the model selected (ThreeLayer Back-Propagation architecture with three slabs in the middle layer, each having a different activation function) gave the best results and it is recommended for good predictions.

Different activation functions applied to hidden layer slabs detect different features in the input data. For example, a network design may include a Gaussian function on one hidden slab to detect features in the mid-range of the data, a Gaussian complement function in another hidden slab to detect features from the upper and lower extremes of the data and a Sigmoid function to emphasize the range of the input data. 
Thus, the output layer will receive different viewpoints of the data. Combining these features in the middle layer definitely lead to better predictions.

Even though the results are reasonably acceptable, the ANN developed in this work has two drawbacks. First, it cannot be used to predict permeability values in any other field since it was trained with spatial coordinates own of this particular location. Second, log-core data correlation was manually developed to the highest $\mathrm{R}^{2}$ coefficient between core porosity and log porosity, by shifting core depth values, in order to find the $\log$ response values correspondent to a given core plug permeability value. This introduces a little uncertainty to the study since the shifting is arbitrary. 


\section{References}

1. Mohaghegh, S., Arefi, R., Bilgesu, H. I., Ameri, S., Rose, D. "Design and Development of an Artificial Neural Network for Estimation of Formation Permeability", SPE 28237, Proceedings of SPE Petroleum Computer Conference, Dallas, TX, July-August 1994.

2. Mohaghegh, Ameri, S., Arefi, R., "Virtual Measurement of Heterogeneous Formation Permeability Using Geophysical Well Log Responses”, Log Analyst, March-April 1996

3. Balan, B., Mohaghegh, S., Ameri, S., "State-Of-The-Art Permeability Determination From Well Log Data: Part 1 - A Comparative Study, Model Development”, SPE 30978, Proceedings of SPE Eastern Regional Meeting, Morgantown, WV, September 1995.

4. Balan, B., Mohaghegh, S., Ameri, S., "State-Of-The-Art Permeability Determination From Well Log Data: Part 2 - Verifiable, Accurate Permeability Predictions, the Touch-Stone of All Models", SPE 30979, Proceedings of SPE Eastern Regional Meeting, Morgantown, WV, September 1995.

5. Mohaghegh, S., "Neural Network: What It Can Do for Petroleum Engineers", Journal of Petroleum Technology, January 1995.

6. Mohaghegh, S., Arefi, R., Ameri, S., “A Methodological Approach for Reservoir Heterogeneity Characterization Using Artificial Neural Networks", SPE 28394, Proceedings of SPE Annual Conference, New Orleans, LA, September 1994.

7. Hohn, M., Avary, K. L., McDowell, R., Matchen, D., "Reservoir Characterization of Upper Devonian Gordon Sandstone, Stringtown Oilfield, Northwestern West 
Virginia", WVU and Appalachian Oil and Natural Gas Research Consortium, SemiAnnual Report, April 1999.

8. Ameri, S., Aminian, K., Avary, K. L., Bilgesu, H. I., McDowell, R., Matchen, D., "Reservoir Characterization of Upper Devonian Gordon Sandstone, Stringtown Oilfield, Northwestern West Virginia”, WVU and Appalachian Oil and Natural Gas Research Consortium, Semi-Annual Report, October 1999.

9. Kumoluyi, A., Daltaban, T., "Higher-Order Neural Networks in Petroleum Engineering”, SPE 27905, Proceedings of SPE Western Regional Meeting, Long Beach, CA, March 1994.

10. Fausett, L., Fundamentals of Neural Networks: Architectures, Algorithms and Applications, Prentice Hall, 1994

11. NeuroShell 2 Help File, Release 4.0, (C) Ward Systems Group, Inc. 1993-1998

12. Molnar, D., Aminian, K., Ameri, S., "The Use of Well Log Data for Estimating Permeability in a Heterogeneous Reservoir", SPE 29175, Proceedings of SPE Eastern Regional Meeting, Charleston, WV, November 1994.

13. Ameri, S., Molnar, D., Mohaghegh, S. and Aminian, K., "Permeability Evaluation in Heterogeneous Formations Using Geophysical Well Logs and Geological Interpretations", SPE 26060, Proceedings of SPE Western Regional Meeting, Anchorage, Alaska, May 1993.

14. Soto, R., Holditch, S., "Development of Reservoir Characterization Models Using Core, Well Log, 3D Seismic Data and Intelligent Software”, SPE 57457, Proceedings of SPE Eastern Regional Meeting, Charleston, WV, October 1999 
15. White, A., Molnar, D., Aminian, K., Mohaghegh, S., Ameri, S., Esposito, P., "The Application of ANN for Zone Identification in a Complex Reservoir", SPE 30977, Proceedings of SPE Eastern Regional Meeting, Morgantown, WV, September 1995.

16. Aminian, K., "Characterization of a Complex Reservoir in West Virginia", SPE 26939, Proceedings of SPE Eastern Regional Meeting, Pittsburgh, PA, November 1993. 


\section{Appendix I}

Cored Well Graphs 


\section{Annex A - Well Cw1}

Figure 38. Core and Log Porosity vs. Depth (Well Cw1)

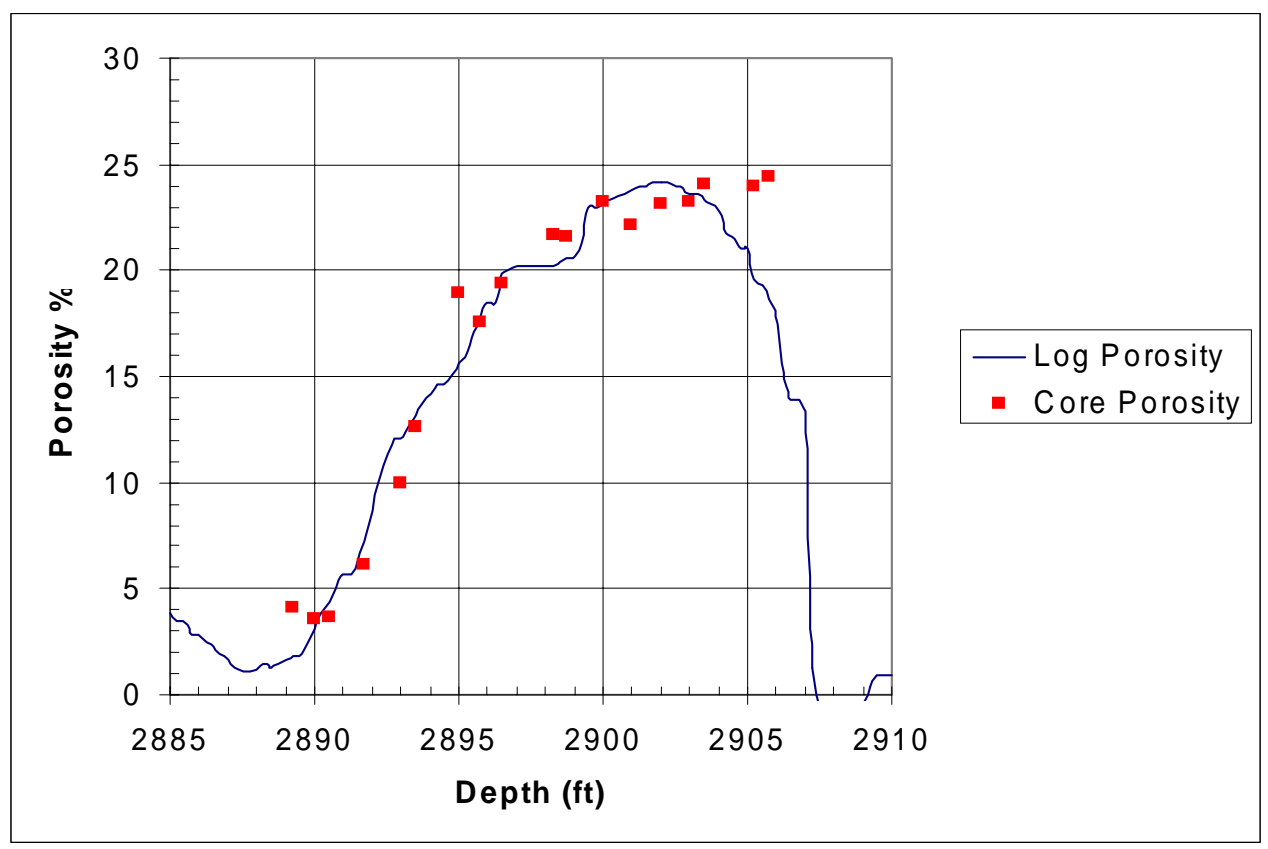

Figure 39. Porosity Correlation for Well Cw1

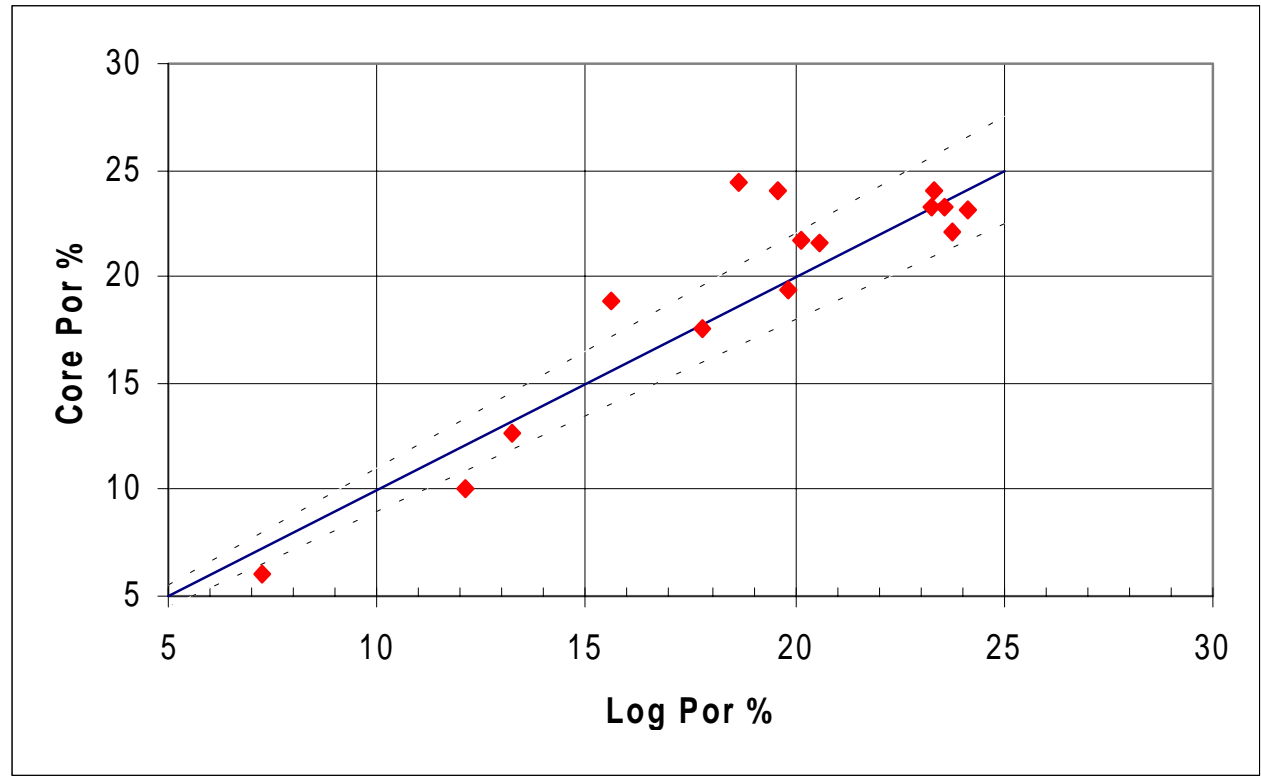


Figure 40. Core Permeability vs. Log Responses (Well Cw1)

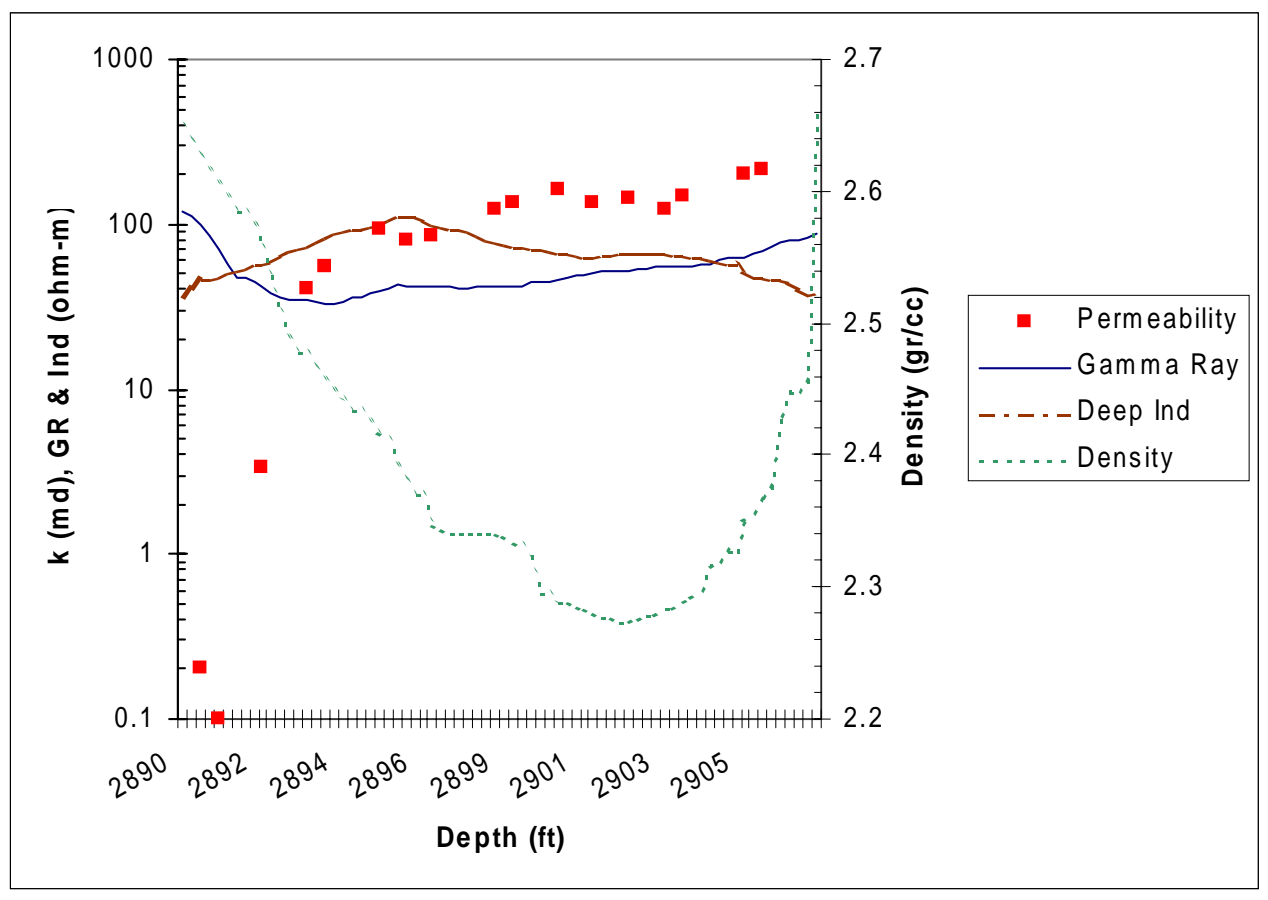

Figure 41. ANN Predictions and Core Permeability vs. Depth (Well Cw1)

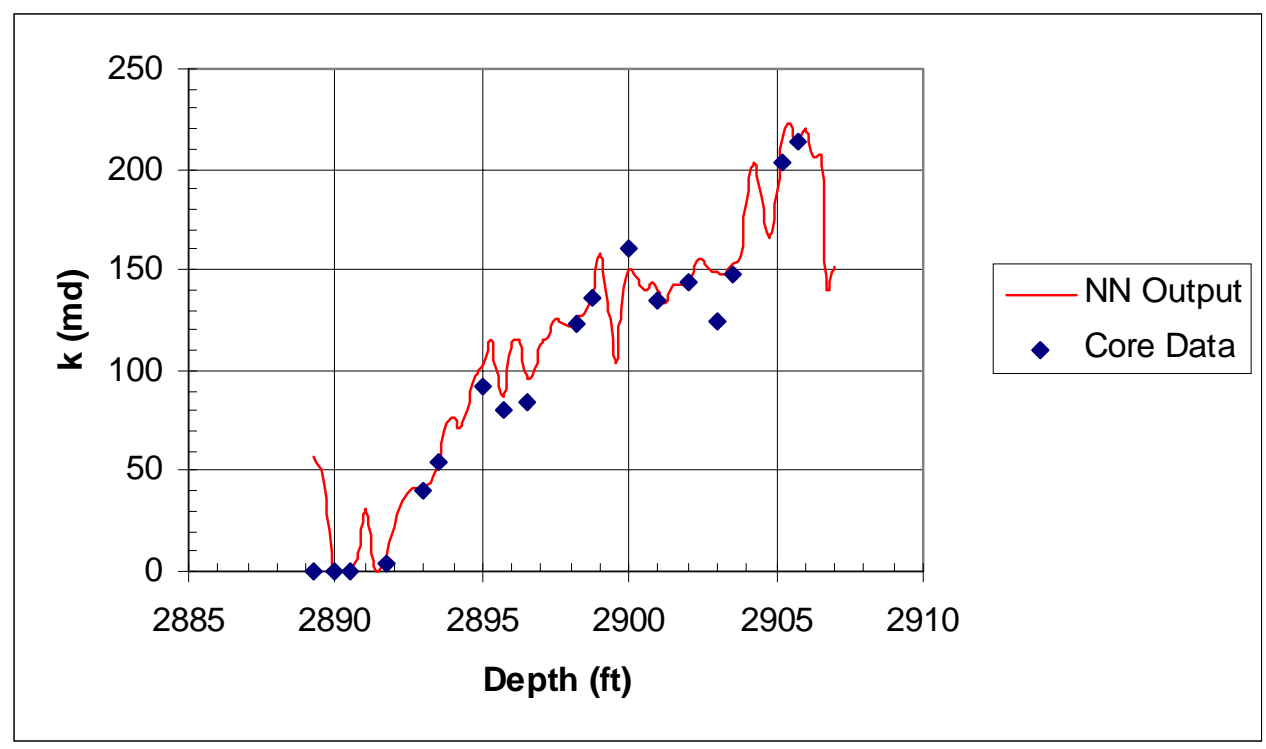




\section{Annex B - Well Cw2}

Figure 42. Core and Log Porosity vs. Depth (Well Cw2)

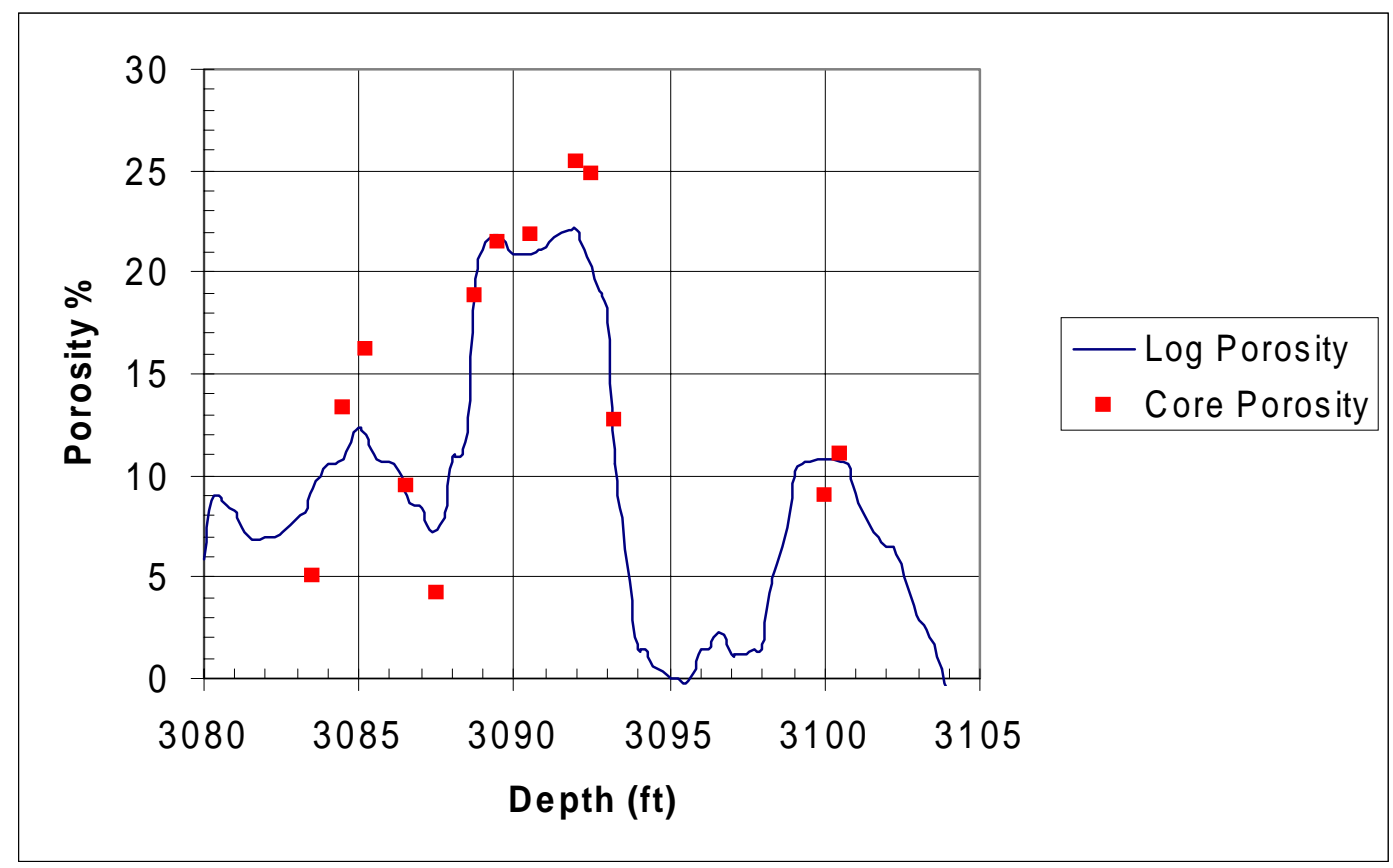

Figure 43. Porosity Correlation for Well Cw2

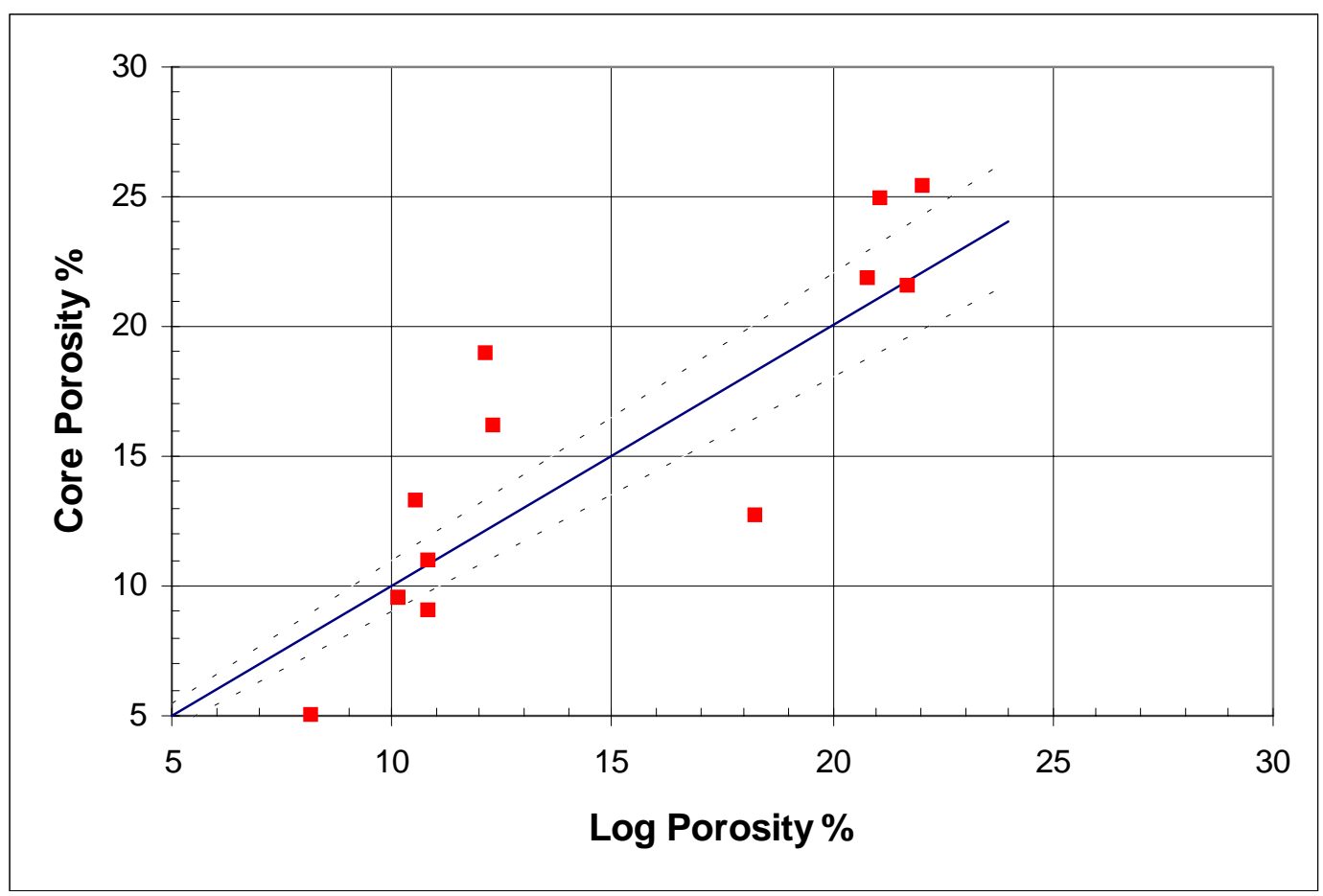


Figure 44. Core Permeability vs. Log Responses (Well Cw2)

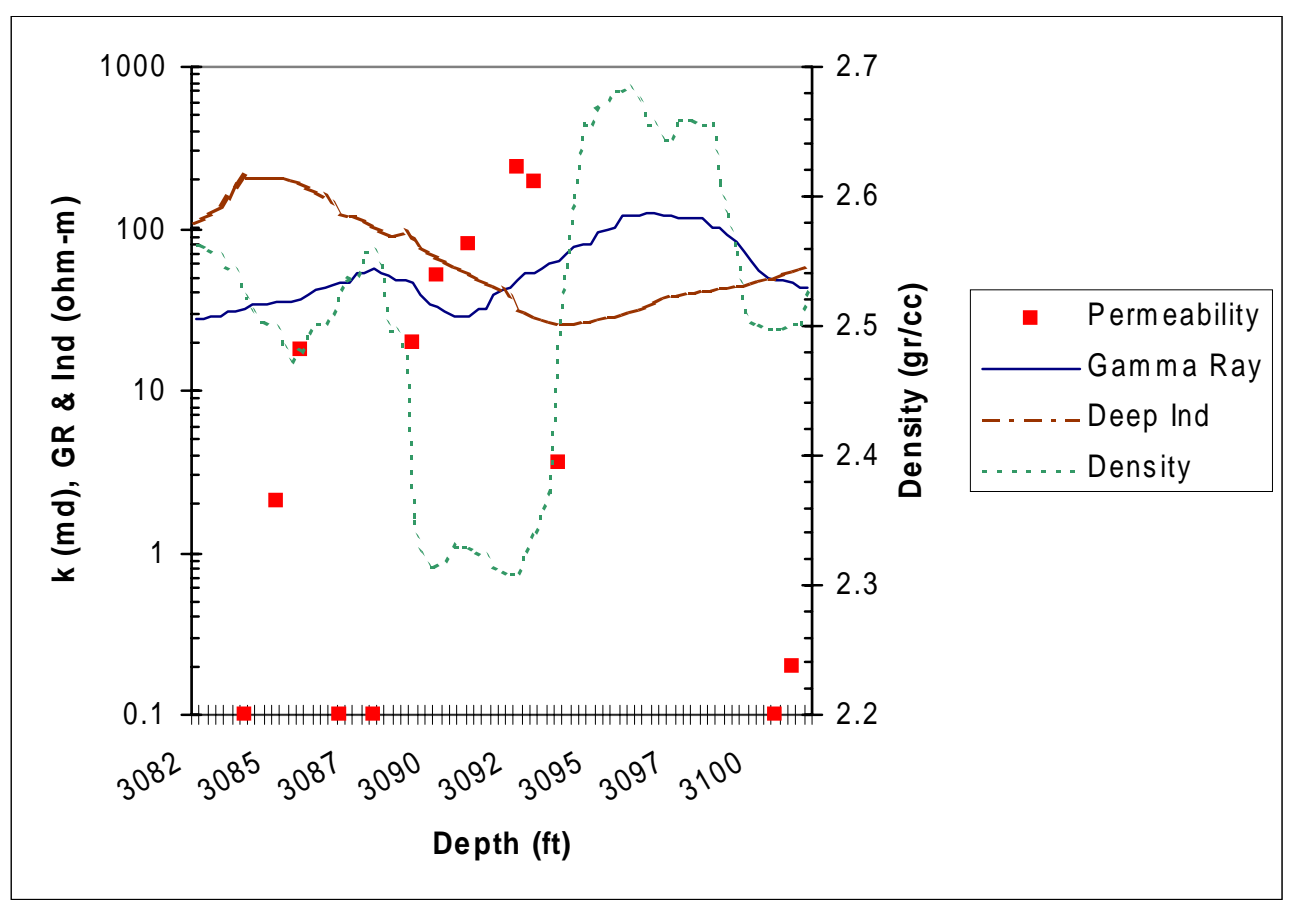

Figure 45. ANN Predictions and Core Permeability vs. Depth (Well Cw2)

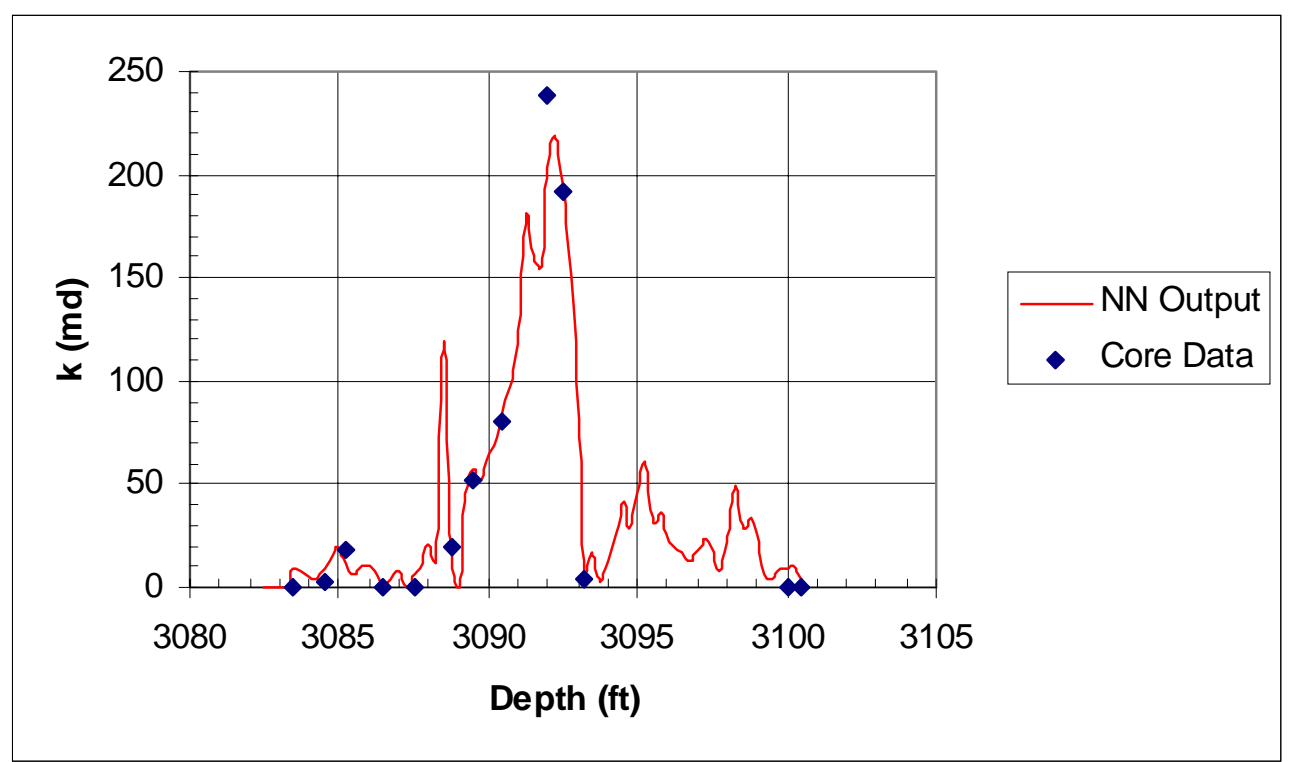




\section{Annex C - Well Cw3}

Figure 46. Core and Log Porosity vs Depth (Well Cw3)

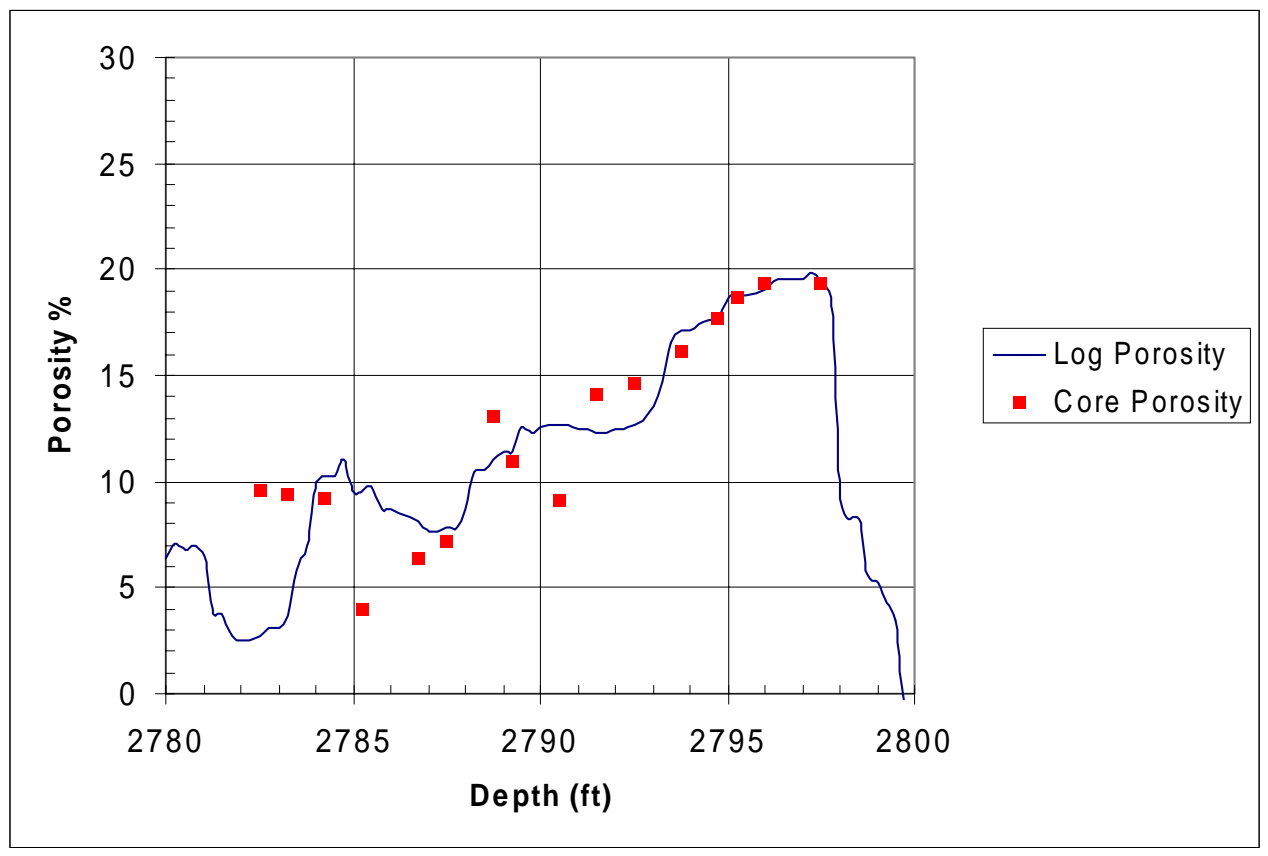

Figure 47. Porosity Correlation for Well Cw3

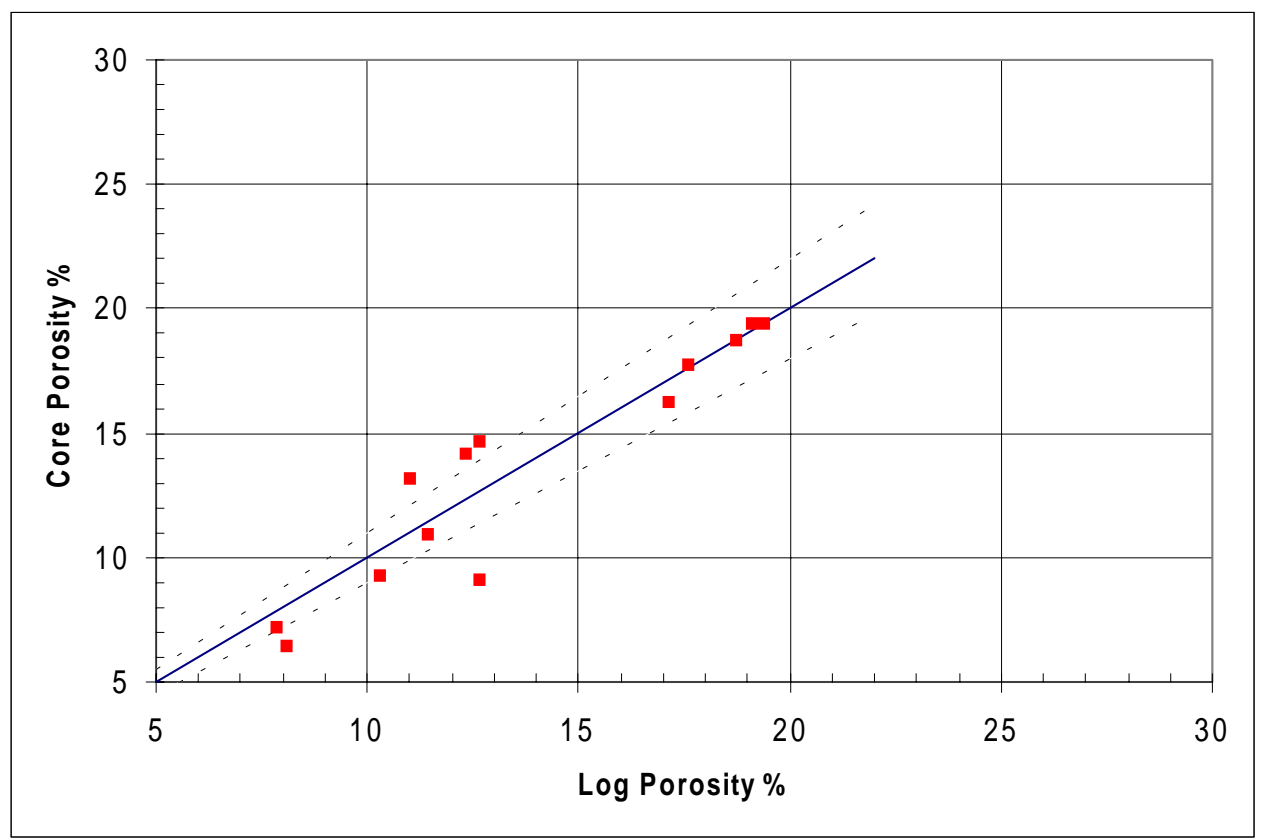


Figure 48. Core Permeability vs. Log Responses (Well Cw3)

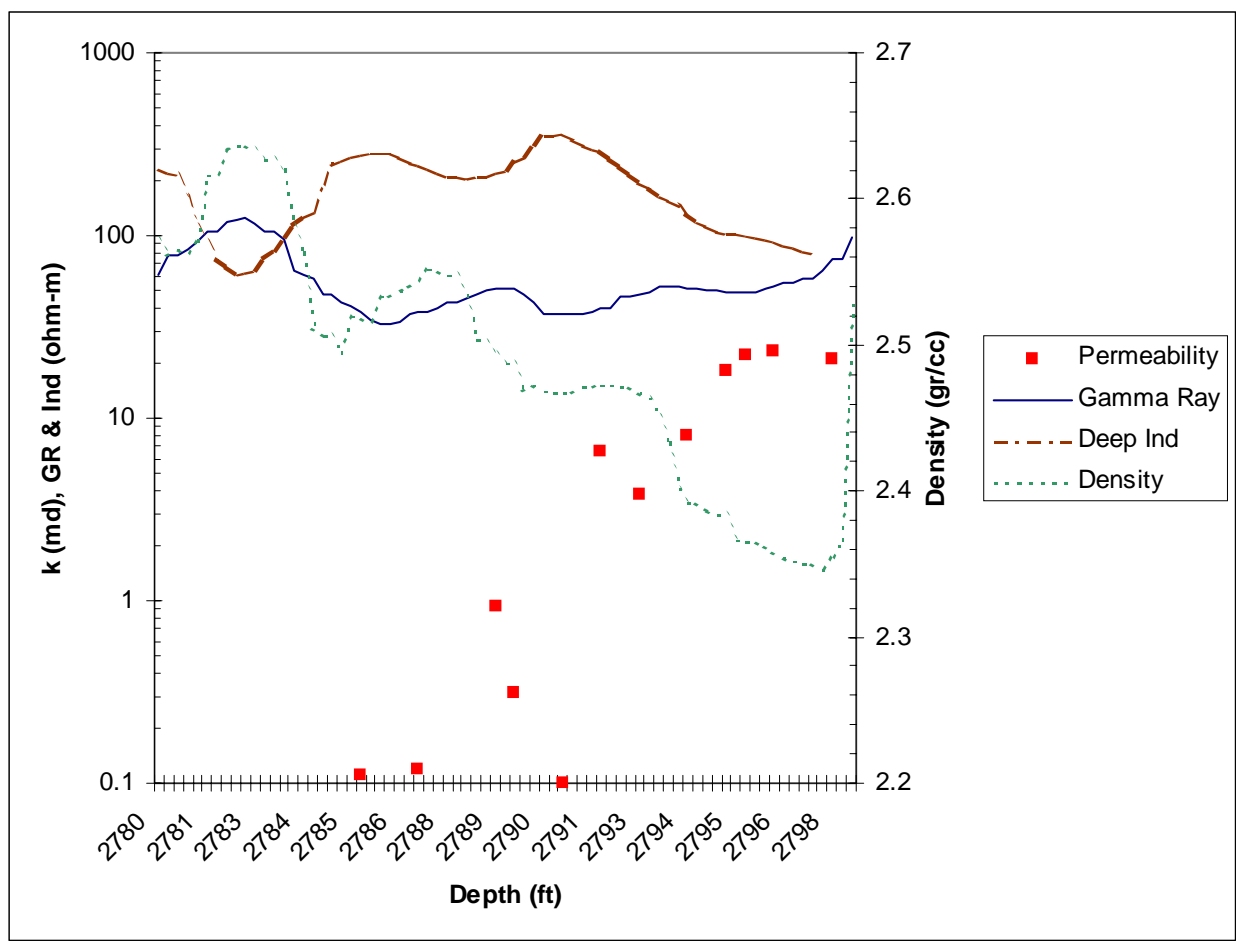

Figure 49. ANN Predictions and Core Permeability vs. Depth

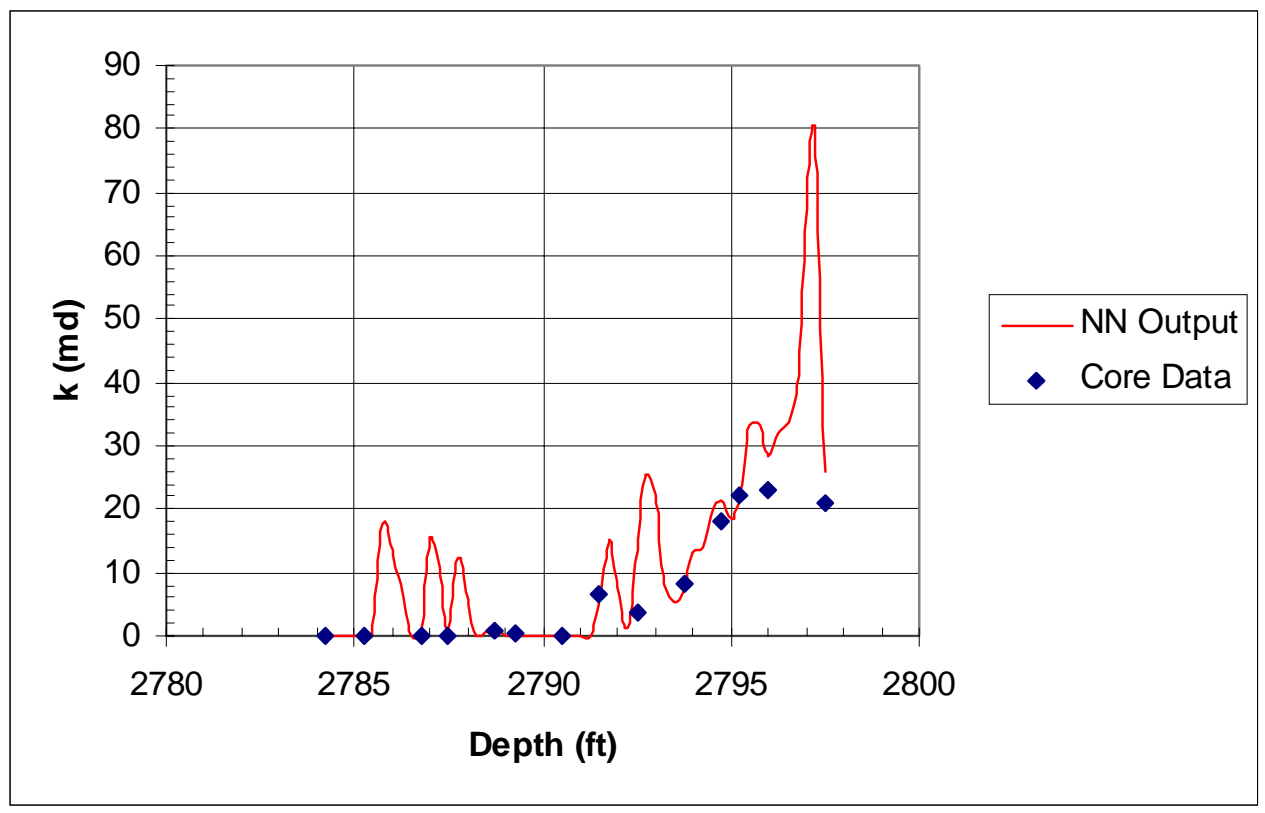




\section{Annex D - Well Cw4}

Figure 50. Core and Log Porosity vs. Depth (Well Cw4)

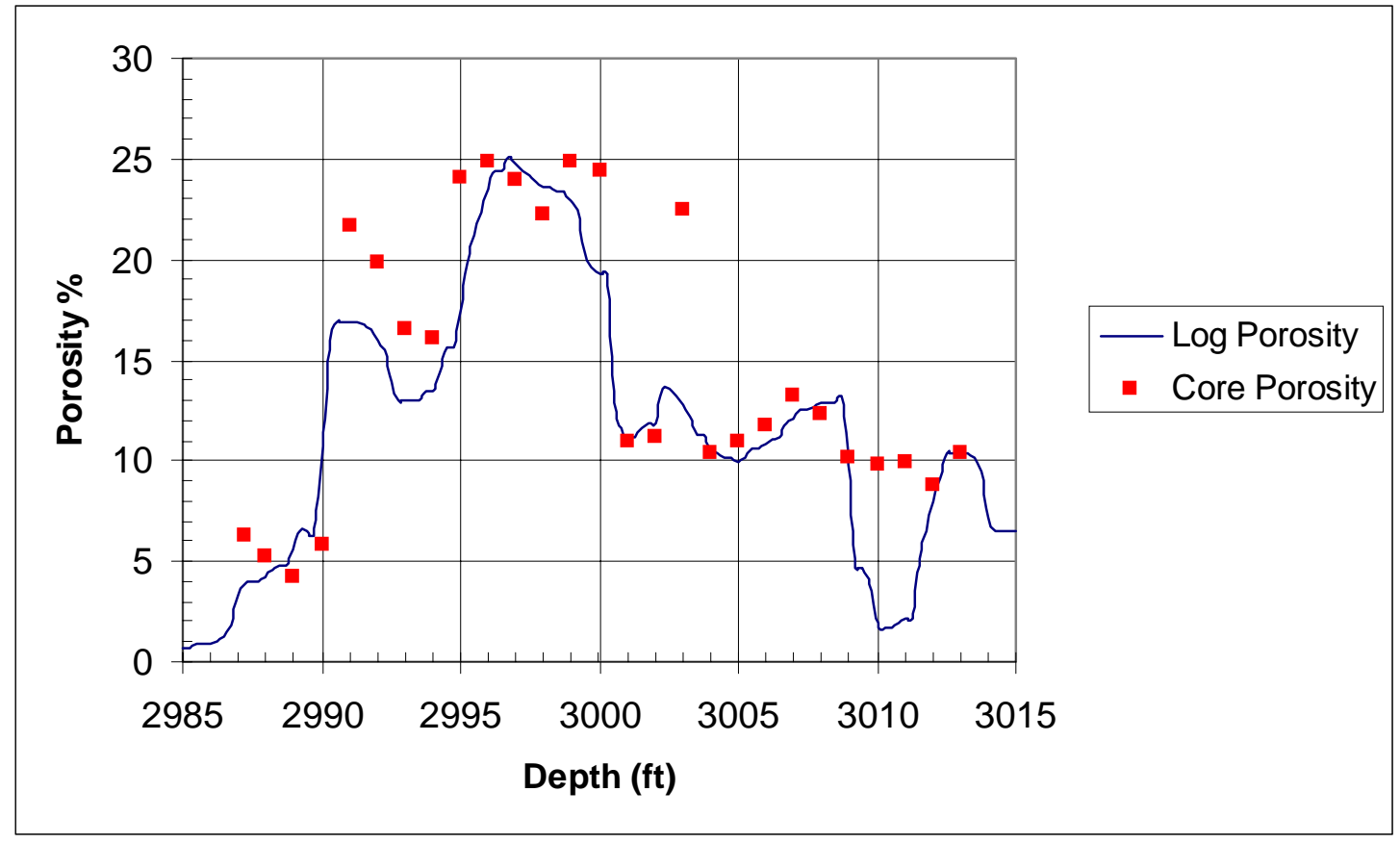

Figure 51. Porosity Correlation for Well Cw4

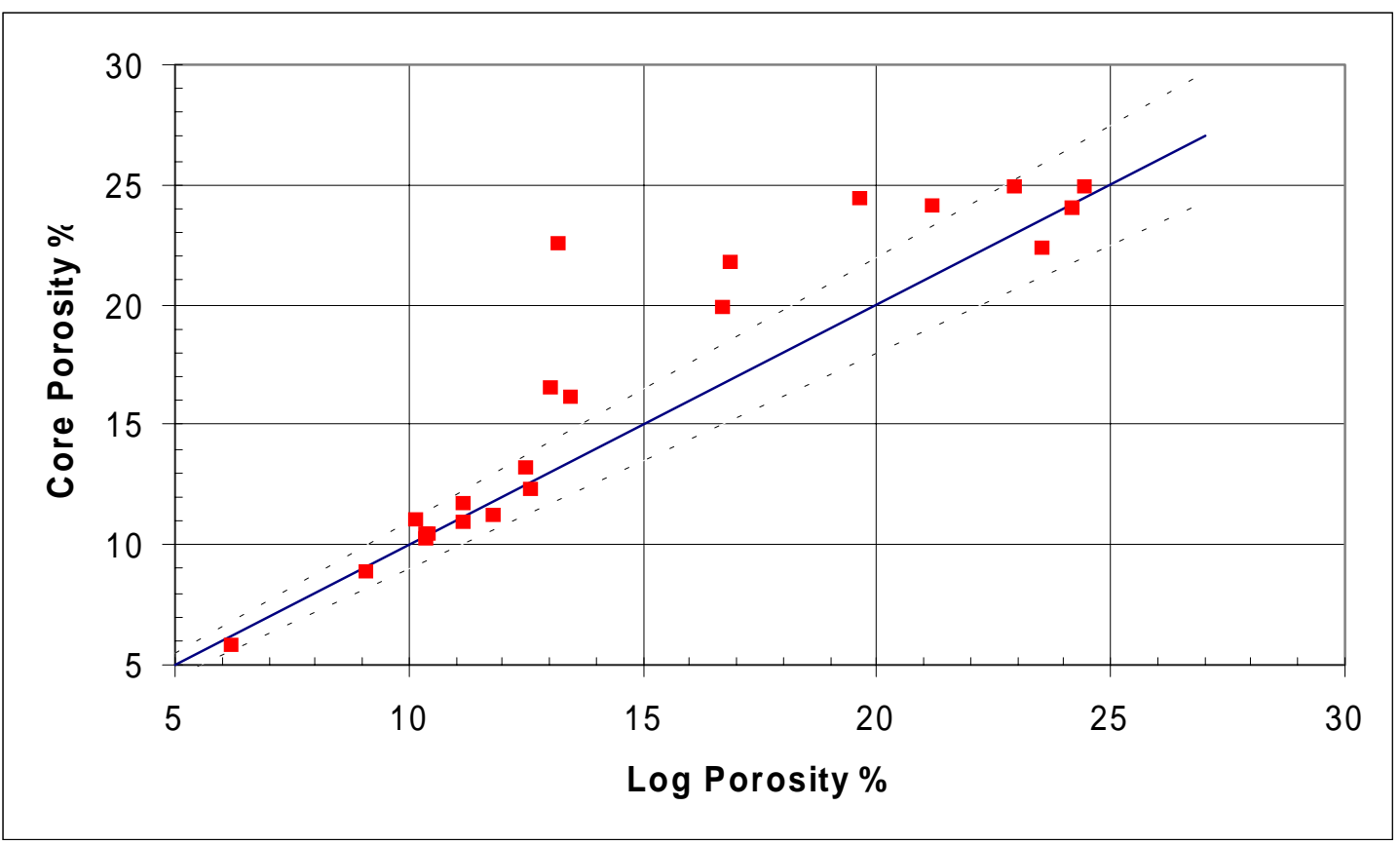


Figure 52. Core Permeability vs. Log Responses (Well Cw4)

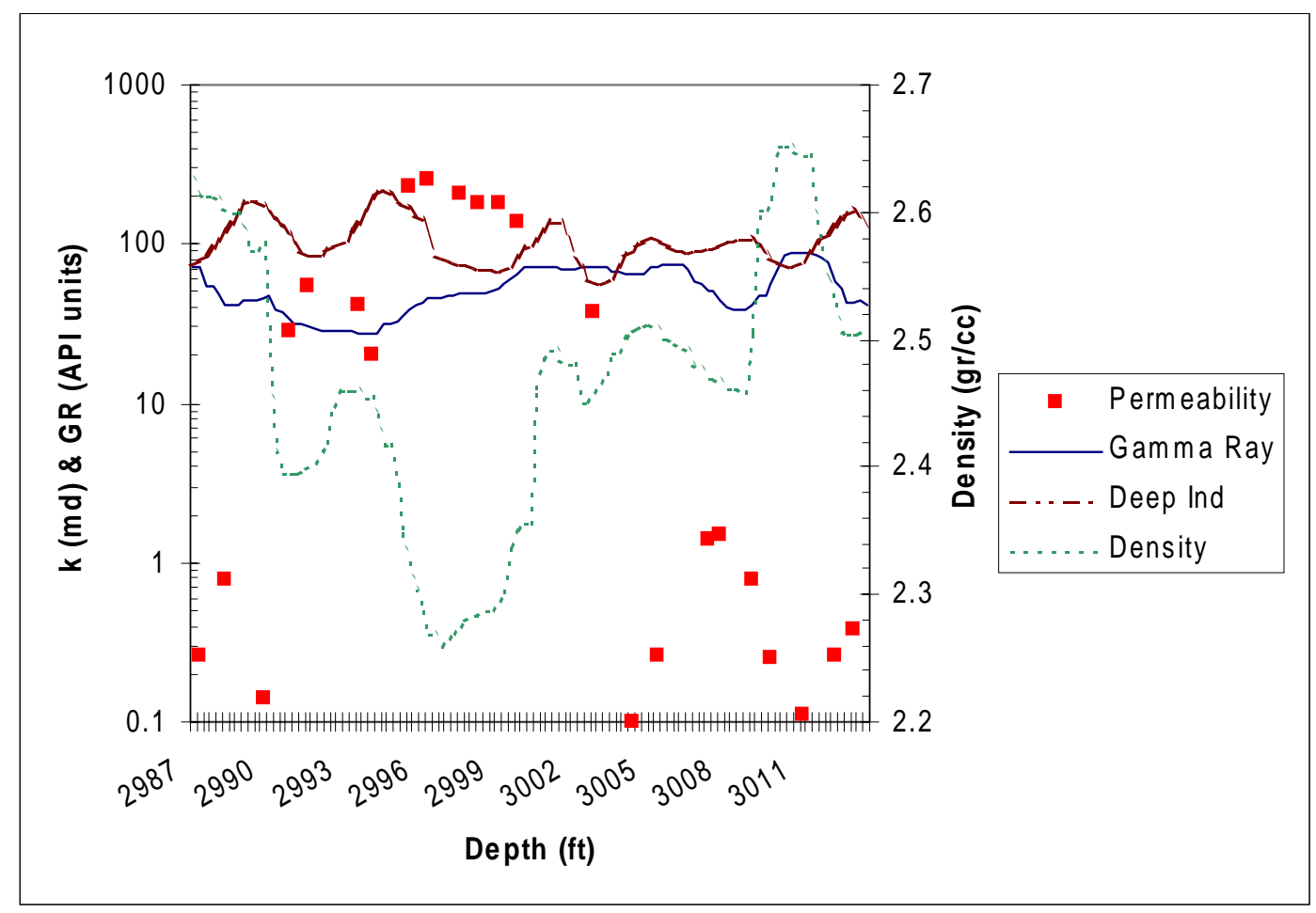

Figure 53. ANN Predictions and Core Permeability vs. Depth (Well Cw4)

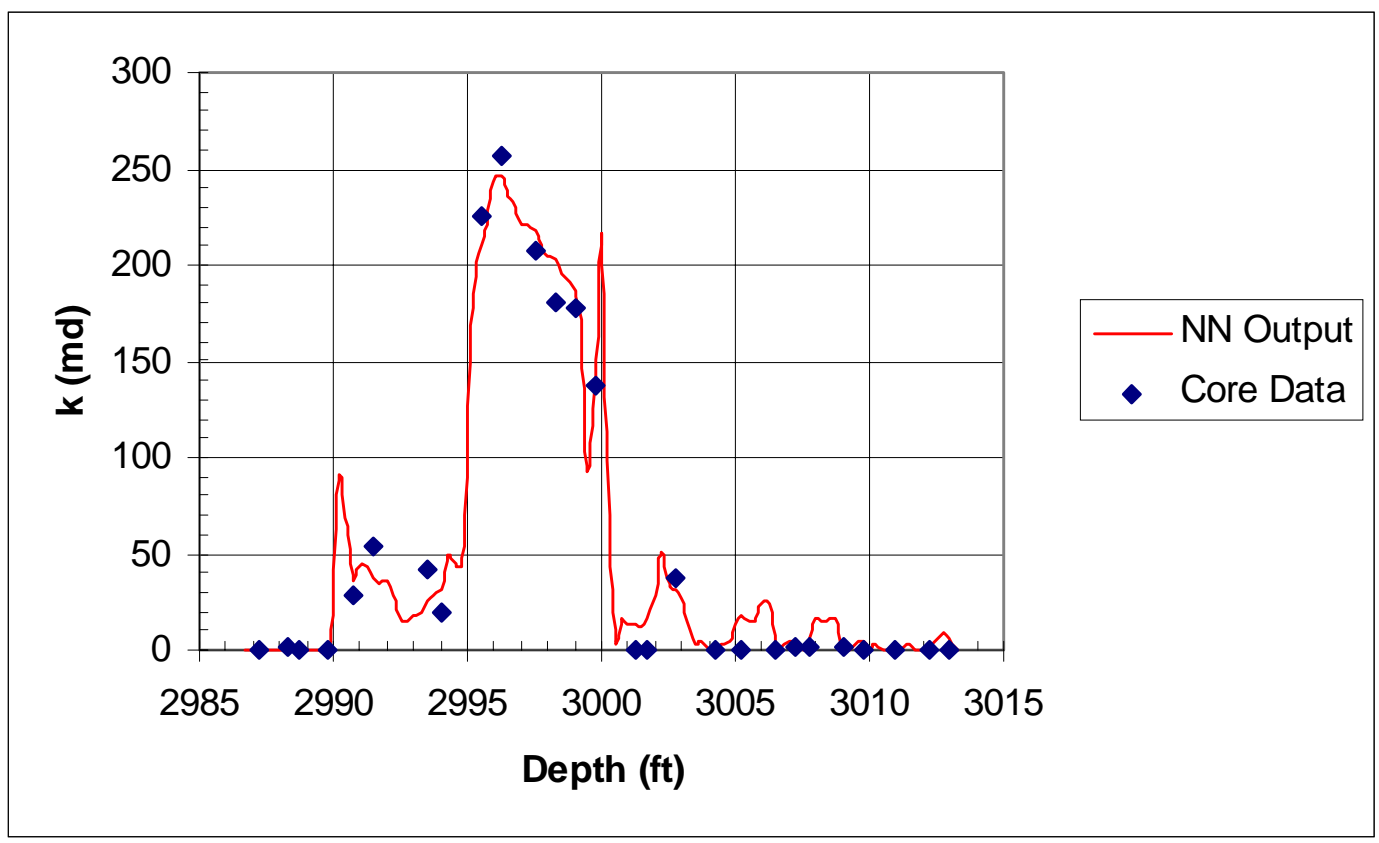




\section{Annex E - Well Cw5}

Figure 54. Core and Log Porosity vs. Depth (Well Cw5)

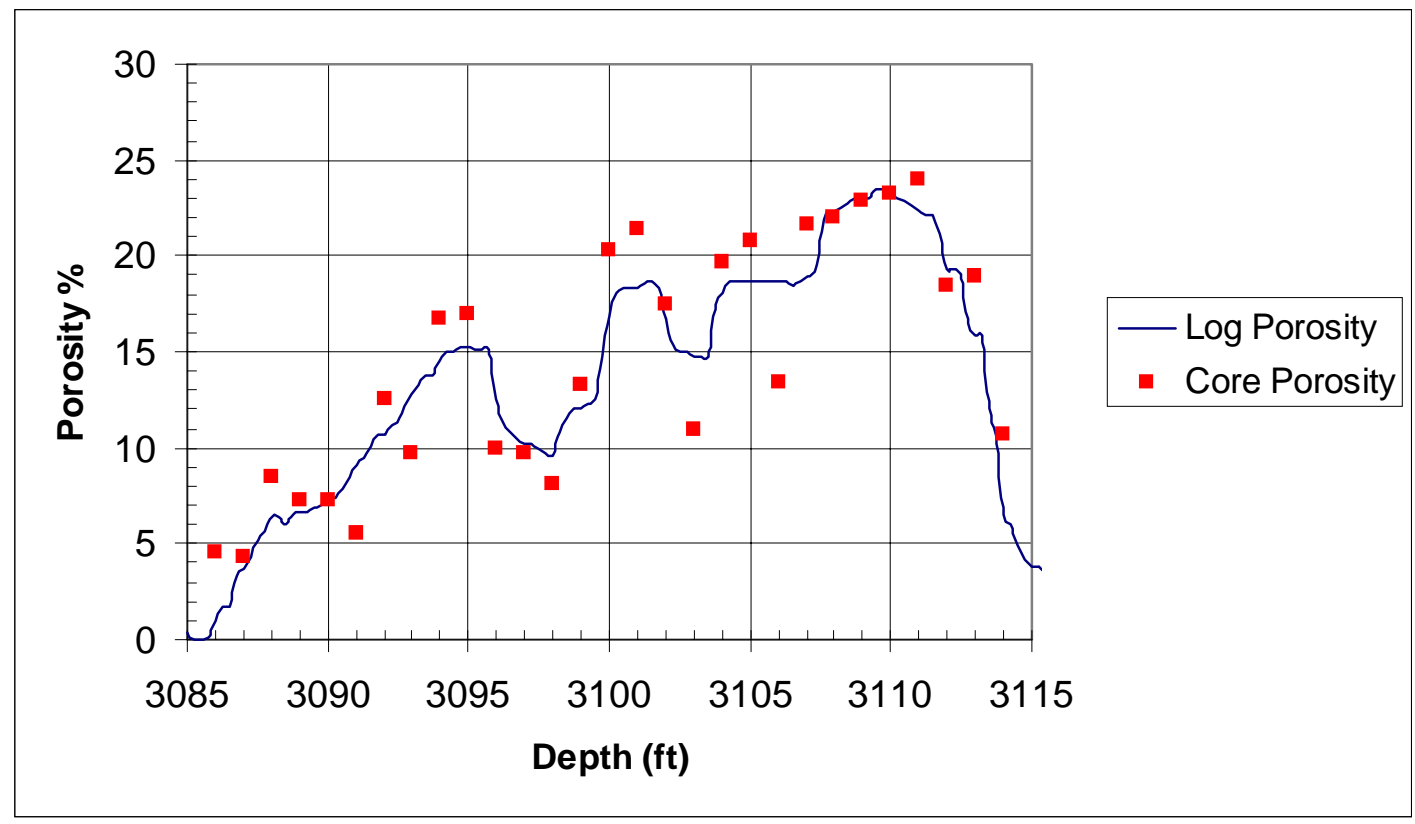

Figure 55. Porosity Correlation for Well Cw5

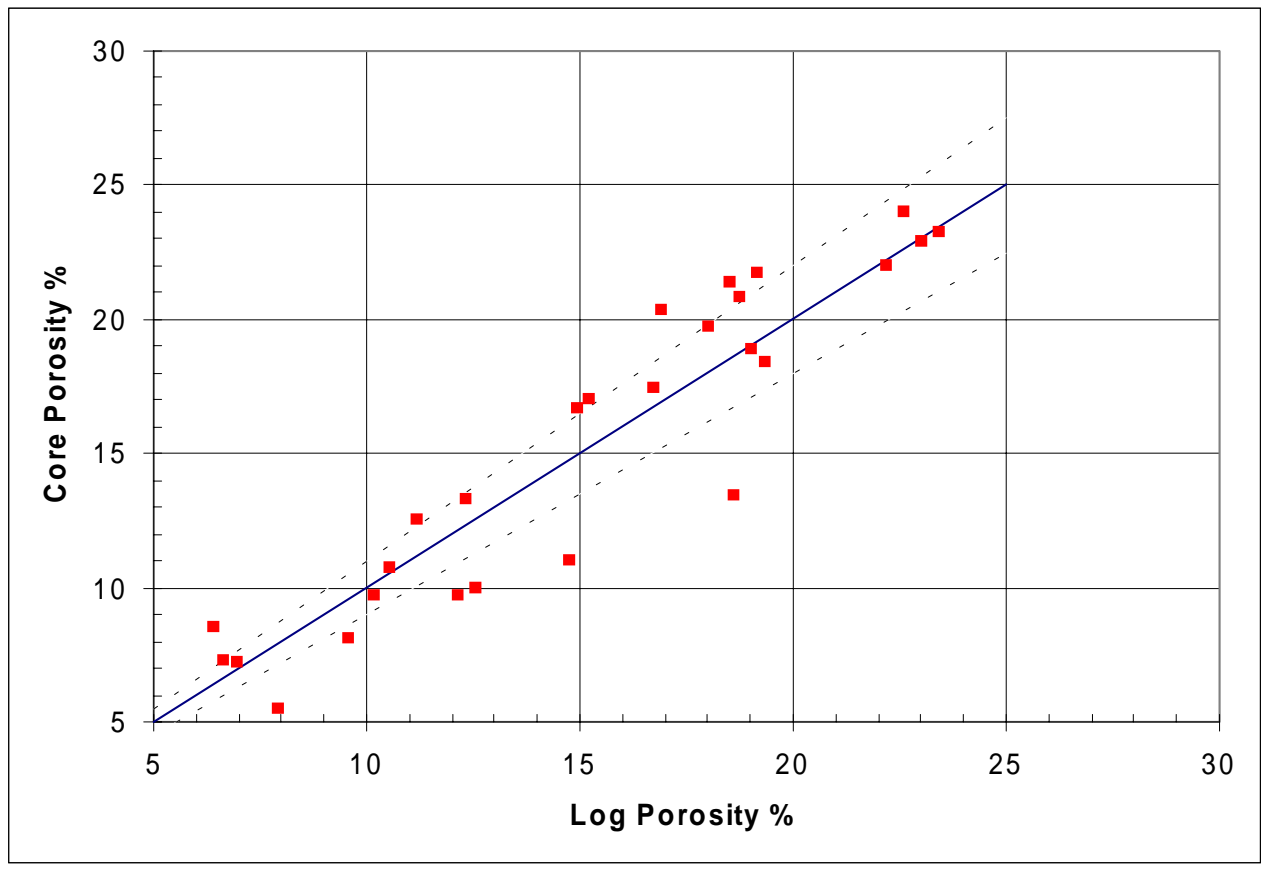


Figure 56. Core Permeability vs. Log Responses (Well Cw5)

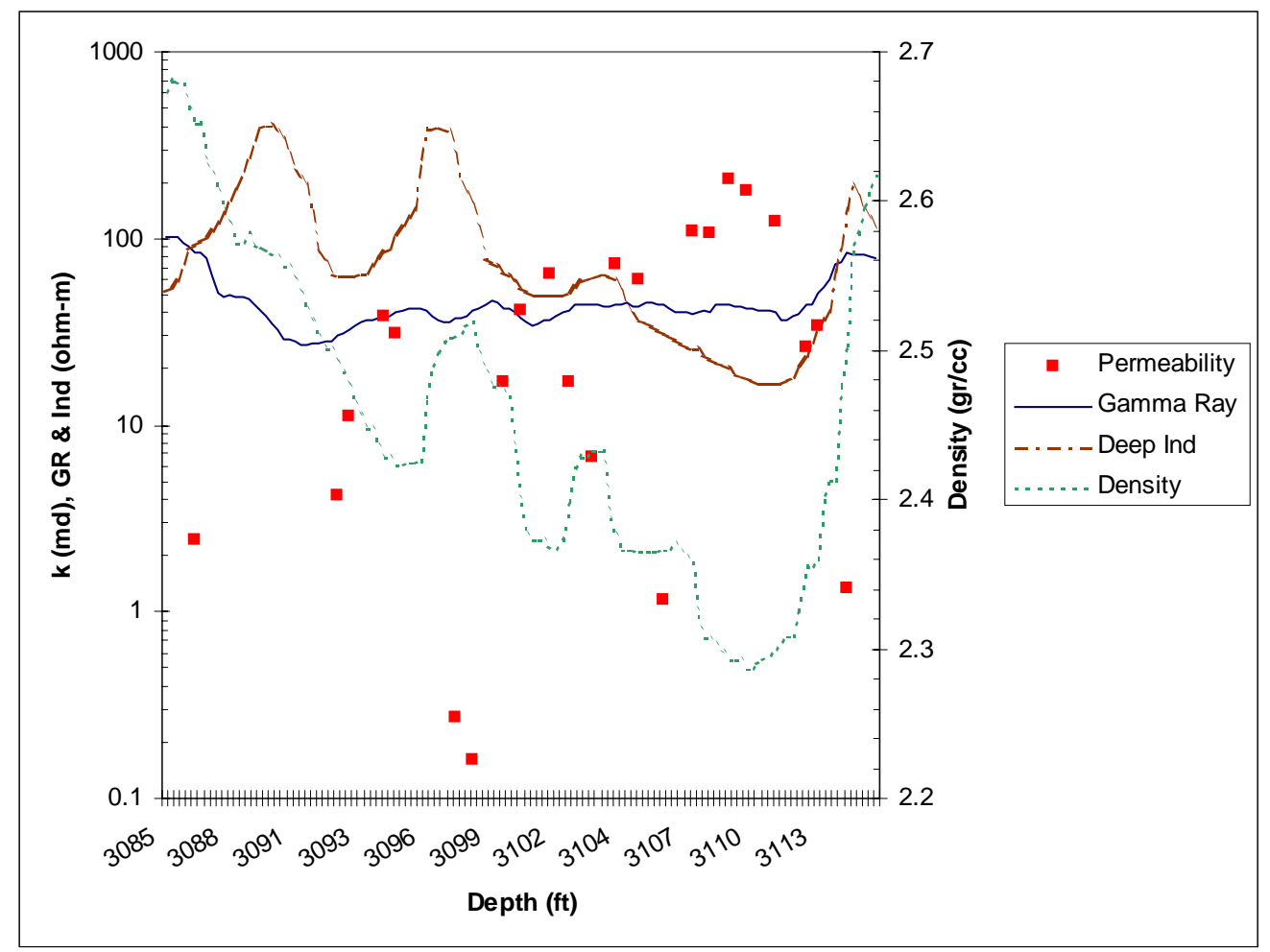

Figure 57. ANN Predictions and Core Permeability vs. Depth

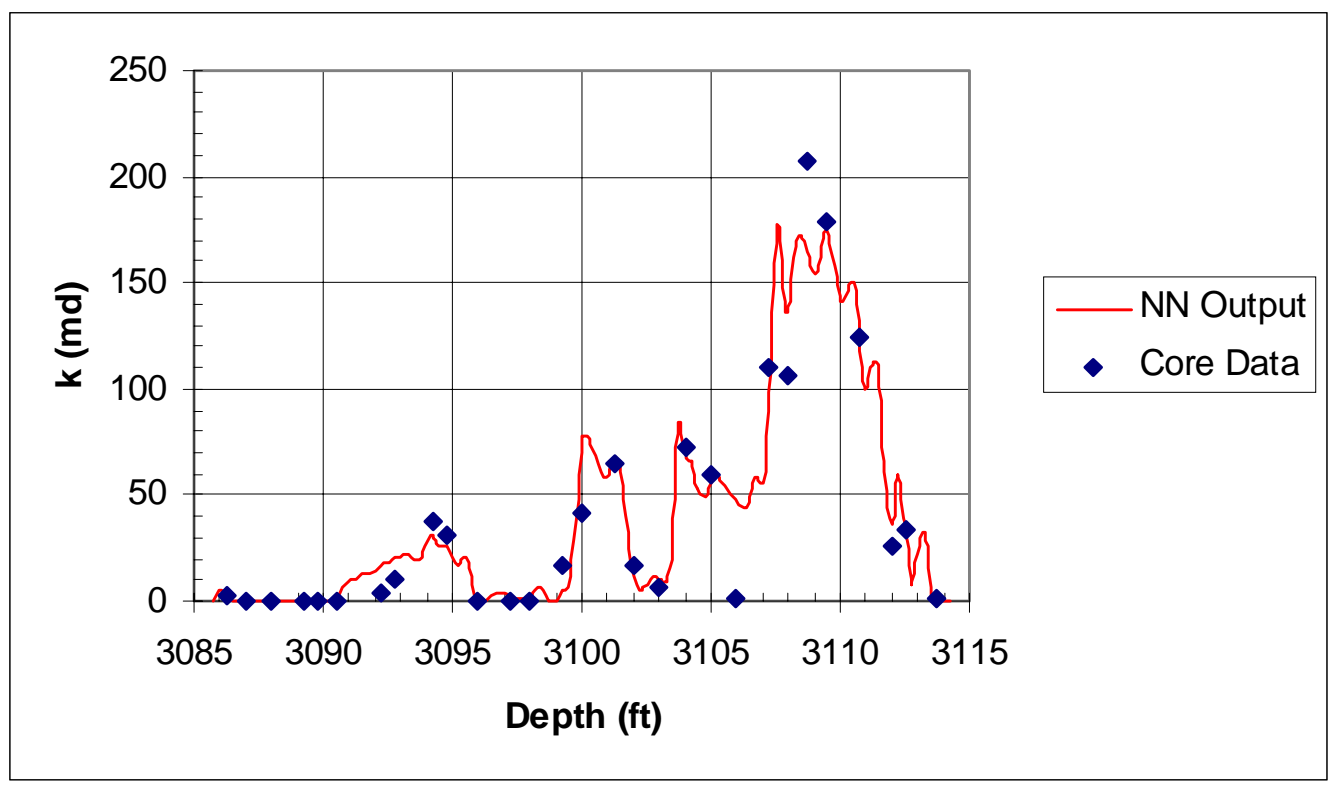




\section{Annex F-Well Cw6}

Figure 58. Core and Log Porosity vs. Depth (Well Cw6)

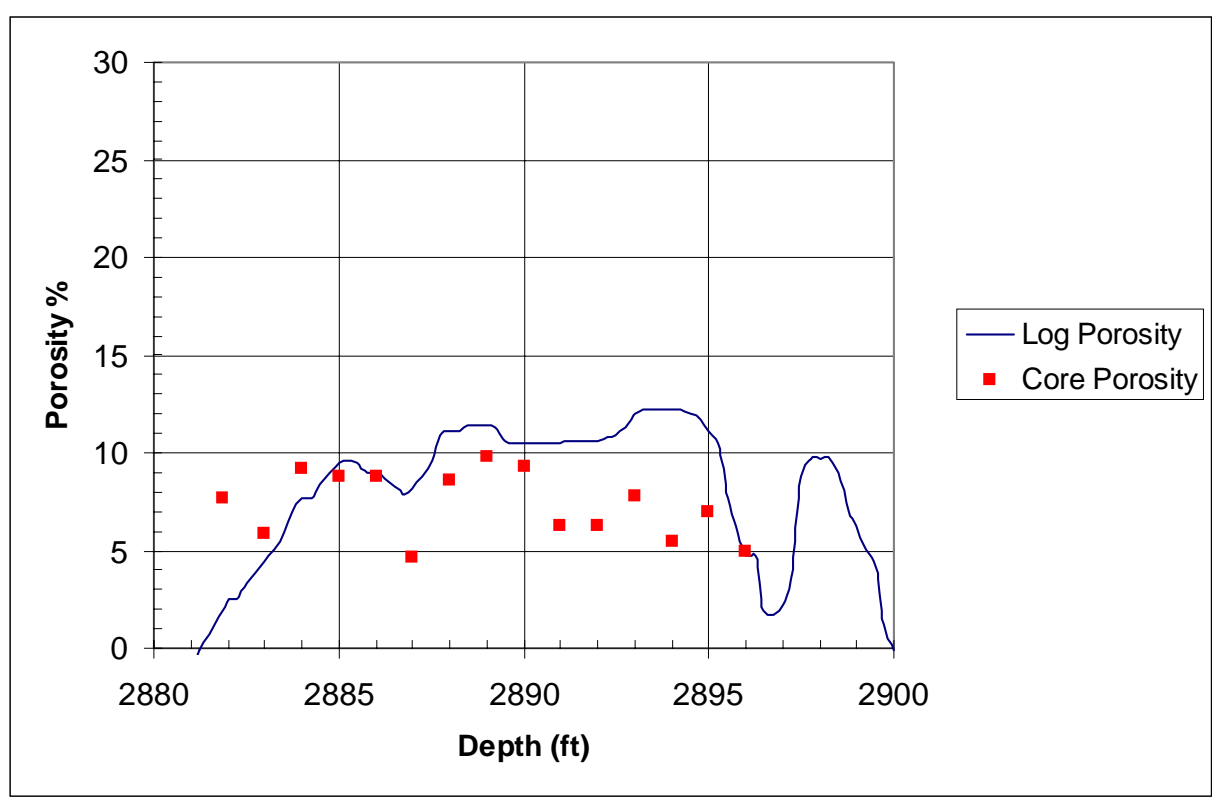

Figure 59. Porosity Correlation for Well Cw6

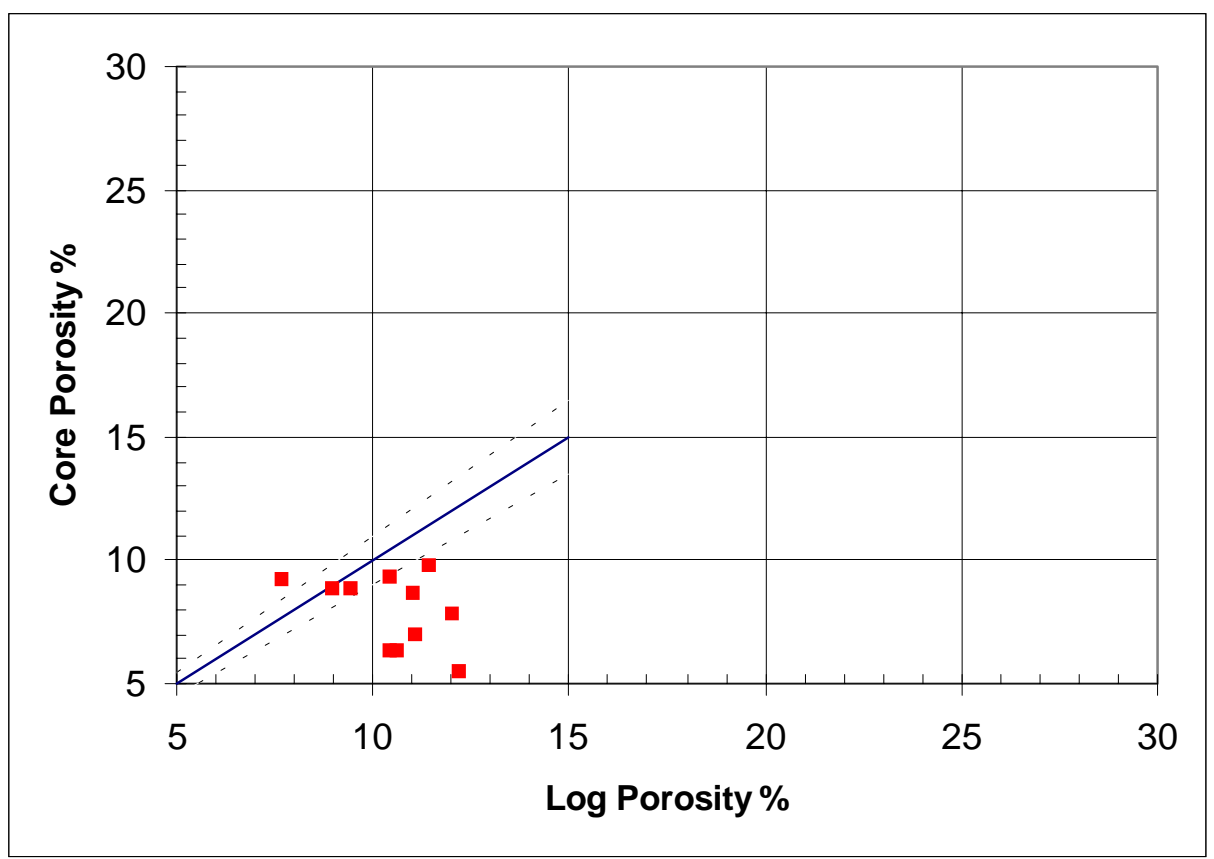


Figure 60. Core Permeability vs. Log Responses (Well Cw6)

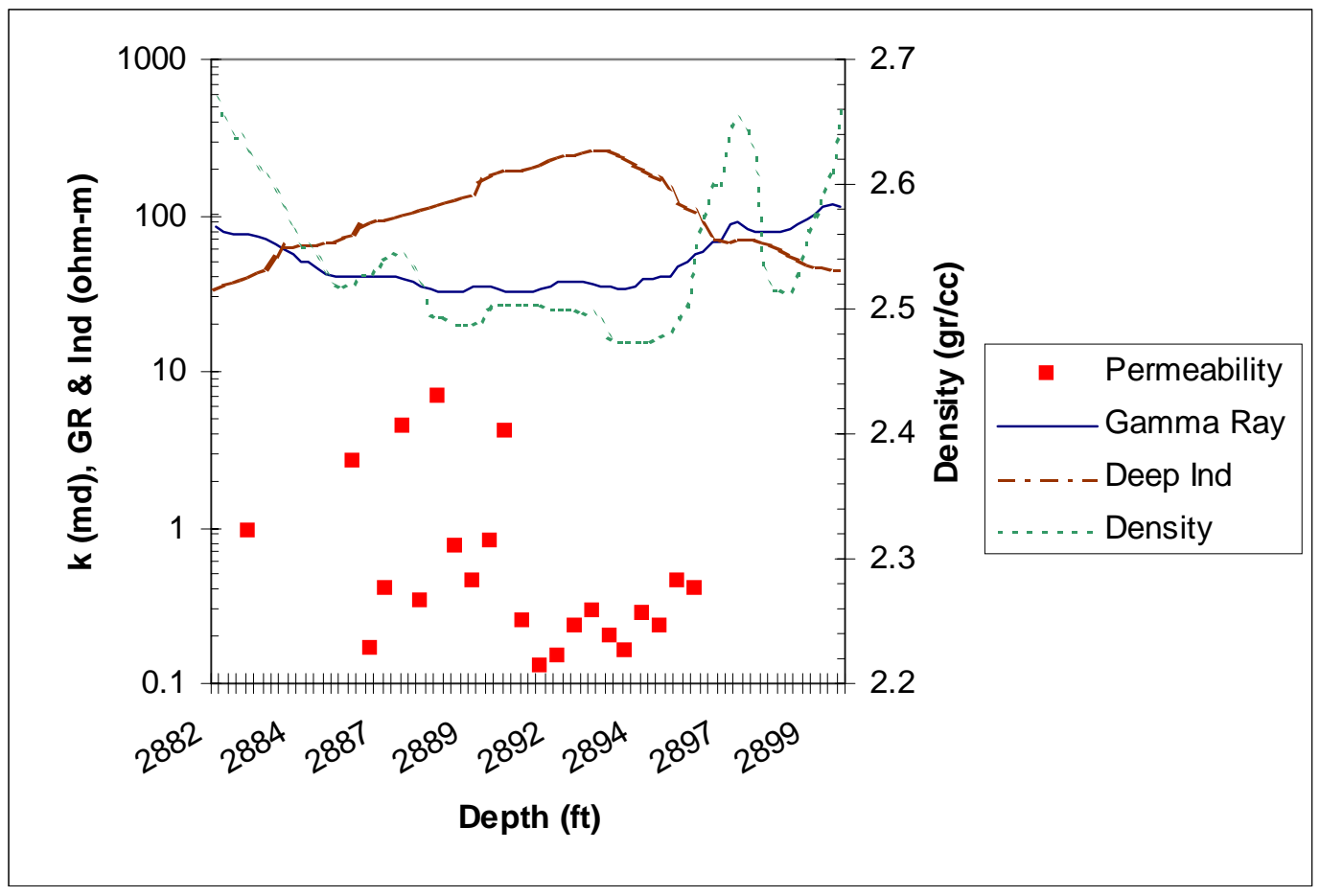

Figure 61. ANN Predictions and Core Permeability vs. Depth (Well Cw6)

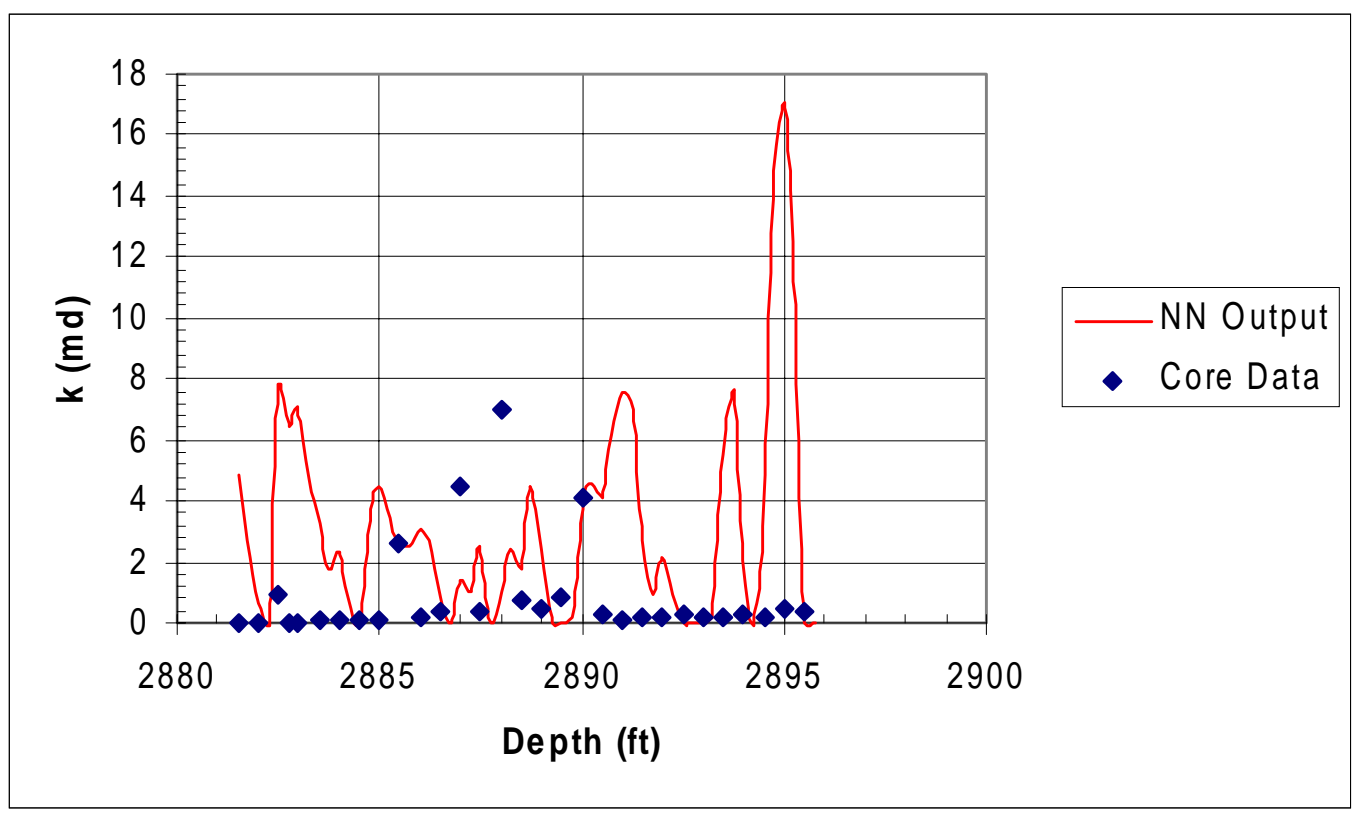


Figure 62. Core and Log Porosity vs. Depth (Well Cw7)

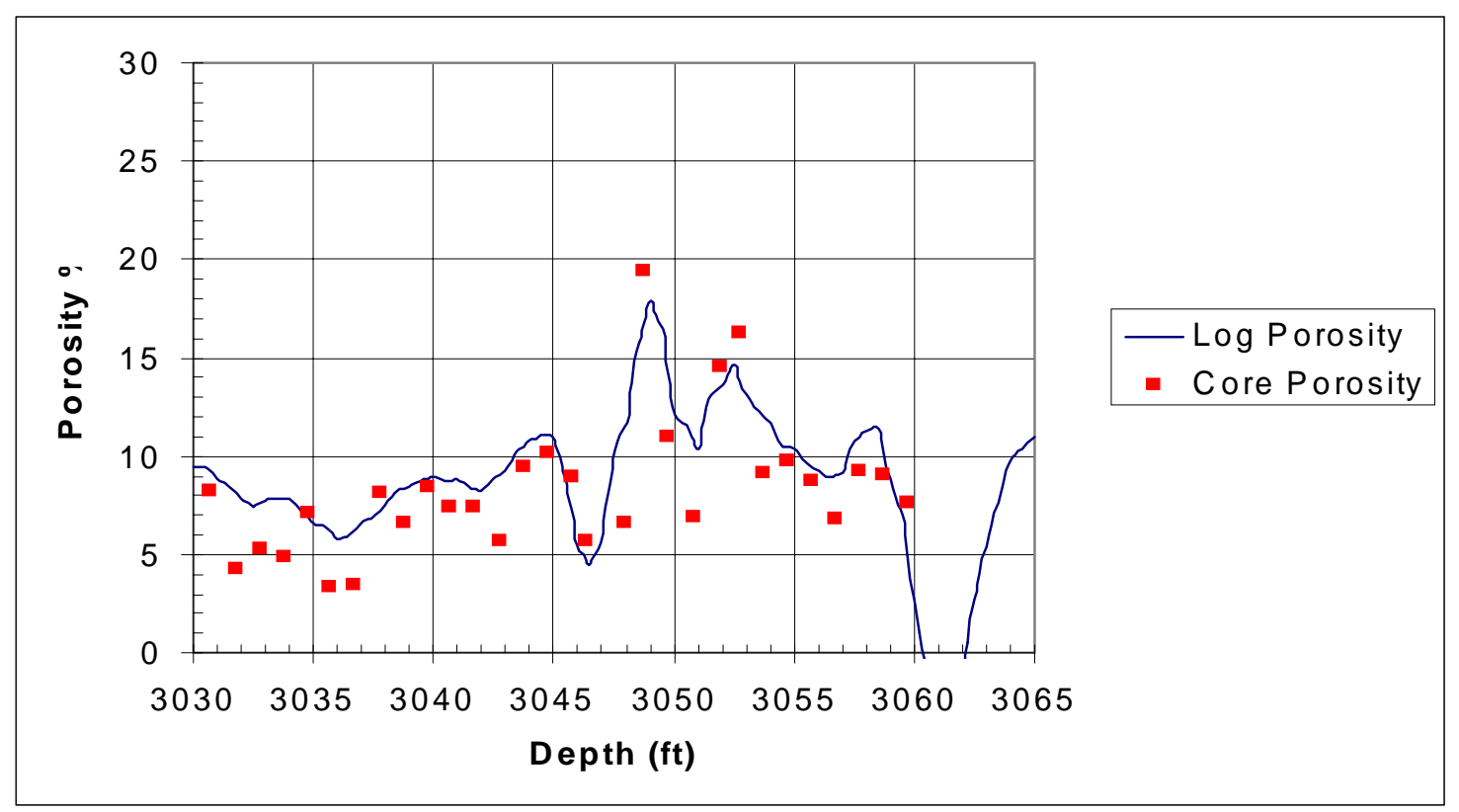

Figure 63. Porosity Correlation for Well Cw7

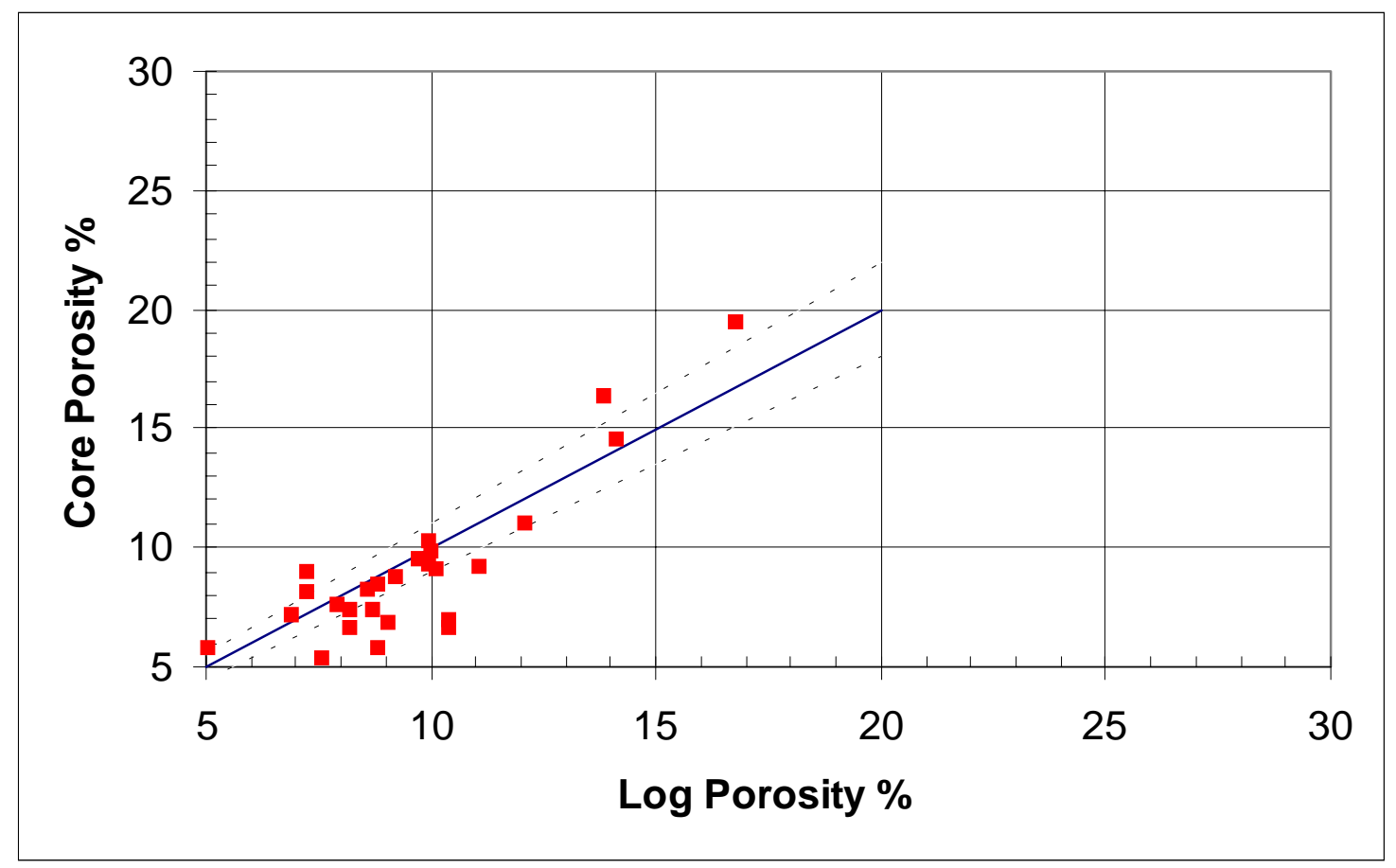


Figure 64. Core Permeability vs. Log Responses (Well Cw7)

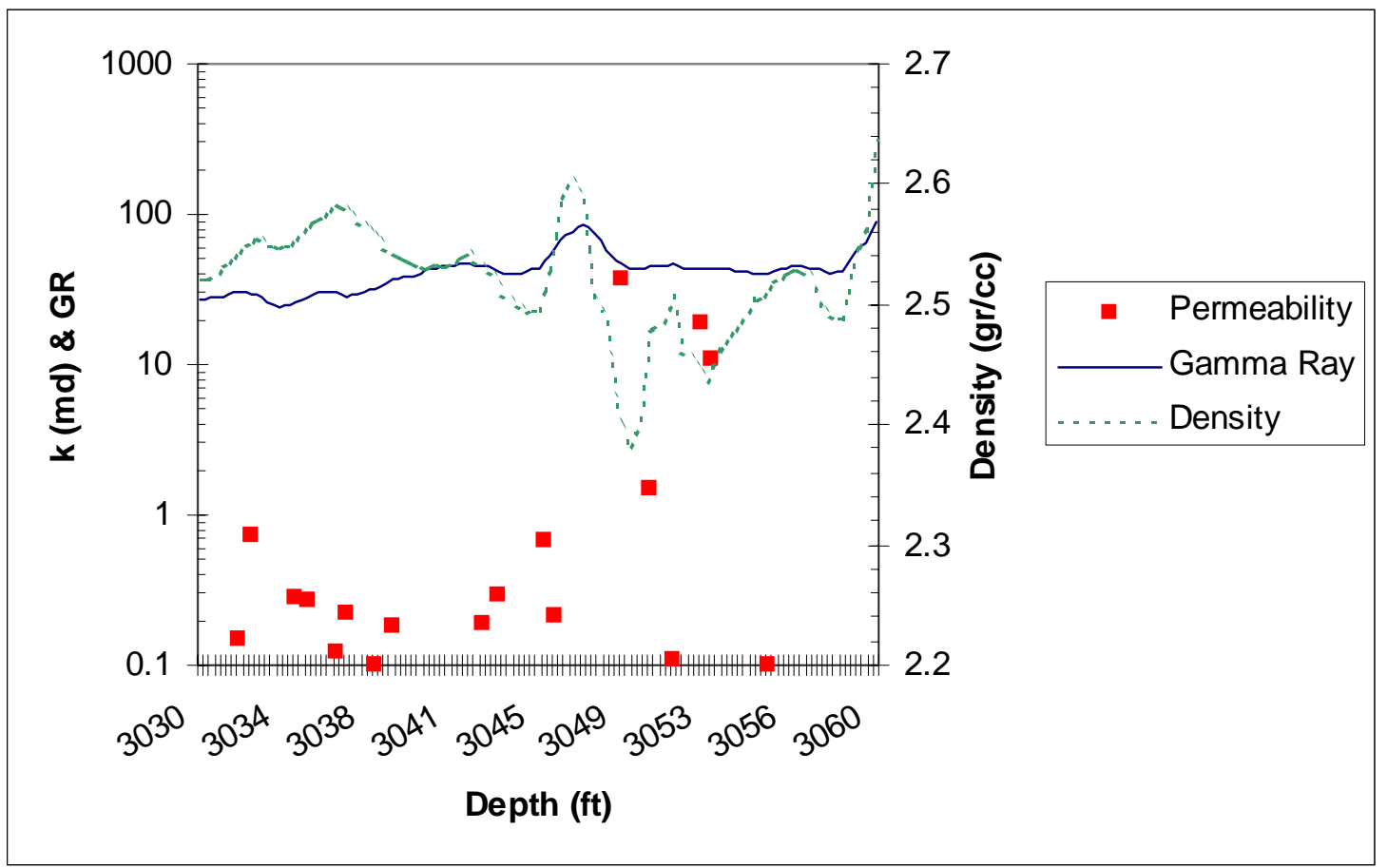

Figure 65. ANN Predictions and Core Permeability vs. Depth (Well Cw7)

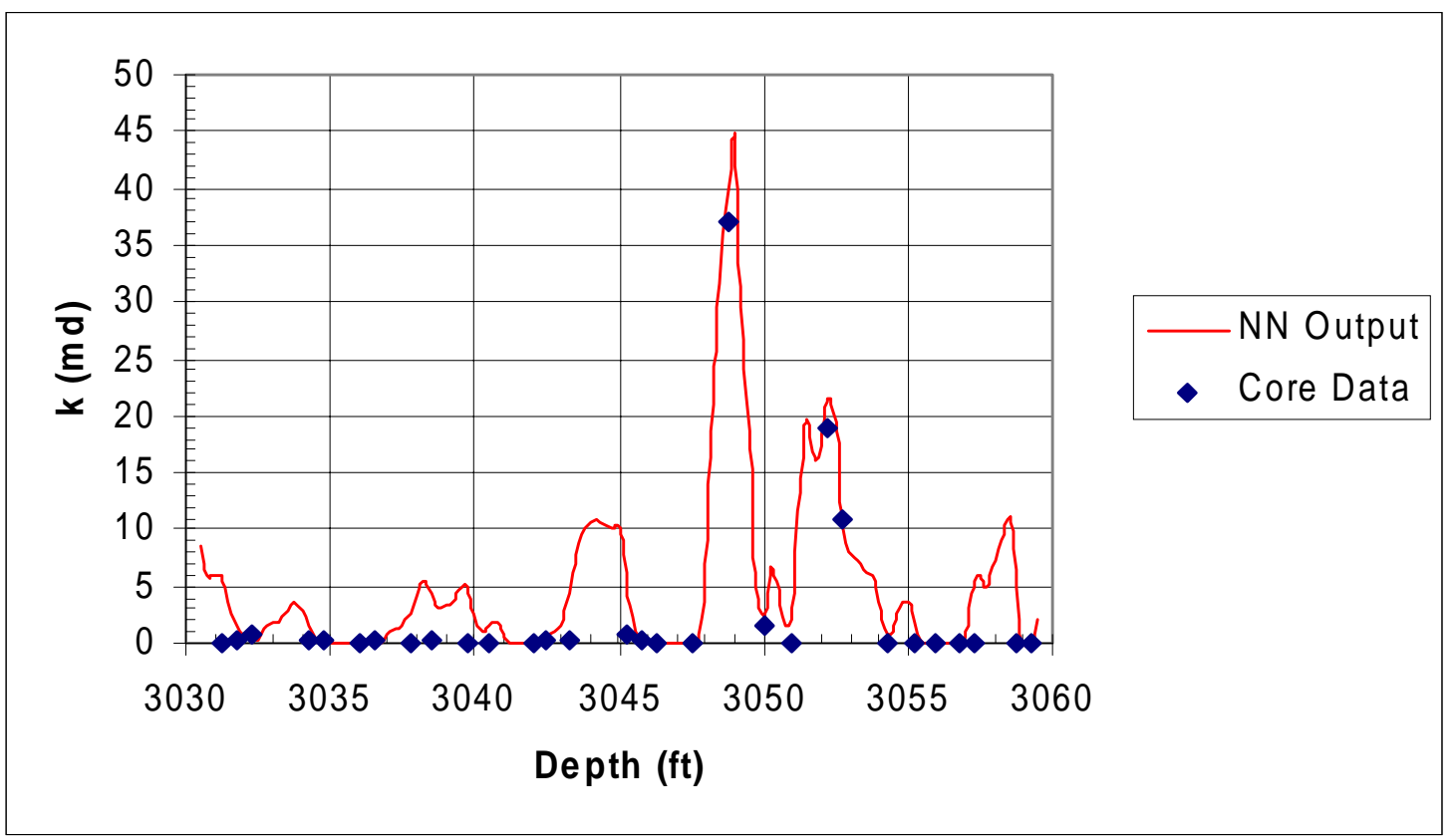




\section{Appendix II}

\section{Permeability Profile (Pilot Wells)}


Figure 66. Permeability Profile based on ANN Predictions (Well Pi1)

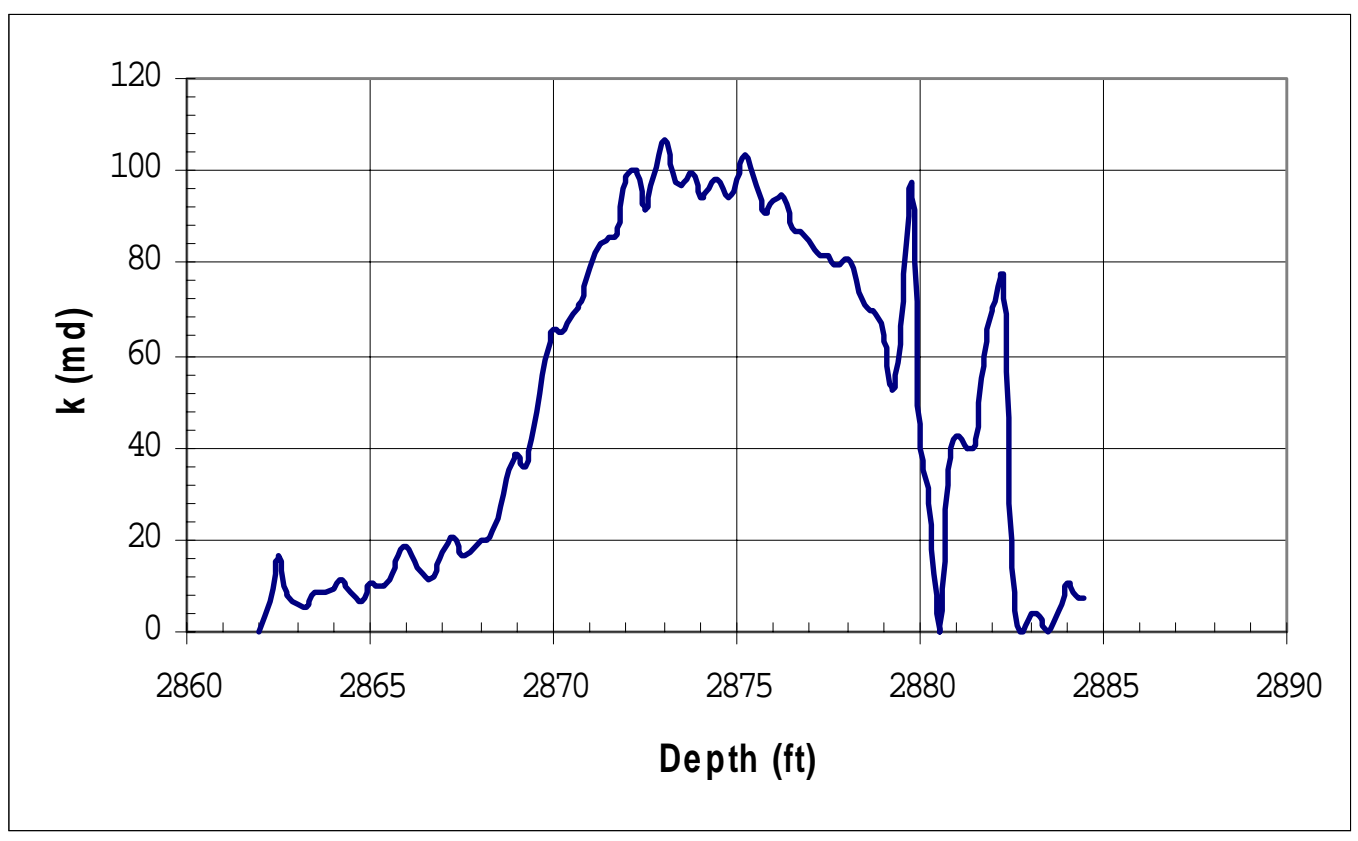

Figure 67. Permeability Profile based on ANN Predictions (Well Pi2)

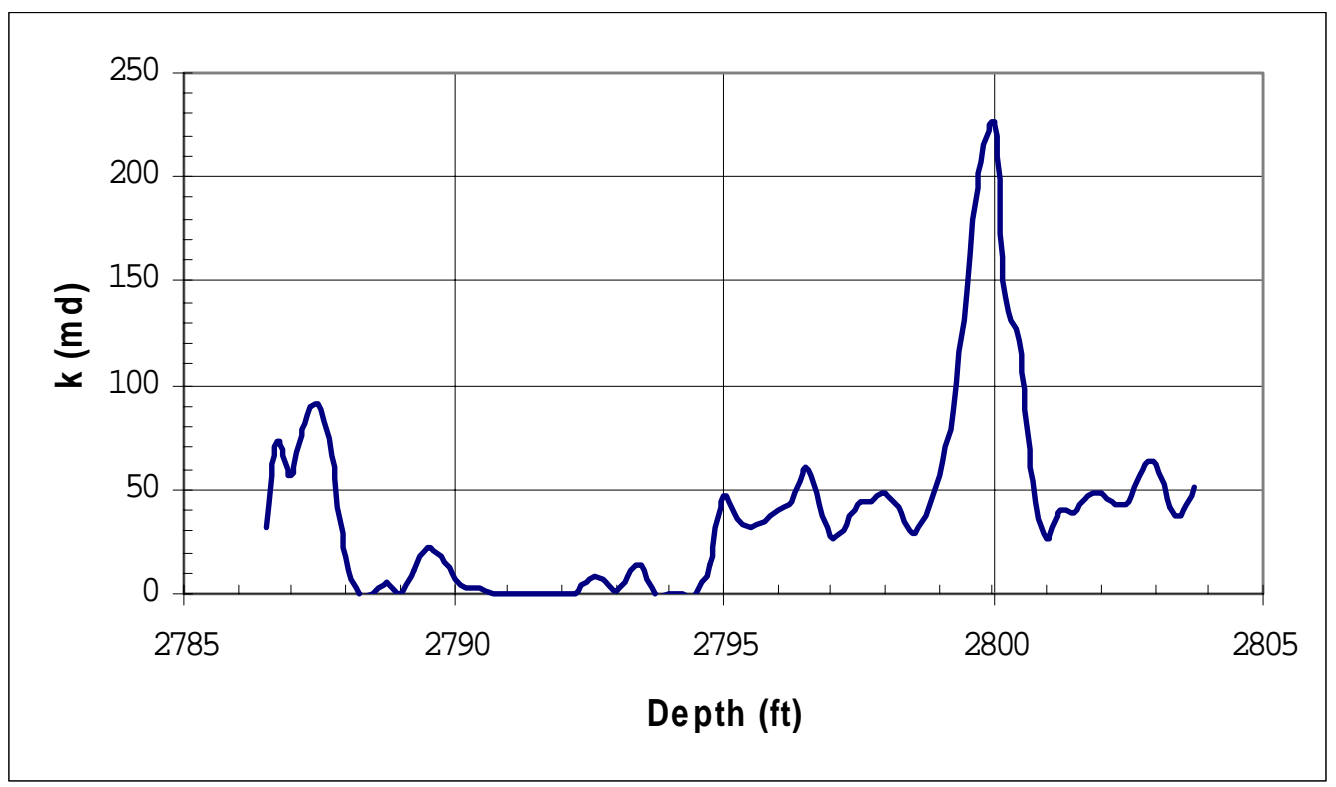


Figure 68. Permeability Profile based on ANN Predictions (Well Pi3)

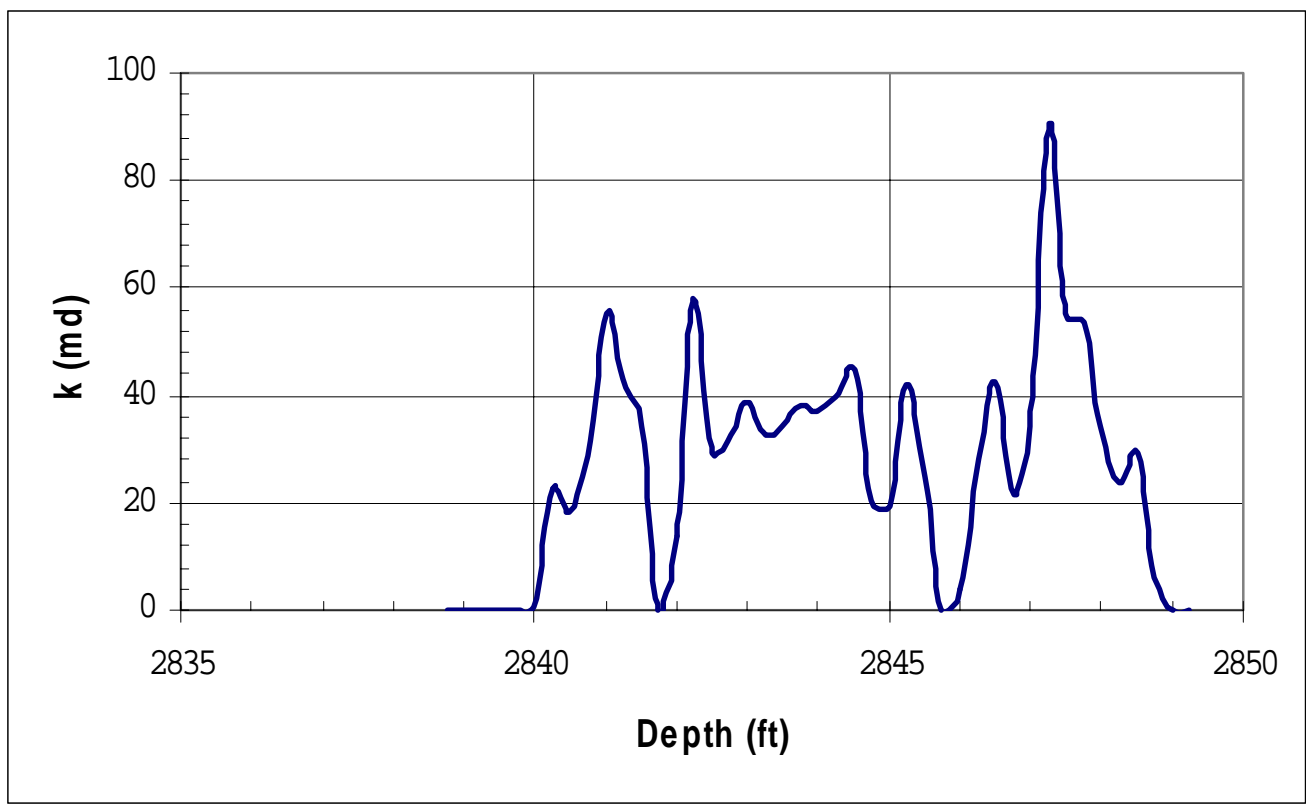

Figure 69. Permeability Profile based on ANN Predictions (Well Pi4)

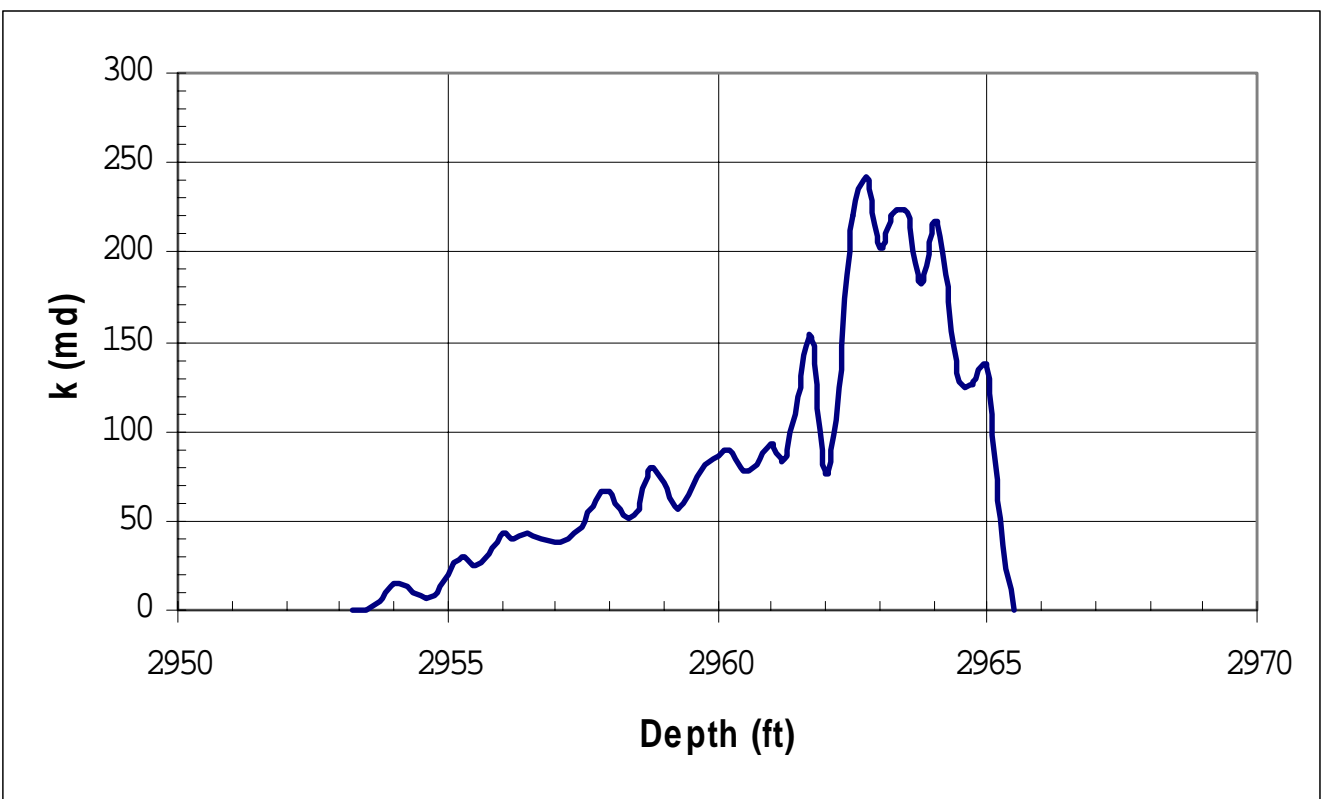


Figure 70. Permeability Profile based on ANN Predictions (Well Pp1)

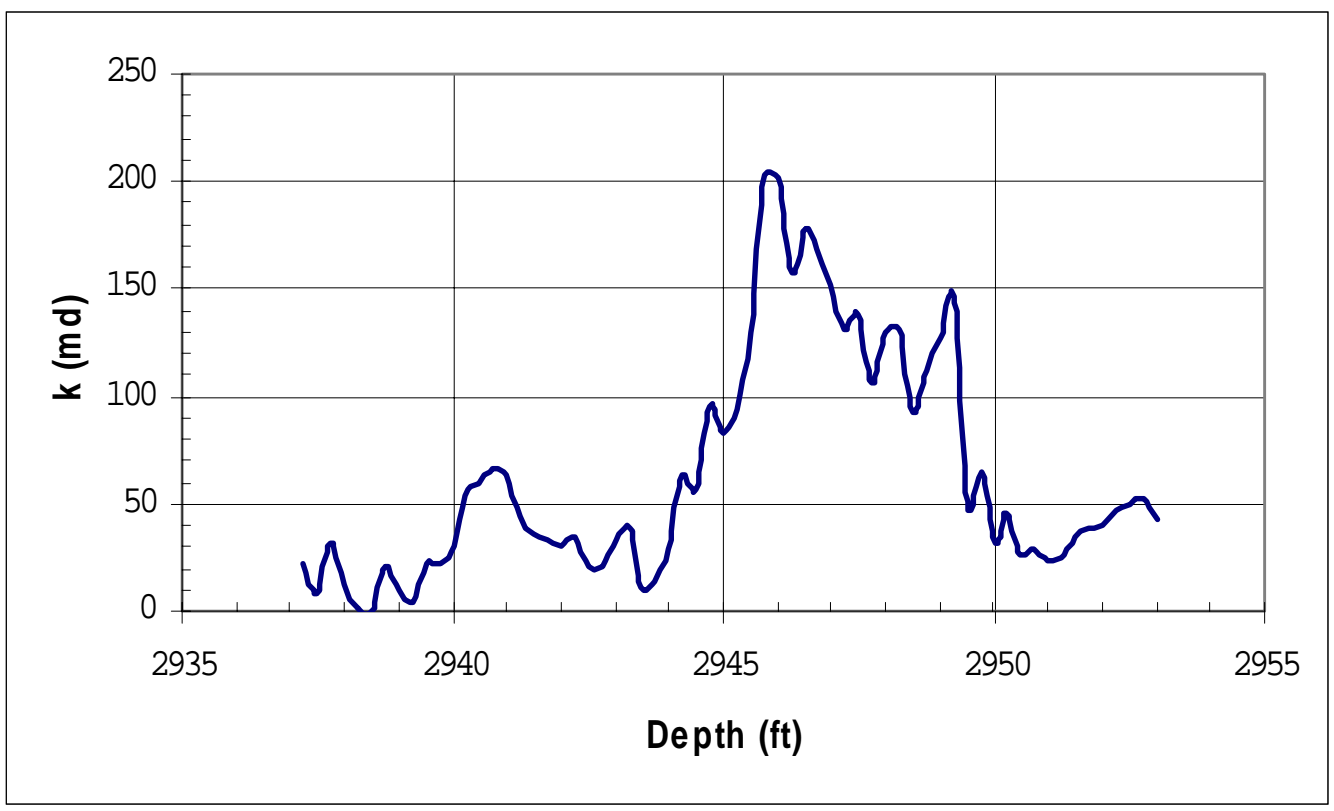

Figure 71. Permeability Profile based on ANN Predictions (Well Cw1)

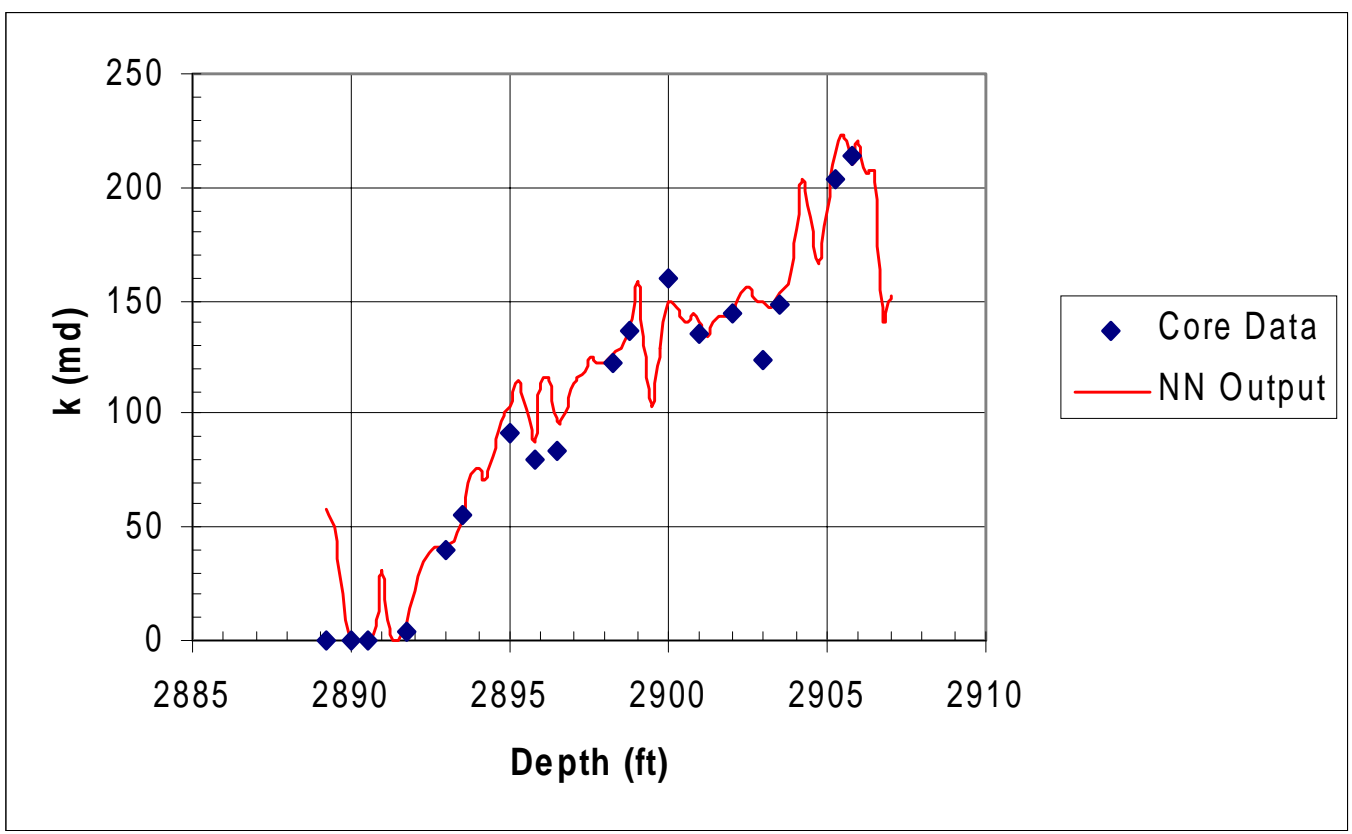


Figure 72. Permeability Profile based on ANN Predictions (Well Cw2)

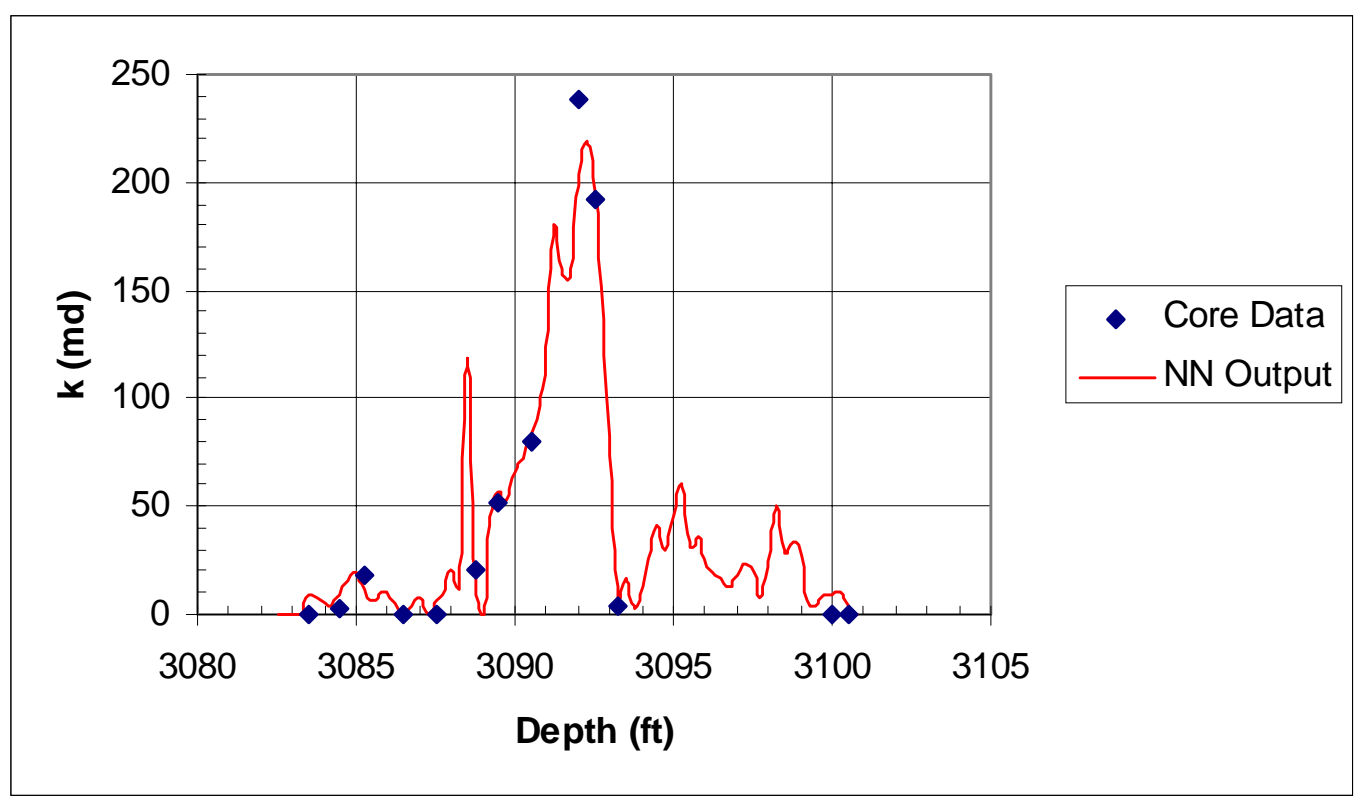




\section{Appendix III}

Thickness Distribution Map of the Stringtown Field 
Figure 73. Thickness Distribution Map of the Stringtown Field

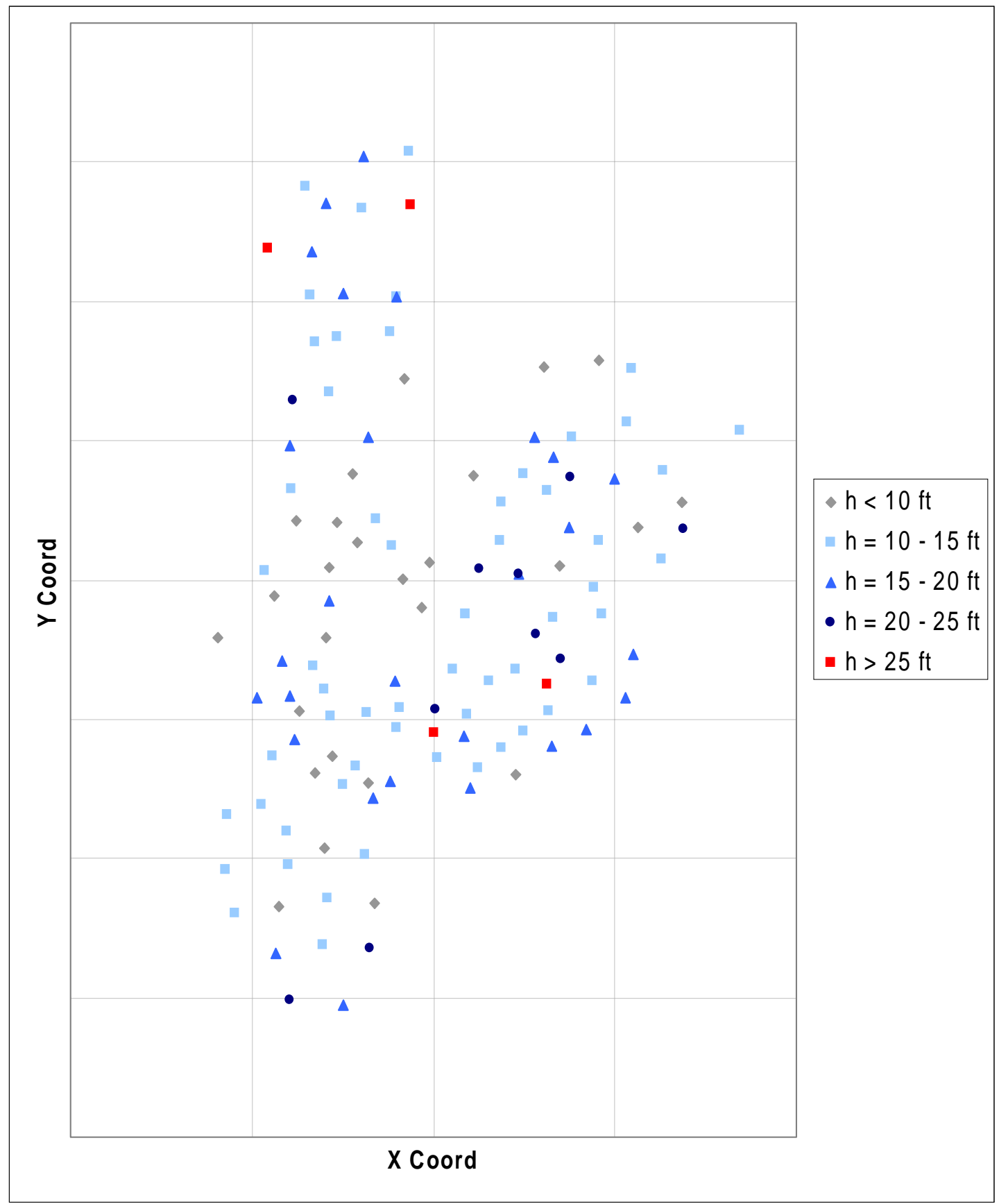


Figure 74. Thickness Distribution Contoured Map of the Stringtown Field

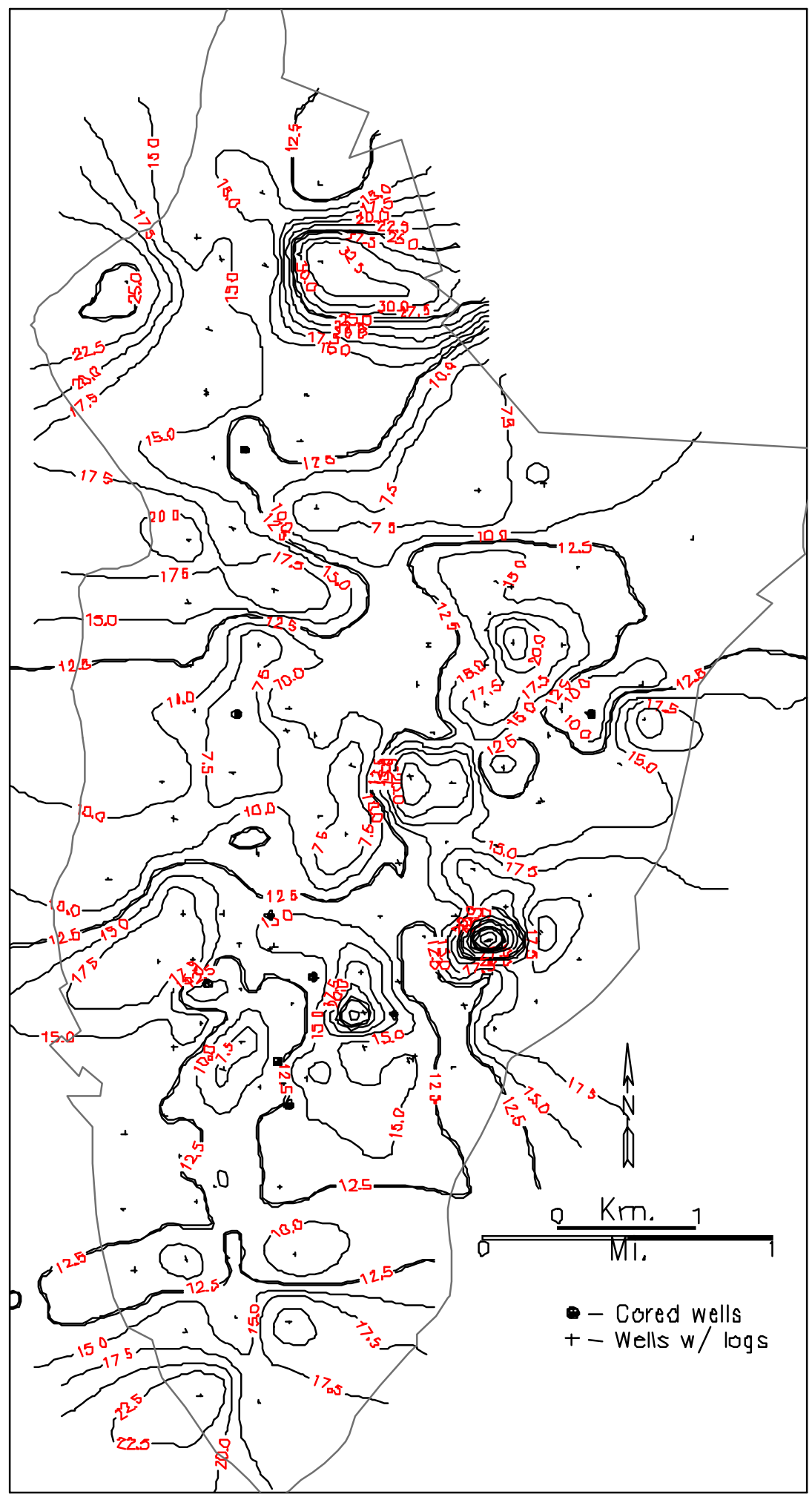

